\title{
Respostas agudas e crônicas de portadores de diabetes mellitus tipo 1 às sessões de exercícios
}

\section{aeróbicos e resistidos}

Tese apresentada à Faculdade de Medicina da Universidade de São Paulo para obtenção do título de Doutor em Ciências

Área de Concentração: Endocrinologia

Orientadora: Dra. Karla Fabiana Santana de Melo Cabral Fagundes

São Paulo 
Ao meu esposo Alex Perazo, meu companheiro, pela dedicação, ensino, paciência, incentivo e apoio, por todo seu amor...

Aos meus pais Geraldo e Marion, pelo amor, por tudo que me ensinaram e pelo que sou.

À toda a família, o meu esteio.

Aos amigos do coração. 


\section{AGRADECIMENTOS}

A Deus por sua presença constante em minha vida, me proporcionando oportunidades e forças.

À Dra. Karla Melo pela confiança em minha capacidade, pela orientação, idéias, carinho, dedicação, amor ao trabalho e pesquisa, por seus ensinamentos. A Floro e Pitz.

Aos meus irmãos Maristela, Marise, Márcia, Geraldinho, Marcelo, Mário, sobrinhos e toda a turma, pelo estímulo, apoio e coragem para viver.

À família de Alex: Leonel, Gelza e Braz Perazo, pelo carinho e por me proporcionarem a companhia de alguém tão especial.

Aos amigos Ricardo e Luciana (e agora também Leonardo) pelo convívio harmonioso, pelo apoio técnico e pessoal.

Aos amigos da graduação, Turma da Sala 4, hoje doutores, mestres, especialistas, mas acima de tudo professores... o tempo passa, mas a saudade fica.

À professora Dra. Edna Hernandez, pesquisadora, incentivadora e responsável pelo despertar de meu interesse científico durante a graduação.

Aos amigos das equipes médicas dos Hospitais do Servidor Público Municipal e Servidor Público Estadual pelas trocas de idéias e conhecimentos.

À Dra. Márcia Nery pelo apoio dado para a realização desta pesquisa.

Ao Dr. Daniel Giannella-Netto, que sem me conhecer abriu as portas para o meu aprendizado; às suas contribuições estatísticas e profissionais.

À Dra. Berenice Mendonça pelo apoio para o desenvolvimento deste projeto.

À Dra. Maria Lúcia Giannella pela recepção em seu grupo e apoio. 
À Dra. Dalva Marrero, Dra. Maria Elizabeth Rossi, Dra. Rosa Santos e Dra. Milene Ursich pelo incentivo, conhecimentos e carinho.

Ao Dr. Carlos Eduardo Negrão, às professoras Dra. Ivani Credidio, Dra. Maria Urbana Rondon, Mestre Luciene Azevedo, à Dra. Ana Maria Braga e Dra. Maria Janieire Alves, às secretárias Mônica e Paula, a todos os aprimorandos da equipe da Unidade de Reabilitação e Fisiologia do Exercício do InCor, obrigada pela colaboração científica.

Ao Dr. José Maria Santarém, aos professores e toda sua equipe do Centro de Estudos em Ciências da Atividade Física - CECAFI, obrigada pela parceria.

Ao professor Caio Rene pela colaboração na supervisão do treinamento de exercícios resistidos.

À equipe de Diabetes: médicos, residentes, enfermeiras, secretários, sempre pronta a ajudar.

A todos os colegas da pós-graduação pela convivência, e respeito.

Aos pacientes deste projeto pela participação, sem eles este estudo não seria possível.

À Cida, Rosana, Rubens, Márcia e Norisa, pelos muitos pedidos atendidos.

A todos que de forma direta ou indireta colaboraram no desenvolvimento deste estudo, seria impossível citar cada um.

A CAPES pelo apoio financeiro durante a pós-graduação. 
Esta tese está de acordo com:

Referências: adaptado de International Committee of Medical Journals Editors (Vancouver).

Universidade de São Paulo. Faculdade de Medicina. Serviço de Biblioteca e Documentação. Guia de apresentação de dissertações, teses e monografias. Elaborado por Anneliese Carneiro da Cunha, Maria Júlia de A. L. Freddi, Maria F. Crestana, Marinalva de Souza Aragão, Suely Campos Cardoso, Valéria Vilhena. São Paulo: Serviço de Biblioteca e Documentação; 2004.

Abreviaturas dos títulos dos periódicos de acordo com List of Journals Indexed in Index Medicus. 


\section{SUMÁRIO}

Lista de Abreviaturas e Siglas

Lista de Símbolos

Lista de Fórmulas

Lista de Figuras

Lista de Tabelas

Resumo

Summary

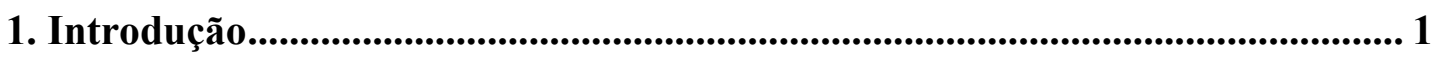

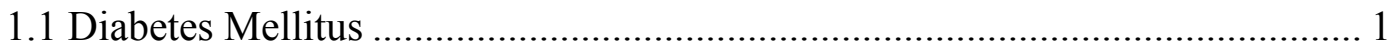

1.2 Atividade física, exercícios aeróbios e exercícios resistidos ......................... 2

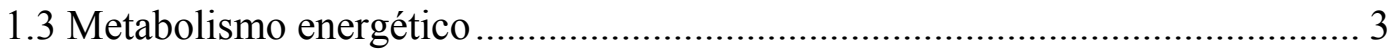

1.4 Captação de glicose pelas células musculares esqueléticas .............................. 6

1.4.1 Captação de glicose mediada pela insulina ......................................... 7

1.4.2 Captação de glicose estimulada pelo exercício .................................... 8

1.5 Respostas agudas de portadores de DM1 ao exercício ............................... 10

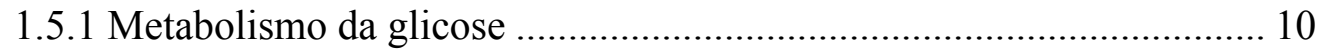

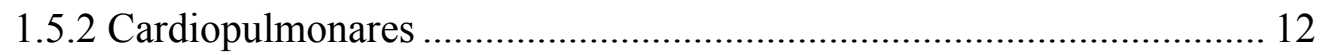

1.6 Respostas crônicas de portadores de DM1 ao exercício ............................... 13

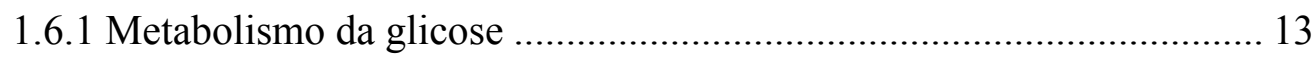

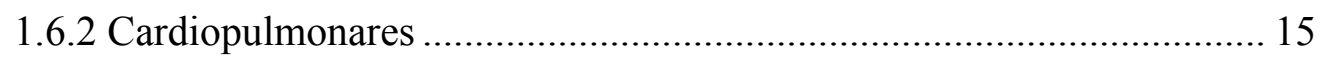


1.7 Recomendações para a prática segura de exercícios por portadores de diabetes

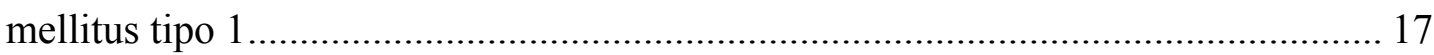

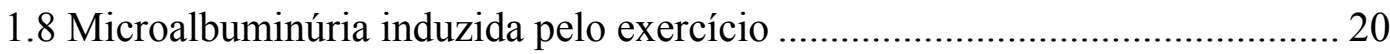

1.9 Sistema de Monitorização Contínua da Glicose (CGMS) ............................... 21

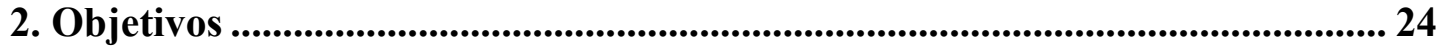

3 Casuística e métodos ........................................................................................ 27

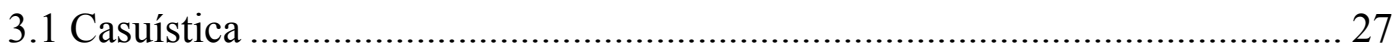

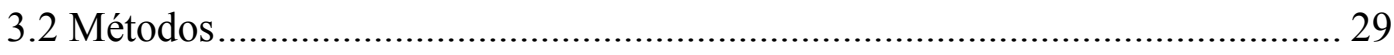

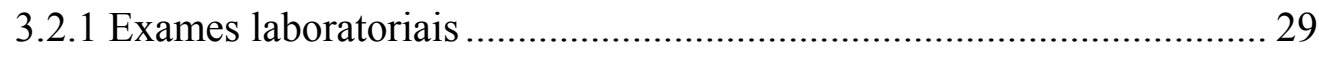

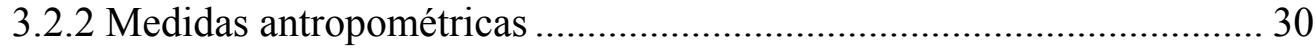

3.2.3 Aferição de freqüência cardíaca e pressão arterial antes e após o

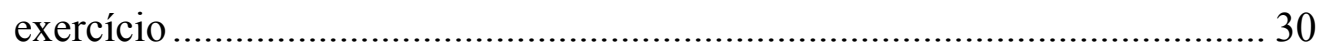

3.2.4 Teste ergoespirométrico .............................................................. 31

3.2.5 Sistema de monitorização contínua da glicose...................................... 33

3.2.6 Protocolo de microalbuminúria induzida pelo exercício ...................... 34

3.2.7 Monitorização da glicemia capilar com glicosímetro .......................... 34

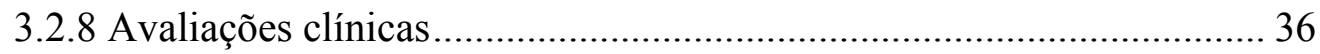

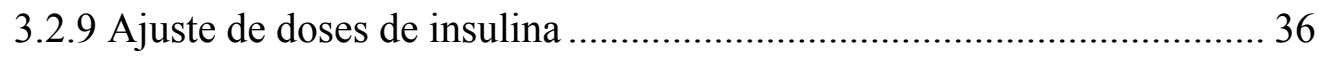

3.2.10 Programa de treinamento de exercício aeróbio .................................. 37

3.2.11 Programa de treinamento de exercícios resistidos ............................ 38

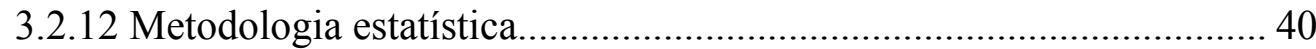

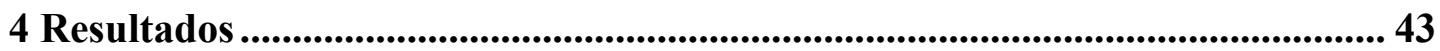

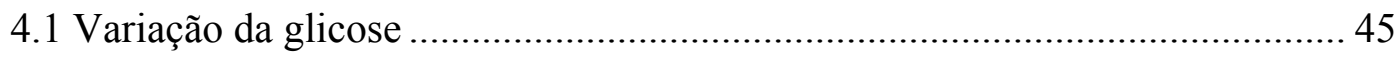

4.1.1 Variação aguda da glicemia capilar ................................................ 45 
4.1.2 Variação aguda da glicose utilizando o sistema de monitorização

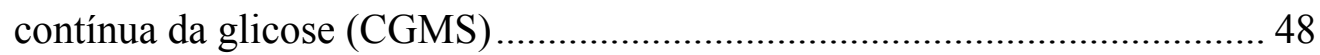

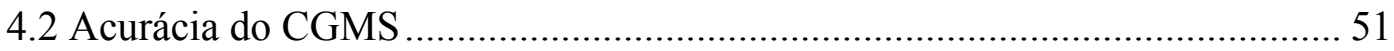

4.2.1 Avaliação do sistema de monitorização da glicose e GC para medidas de glicose durante a realização de exercícios físicos

4.2.2 Correlação entre as médias de glicose obtidas pelo glicosímetro e CGMS durante o teste ergoespirométrico 55

4.3 Análise temporal do comportamento da glicose durante os exercícios 57

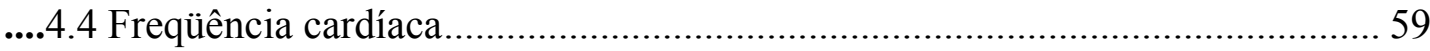

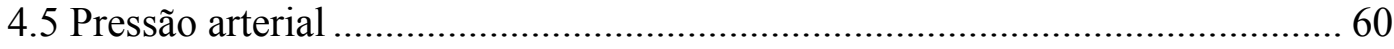

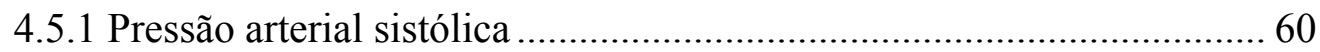

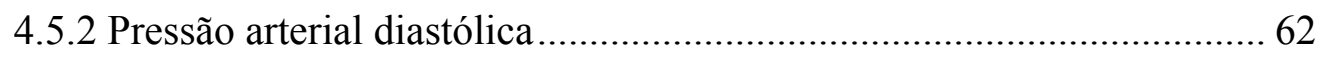

4.6 Freqüência e resolução de hipoglicemia .................................................... 63

4.6.1 Freqüência de consumo de gel durante os exercícios .......................... 63

4.6.2 Quantidade consumida de gel durante os exercícios............................6 65

4.6.3 Freqüência de hipoglicemia durante os exercícios...............................67

4.6.4 Freqüência de hipoglicemia e esquema de redução de dose de insulina UR de $50 \times 75 \%$

4.6.5 Quantidade consumida de gel por grupo e esquema de redução de insulina UR 71

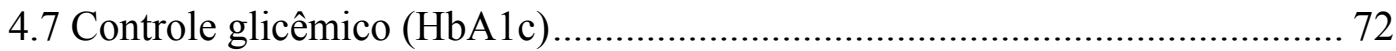

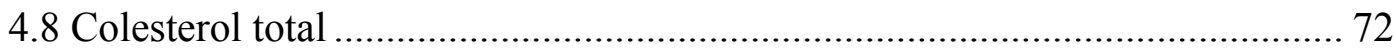

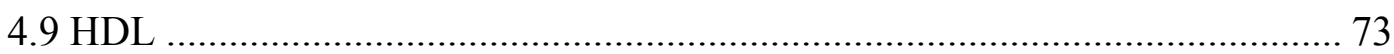

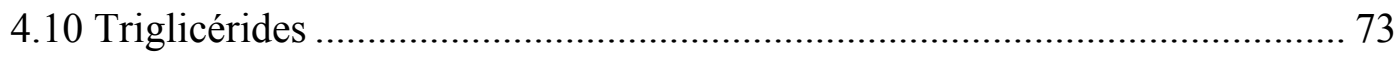




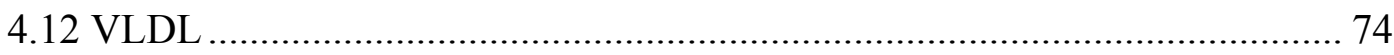

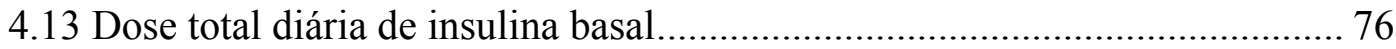

4.13.1 A redução das doses de insulina NPH.............................................. 77

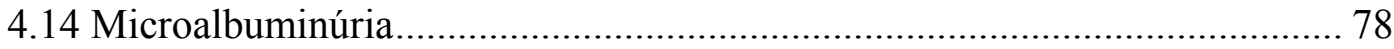

4.14.1 Microalbuminúria em repouso ……............................................... 78

4.14.2 Microalbuminúria induzida pelo exercício …................................... 80

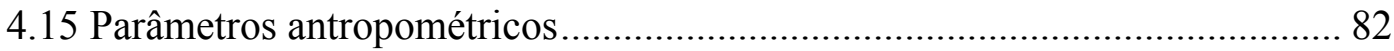

4.15.1 Altura, peso, IMC e circunferência da cintura ................................. 82

4.15.2 Avaliação da composição corporal (DEXA)..................................... 87

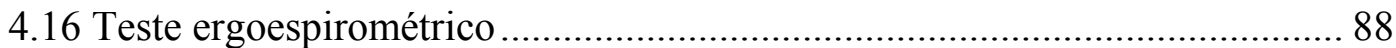

4.16.1 Avaliação dos dados cardiopulmonares ........................................... 91

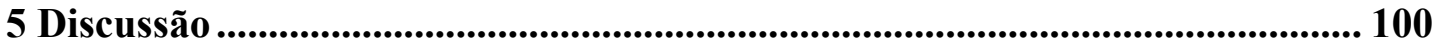

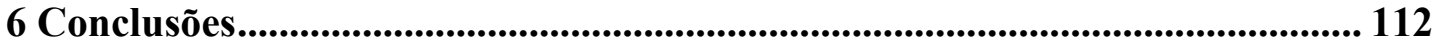

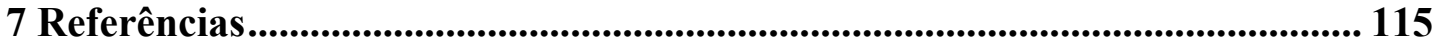

8 Anexos 
LISTA DE ABREVIATURAS E SIGLAS

\begin{tabular}{|c|c|}
\hline A & exercício aeróbio \\
\hline AMP & adenosina monofosfato \\
\hline AMPK & adenosina monofosfato proteína quinase ativada \\
\hline Anti-GAD & anticorpo descarboxilase do ácido glutâmico \\
\hline ATP & adenosina trifosfato \\
\hline $\mathrm{BMC}$ & bone mineral contend \\
\hline BMD & bone mineral density \\
\hline CAMK & calmodulina dependente de proteína quinase \\
\hline $\mathrm{CC}$ & circunferência da cintura \\
\hline CGMS & sistema de monitorização contínua da glicose \\
\hline $\mathrm{CP}$ & fosfocreatina \\
\hline $\mathrm{CT}$ & colesterol total \\
\hline DEXA & dual energy x-ray absorptiometry \\
\hline DM1 & diabetes mellitus tipo 1 \\
\hline DTDIB & dose total diária de insulina basal \\
\hline Et al. & e colaboradores \\
\hline $\mathrm{F}$ & fim \\
\hline $\mathrm{FC}$ & freqüência cardíaca \\
\hline $\mathrm{GC}$ & glicemia capilar \\
\hline GLUT & transportador de glicose \\
\hline HbAlc & hemoglobina glicada \\
\hline HDL & high density lipoprotein \\
\hline
\end{tabular}




\begin{tabular}{|c|c|}
\hline HPLC & high performance liquid chromatography \\
\hline I & início \\
\hline IMC & índice de massa corpórea \\
\hline IRS & substrato de receptor de insulina \\
\hline LA & limiar anaeróbio \\
\hline LDL & low density lipoprotein \\
\hline MLG & técnicas de modelos lineares gerais \\
\hline NPH & neutron protamine hagedorm \\
\hline PAD & pressão arterial diastólica \\
\hline PAS & pressão arterial sistólica \\
\hline PCR & ponto de compensação respiratória \\
\hline PI3-K & fosfatidilinositol-3 Kinase \\
\hline $\mathrm{PKC}$ & proteína quinase $\mathrm{C}$ \\
\hline $\mathrm{R}$ & exercício resistido \\
\hline RQ & razão de troca respiratória \\
\hline SIM & sistema de informação sobre mortalidade \\
\hline $\mathrm{T} 3$ & triiodotironina \\
\hline T4 Livre & tiroxina livre \\
\hline TE & teste ergoespirométrico \\
\hline TG & triglicérides \\
\hline TSH & hormônio tireoestimulante \\
\hline UR & insulina de ação ultra-rápida \\
\hline VLDL & very low lipoprotein \\
\hline
\end{tabular}




\section{LISTA DE SÍMBOLOS}

\begin{tabular}{|c|c|}
\hline$>$ & maior que \\
\hline$<$ & menor que \\
\hline$=$ & igual \\
\hline$\%$ & por cento \\
\hline bpm & batidas por minuto \\
\hline $\mathrm{cm}$ & centímetro \\
\hline $\mathrm{cm}^{2}$ & centímetro quadrado \\
\hline g & grama \\
\hline $\mathrm{F}$ & teste de Fisher \\
\hline $\mathrm{h}$ & hora \\
\hline $\mathrm{kg}$ & kilograma \\
\hline $\mathrm{L}$ & litro \\
\hline $\mathrm{m}$ & metro \\
\hline $\mathrm{mL}$ & mililitro \\
\hline $\mathrm{mg}$ & miligrama \\
\hline $\mathrm{mmHg}$ & milímetro de mercúrio \\
\hline $\mathrm{p}$ & significância estatística \\
\hline $\mathrm{r}$ & coeficiente de Pearson \\
\hline ( & marca registrada \\
\hline $\mathrm{t}$ & teste t-Student \\
\hline $\mathrm{u}$ & unidade \\
\hline $\mathrm{W}$ & watts \\
\hline
\end{tabular}




\section{LISTA DE FÓRMULAS}

$\begin{array}{ll}\text { VO2 } & \text { consumo de oxigênio máximo } \\ \text { VE } & \text { ventilação pulmonar } \\ \mathrm{O} 2 & \text { oxigênio } \\ \mathrm{CO} 2 & \text { dióxido de carbono } \\ \mathrm{VO} 2 & \text { consumo de oxigênio } \\ \text { VCO2 } & \text { produção de dióxido de oxigênio } \\ \text { PET O2 } & \text { pressão parcial final de oxigênio } \\ \text { PET CO2 } & \text { pressão parcial final de dióxido de carbono }\end{array}$




\section{LISTA DE FIGURAS}

Figura 1. Ressíntese aeróbio e anaeróbia de ATP

Figura 2. Ativação dos sistemas de transferência de energia aeróbio e anaeróbio, em diferentes durações do exercício

Figura 3. Sinalização da insulina

Figura 4. Delineamento do estudo

Figura 5. Escala de percepção de esforço de Borg

Figura 6. Evolução da variação da glicemia capilar com as sessões de exercícios

Figura 7. Ajustes de curvas para a variação da $\mathrm{GC}$ em função do número de sessões de exercício realizadas

Figura 8.

Figura 9.

Figura 10.

Figura 11.

Figura 12.

Figura 13.

Figura 14.

Figura 15.

Figura 16. 


\section{LISTA DE TABELAS}

Tabela 1 - Métodos e valores de referência

Tabela 2 - Características clínicas dos portadores de DM1

Tabela 3 - Variação da glicemia capilar nas sessões de exercícios segundo o tipo

Tabela 4 - Parâmetros das equações de reta ajustada para a queda da GC

Tabela 5 - Testes do MLG para as medidas de glicose feitas com o CGMS durante os exercícios

Tabela 6 - Níveis médios de glicose por grupo - CGMS

Tabela 7 - Variáveis dependentes: CGMS

Tabela 8 - Resultados do ajuste do modelo saturado para GC em função do CGMS

Tabela 9 - Seqüência de variáveis com contribuição não significativas

Tabela 10 - Resultados do modelo final ajustado para as dosagens de glicose durante os exercícios

Tabela 11 - Equações dos modelos preditivos de dosagens de glicose (GC) em função das observadas com o CGMS nos dois grupos de exercício

Tabela 12 - Efeito dos treinamentos sobre a freqüência cardíaca

Tabela 13 - Efeito dos treinamentos sobre a pressão arterial sistólica

Tabela 14 - Efeito dos treinamentos sobre a pressão arterial diastólica

Tabela 15 - Freqüência média de consumo de gel segundo o período de treinamento

Tabela 16 - Freqüência média de consumo de gel segundo grupo 
Tabela 17- Quantidade média de consumo de gel segundo o período de treinamento

Tabela 18 - Quantidade média de consumo de gel segundo grupo

Tabela 19 - Freqüência de hipoglicemia segundo o período de treinamento

Tabela 20 - Freqüência de hipoglicemia segundo o grupo

Tabela 21 - Freqüência de hipoglicemia durante exercícios e esquemas de redução de insulina UR

Tabela 22 - Quantidade média consumida de gel segundo o grupo e esquema UR Tabela 23 - Médias dos parâmetros de controle glicêmico e perfil lipídico em função do grupo e período

Tabela 24 - $\quad$ Modelo para a DTDIB - testes dos parâmetros

Tabela 25 - Médias corrigidas de DTDIB, segundo o grupo

Tabela 26 - Modelo para a NPH no exercício - testes dos parâmetros

Tabela 27 - Médias de microalbuminúria em repouso

Tabela 28 - ANOVA para o modelo ajustado para a microalbuminúria em repouso

Tabela 29 - Médias de microalbuminúria em exercício

Tabela 30 - ANOVA para o modelo ajustado para a microalbuminúria em exercício

Tabela 31 - Médias das idades das pacientes por grupo

Tabela 32 - Médias de IMC segundo o grupo e período de treinamento

Tabela 33 - Testes estatísticos para o IMC em função dos grupos e período de treinamento

Tabela 34 - Circunferência média das cinturas dos pacientes segundo o grupo e o período 
Tabela 35 - Teste de significância para a circunferência da cintura

Tabela 36 - Resultados dos testes de significância para a composição corporal

Tabela 37 - Modelo para a GC no teste ergoespirométrico

Tabela 38 - Médias corrigidas de GC, por grupo, no teste ergoespirométrico

Tabela 39 - Medias corrigidas de GC, por período, no teste ergoespirométrico

Tabela 40 - Teste de significância para o tipo de exercício e período de treinamento na avaliação cardiopulmonar

Tabela 41 - Médias por grupo e período de treinamento observadas na avaliação cardiopulmonar 


\section{RESUMO}

PERAZO, MNA. Respostas agudas e crônicas de portadores de diabetes mellitus tipo 1 às sessões de exercícios aeróbio e resistidos [tese]. São Paulo: Faculdade de Medicina da Universidade de São Paulo; 2007.

INTRODUÇÃO: A atividade física faz parte do tratamento do portador de diabetes mellitus tipo 1 (DM1), devendo ser encorajada pelas mesmas razões que é em não portadores. Os portadores de DM1, como evidenciam os estudos, apresentam póstreino: redução dos fatores de risco para o desenvolvimento de doenças cardiovasculares, melhora do condicionamento físico, da sensibilidade à ação da insulina e do bem-estar. Mas é fundamental realizar a monitorização glicêmica, adequar alimentação e dose de insulina para a prática de exercícios, a fim de evitar hipo ou hiperglicemias antes, durante ou após as sessões, e consequentemente, obter melhora ou manutenção do controle glicêmico. Além disso, o nível de atividade física relaciona-se inversamente ao aparecimento de complicações do diabetes e risco de mortalidade em portadores de DM1. Porém, poucos estudos demonstram o comportamento da glicemia destes pacientes em diferentes tipos de exercícios. $\mathrm{O}$ conhecimento da variação glicêmica durante o exercício é fundamental para a conduta terapêutica do médico, para a prescrição e orientação segura de exercícios pelos professores de educação física. OBJETIVOS: Analisar a variação da glicose de DM1, submetidos às sessões de exercício aeróbio, exercícios resistidos e teste ergoespirométrico, utilizando o Sistema de Monitorização Contínua da Glicose (CGMS) e o glicosímetro portátil para monitorização da glicemia capilar. E como objetivo secundário, analisar a acurácia do CGMS e as respostas agudas e crônicas às sessões de exercícios aeróbio, resistidos e teste ergoespirométrico por portadores de DM 1. CASUÍSTICA E MÉTODOS: Dez portadores de DM1, de ambos os sexos, com idade entre 16 e 45 anos, sem complicações da doença. Os pacientes foram submetidos ao teste ergoespirométrico máximo (TE) e a 40 sessões de exercícios aeróbios (A) ou resistidos (R). As sessões foram realizadas no período pós-prandial do almoço e nestes dias, os pacientes foram orientados pela equipe médica a reduzir: $1 \mathrm{U}$ (se dose <20U) ou $2 \mathrm{U}$ (se dose $>20 \mathrm{U}$ ) da insulina basal (NPH) da manhã e 50 a $75 \%$ da insulina pré-prandial ultra-rápida (UR) do almoço; não houve redução para o TE. Os pacientes mediam a glicemia capilar antes, durante (se, necessário) e após as sessões. RESULTADOS: Os exercícios aeróbios promoveram uma queda maior na GC $(67 \mathrm{mg} / \mathrm{dL})$, quando comparada a queda causada pelos exercícios resistidos $(37 \mathrm{mg} / \mathrm{dL})(\mathrm{p}=0,047)$. A correlação entre os dados obtidos pelo CGMS e pelo glicosímetro durante o exercício é significativa $(\mathrm{p}<0,001)$, positiva e direta $(\mathrm{r}=+0,925)$. A freqüência cardíaca e a pressão arterial sistólica apresentaram aumento durante $A(p<0,001)$, não apresentando diferença para R. A pressão arterial diastólica não mostrou diferença em nenhum dos dois grupos. A freqüência média de consumo $[(\mathrm{A}=19,8)$ e $(\mathrm{R}=16,7)]$ e a quantidade de gel $[(\mathrm{A}=28,2)$ e $(\mathrm{R}=21,3)]$ utilizada durante o período de treinamento foram similares em ambos os grupos. A freqüência de hipoglicemias foi igual em ambos os grupos $[(\mathrm{A}=1,5)$ e $(\mathrm{R}=1,5)]$ durante $\mathrm{O}$ treinamento, não apresentando diferenças em relação às reduções de dose de insulina UR ou período de treinamento. As respostas crônicas foram obtidas ao final do período de treinamento (40 sessões): o controle glicêmico (HbAlc), o perfil lipídico 
(colesterol total, triglicérides, HDL, LDL, VLDL) e os parâmetros antropométricos não foram influenciados pelo treinamento. Os níveis médios de microalbuminúria em repouso não modificaram, mas os níveis médios de microalbuminúria induzida pelo exercício praticamente dobraram. CONCLUSÕES: O grupo A apresentou maior declínio da glicose quando comparado ao grupo R. O CGMS pode ser considerado um método acurado para a sua utilização durante o exercício. $\mathrm{O}$ comportamento da freqüência cardíaca e pressão arterial foram similares aos não portadores de diabetes. $\mathrm{O}$ protocolo de redução de insulina se mostrou efetivo durante o período de treinamento. Houve mudanças na composição corporal detectadas pelo DEXA.

Descritores: 1. DIABETES MELLITUS TIPO 1 2. AUTO-MONITORIZAÇÃO DA GLICEMIA 3. EXERCÍCIOS 4. TESTE DE ESFORÇO 


\section{SUMMARY}

PERAZO, MNA. Acute and chronic responses of type 1 diabetes patients submitted to aerobic and resistance exercises bout [tese]. São Paulo: Faculdade de Medicina da Universidade de São Paulo; 2007.

Background and Aims: For type 1 diabetes patients is essential self monitoring of blood glucose and adjustment of carbohydrate intake and insulin dose for exercise practice. The aim of this study was to assess glucose variability during: spiroergometric test (ST) and aerobic (A) and resistance exercises(R). Materials and Methods: 10 DM1 patients performed ST, and 40 A and R bouts and they reduced their insulin dose in A and $\mathrm{R}$ exercise days. Results: Glycemia variation groups were: $A=67 \mathrm{mg} / \mathrm{dL}$ and $\mathrm{R}=37 \mathrm{mg} / \mathrm{dL}$. Heart rate and systolic blood pressure increased during A. Diastolic blood pressure was not modified. Glycemic control, lipids and body measurements were not influenced by training. Conclusions: Aerobic and resistance exercise produced glycemia reduction but glycemia fall was higher during aerobic exercise bouts when compared with resistance exercise bouts.

Key words: 1. TYPE 1 DIABETES MELLITUS 2. GLUCOSE SELF MONITORING 3. AEROBIC EXERCISE 4. RESISTANCE EXERCISE 5. GLYCEMIC VARIATION 6. ACUTE AND CHRONIC RESPONSES 
1. Introdução 


\subsection{Diabetes Mellitus}

O diabetes mellitus é um grupo de doenças metabólicas caracterizado por hiperglicemia, resultante de defeitos na secreção da insulina, ação da insulina ou ambos. A hiperglicemia crônica do diabetes é associada com danos, disfunção e falência de vários órgãos a longo prazo, especialmente: olhos, rins, nervos, coração e vasos sangüíneos (ADA, 2007).

Classificação do diabetes mellitus (ADA, 2007):

- Diabetes tipo 1 (DM1) - destruição de células $\beta$, levando à deficiência de insulina.

- Diabetes tipo 2 (DM2) - determinado pela resistência à insulina e deficiência relativa ou absoluta de secreção insulínica.

- Outros tipos específicos.

- Diabetes gestacional.

O diabetes constitui um dos principais fatores de risco para as doenças do aparelho circulatório e representa um problema importante de saúde pública em nosso país. Entre as complicações mais freqüentes, dele decorrentes, encontram-se: o infarto agudo do miocárdio, o acidente vascular cerebral, a insuficiência renal crônica, as amputações de pés e pernas, a cegueira definitiva, os abortos e as mortes perinatais (MINISTÉRIO DA SAÚDE, 2001). 
O acompanhamento e o controle evitam o agravamento do diabetes e a progressão de complicações, reduzindo o número de internações hospitalares, bem como a mortalidade por doenças cardiovasculares que, segundo registros oficiais do Sistema de Informação sobre Mortalidade (SIM), há algumas décadas, têm sido a primeira causa de morte no Brasil (MINISTÉRIO DA SAÚDE, 2001).

A atividade física regular, utilizando grandes grupos musculares, produz adaptações cardiovasculares e melhora a capacidade física, a resistência e a força muscular (THOMPSON et al, 2003). Também previne o desenvolvimento de doenças cardiovasculares (ACSM, 2002; IV DIRETRIZES BRASILEIRAS DE HIPERTENSÃO ARTERIAL, 2001; MINISTÉRIO DA SAÚDE, 1995) e reduz os sintomas em pacientes com a doença já estabelecida (THOMPSON et al, 2003).

\subsection{Atividade física, exercícios aeróbios e exercícios resistidos}

Atividade física é qualquer movimento corporal, produzido por ação muscular, que aumenta o gasto energético. O exercício é uma atividade física planejada, estruturada, repetitiva, traduzindo-se num estímulo capaz de gerar respostas agudas e crônicas, que conduzem a ajustes morfológicos e específicos do organismo. Seu objetivo é aumentar ou manter o condicionamento físico, o qual inclui um conjunto de atributos que as pessoas têm ou obtêm relacionados à habilidade para desempenhar a atividade física: condicionamento cardiorrespiratório, força muscular, composição corporal e flexibilidade (THOMPSON et al, 2003; McARDLE et al, 
2001). O treinamento físico relaciona-se à regularidade com a qual o exercício é realizado e seus benefícios crônicos, dependentes do tempo (RUDERMAN, 2002).

Em relação ao tipo de exercício, é denominado aeróbio quando consiste de movimentos contínuos, repetidos e rítmicos de grandes grupos musculares por no mínimo 10 minutos, como por exemplo: caminhar, pedalar, correr, nadar, etc. Quando o exercício aeróbio é realizado na intensidade, freqüência e tempo de treinamento adequados, pode melhorar o condicionamento físico, representado pela resposta cardiorrespiratória (habilidade dos sistemas cardiopulmonares e circulatório em prover oxigênio durante a atividade física sustentada). O VO2 máximo é a capacidade de captação máxima de oxigênio, sendo considerado o padrão-ouro para avaliar o condicionamento físico ou aeróbio. (SIGAL et al, 2004).

O treinamento de força ou exercício resistido usa a força muscular para mover um peso contra uma determinada resistência, exemplo: exercícios com halteres ou máquinas. Se realizado com regularidade e intensidade moderada a alta, aumenta o condicionamento muscular, que diz respeito à força (quantidade de força que o músculo pode exercer) e resistência (habilidade do músculo para continuar trabalhando sem entrar em fadiga) (SIGAL et al, 2004).

\subsection{Metabolismo Energético}

Adenosina Trifosfato (ATP) é o intermediário químico comum para prover energia a todas as formas de trabalho biológico, tornando-se essencial para a ação muscular. 
Uma pequena quantidade de ATP é estocada nos músculos, para manter o metabolismo basal. Quando a demanda energética aumenta, o ATP é rapidamente sintetizado, o que também requer energia.

Existem três processos comuns para a produção de ATP que devem ser compreendidos como eventos inter-relacionados, onde ocorre o predomínio de um sobre os outros, e não sua exclusividade (BURTON et al, 2004; McARDLE et al, 2001; HARGREAVES, 2000) (Figura 1).

(1) Sistema ATP-CP ou Anaeróbio Alático,

(2) Sistema Anaeróbio Lático ou Glicólise Anaeróbia

(3) Sistema Aeróbio ou Oxidativo.

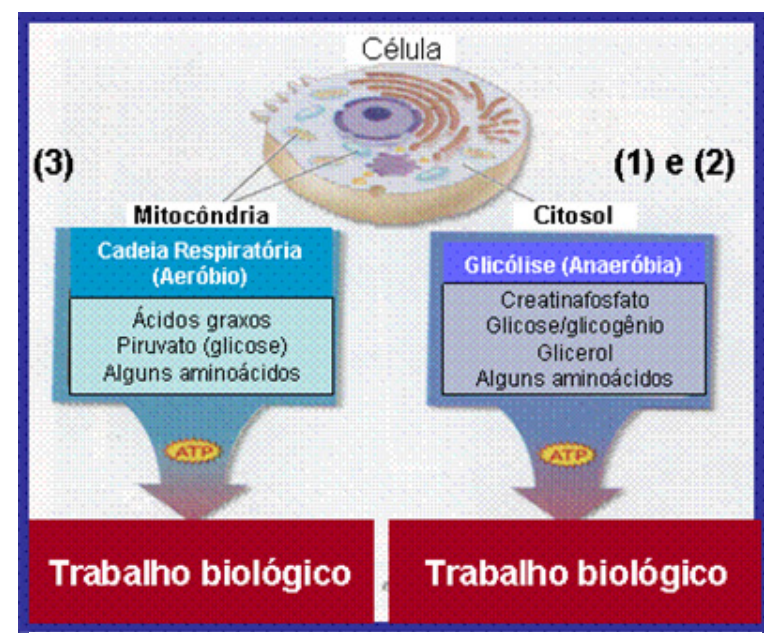

Figura 1. Ressíntese aeróbia e anaeróbia de ATP.

Adaptada de McArdle et al., 2001.

Ao deixarmos a condição de repouso, onde o sistema predominante de ressíntese de ATP é o aeróbio, com o incremento da demanda energética, o sistema imediato a contribuir é o sistema ATP-CP, o qual tem alta capacidade, porém curta duração. Mantida a atividade física, outro sistema energético aumenta sua predominância, o sistema anaeróbio lático ou glicólise anaeróbia, que também não 
manterá sua capacidade total se a atividade continuar. Aumenta então, a contribuição do sistema aeróbio, se mantidas a atividade e sua intensidade (Figura 2).

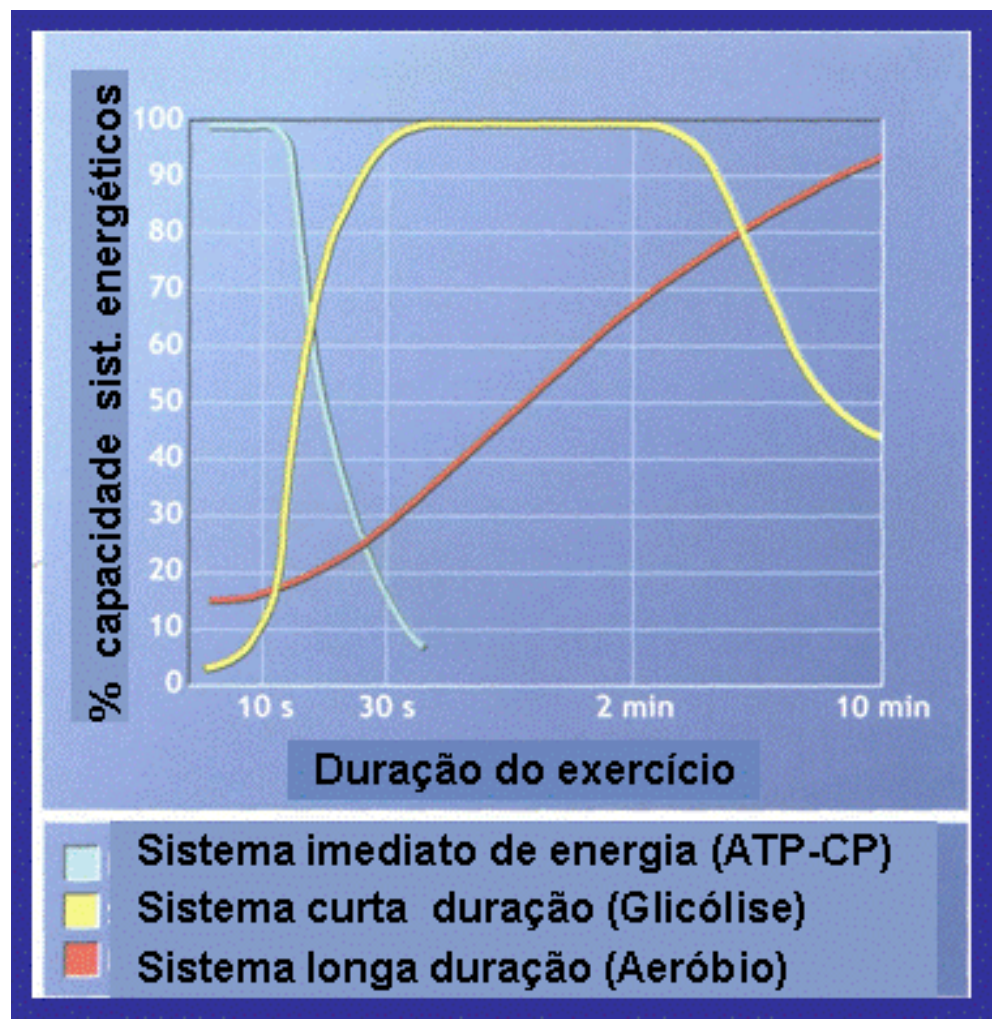

Figura 2. Ativação dos sistemas de transferência de energia Aeróbio e anaeróbio, em diferentes durações do exercício. Adaptada de McArdle et al., 2001.

O fornecimento de substratos energéticos intra e extra-musculares (CP, glicogênio muscular, glicose, lactato e ácidos graxos livres) a serem utilizados pelos diversos sistemas dependerá do tipo de atividade física, principalmente de sua intensidade, freqüência e duração, bem como do nível de treinamento físico, dieta e fatores ambientais. (McARDLE et al, 2001; HARGREAVES, 2000; McARDLE et al, 1998; FOX et al, 1991) Ao contrário do que ocorre em exercícios de baixa a 
moderada intensidade, a glicose torna-se o combustível muscular exclusivo, à medida que a intensidade do exercício aumenta. (MARLISS \& VRANIC, 2002)

\subsection{Captação de glicose pelas células musculares esqueléticas}

A captação de glicose pelas células ocorre por difusão facilitada através da membrana celular, sendo necessária a mediação de proteínas transportadoras de glicose (GLUT). A principal isoforma de transportadores de glicose expressa no músculo esquelético é o GLUT 4, que durante o repouso, fica armazenado em compartimentos intracelulares. Quando estimulado, pelo exercício ou insulina, o GLUT4 transloca-se em direção a membrana plasmática e túbulos $\mathrm{T}$, para o transporte de glicose no músculo esquelético (REA et al, 1997, MACHADO, 2006).

Insulina e atividade física são os maiores estimuladores físiológicos do transporte de glicose no músculo esquelético (RUDERMAN et al, 2002). Estudos demonstram que existem mecanismos distintos para a estimulação do transporte de glicose pelo exercício e pela insulina (JESSEN et al, 2005; McCONELL et al, 2005; RUDERMAN et al, 2002; SHEPHERD et al, 1999) (Figura 3). 


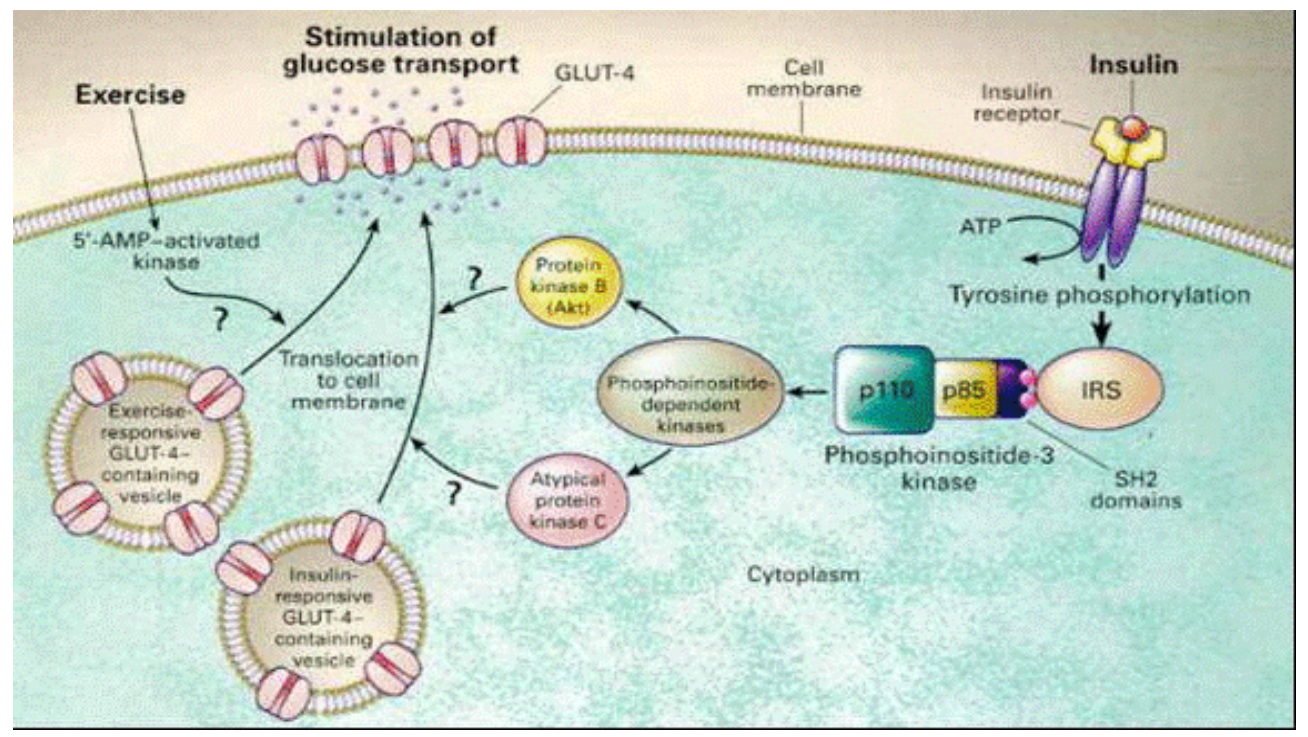

Figura 3. Sinalização da insulina que regula o metabolismo da glicose das células musculares e adiposas. O exercício estimula o transporte da glicose independente da fosfatidilinositol-3quinase e pode envolver a 5'AMP quinase ativada.

\subsubsection{Captação de glicose mediada pela insulina}

A captação de glicose pelas fibras musculares, mediada pela insulina, depende da ligação desta ao seu receptor. O receptor de insulina é uma proteína heterotetramérica, formada por duas subunidades alfa e duas subunidades beta. As duas subunidades alfa são extracelulares, contêm o sítio de ligação para insulina e inibem a atividade tirosina quinase das subunidades beta. Estas subunidades penetram através da membrana para dentro do citoplasma celular e possuem atividade tirosina quinase intrínseca (CARVALHEIRA et al, 2002). A ligação da insulina às subunidades alfa ativa a tirosina quinase, resultando em alteração conformacional e autofosforilação de resíduos de tirosina das subunidades beta do 
receptor. Desta forma, uma cascata de sinalização é desencadeada, levando à fosforilação em tirosina quinase, de muitas outras enzimas intracelulares, incluindo um grupo chamado insulin-receptor substrates (IRS-1 e IRS-2) e ativação da phosphatidylinositol 3- kinase (PI3-quinase) e PKB/Akt, que inativa a glicogênio sintase quinase 3 (GSK-3), estimulando a síntese de glicogênio. A ativação da PKB também resulta na translocação das vesículas de GLUT4 do meio intracelular para a membrana plasmática, onde elas captam a glicose para o interior da célula. Estas reações são fundamentais para a transmissão do sinal do receptor em direção ao interior da célula para a regulação do metabolismo da glicose, lípides e proteínas, via translocação dos GLUTs, síntese de proteínas, ativação e inativação de enzimas e expressão gênica (GUYTON, 2006; JESSEN et al, 2005; CARVALHEIRA et al, 2002; RHODES et al, 2002; BEVAN, 2001; SALTIEL et al, 2001; SHEPHERD et al, 1999).

\subsubsection{Captação de glicose estimulada pelo exercício}

O aumento da captação de glicose durante o exercício resulta do incremento coordenado de seus importantes mecanismos regulatórios: oferta de glicose, transporte celular e fluxo intracelular de substratos por meio da glicólise (ROSE et al, 2005).

Apesar das pesquisas, ainda é pouco conhecido sobre como o exercício ou a ação muscular regula o transporte da glicose do músculo esquelético (ROSE et al, 2005). Existem evidências de que a captação de glicose estimulada pelo exercício 
inclui, como possíveis candidatos envolvidos em sua sinalização: cálcio (CA), calmodulina dependente de proteína quinase (CaMK), proteína quinase $\mathrm{C}(\mathrm{PKC})$, bradicinina, adenosina, AMP-proteína quinase ativada (AMPK) e óxido nítrico (NO). (JESSEN et al, 2005; McCONNELL et al, 2005)

A ação das fibras musculares é iniciada pela despolarização da membrana plasmática e túbulos $\mathrm{T}$, desencadeando a liberação de cálcio do retículo sarcoplasmático. O aumento do cálcio intracelular promove a interação dos filamentos de actina e miosina, resultando em tensão das fibras. $\mathrm{O}$ aumento dos níveis de cálcio e a ativação da AMPK muscular, durante o exercício, devem ser responsáveis, ao menos em parte, pelo aumento da captação de glicose durante a atividade física. AMPK é estimulada pelo aumento da razão de adenosina monofosfato (AMP) para adenosina trifosfato (ATP) e creatina para fosfocreatina. A atividade contrátil altera o padrão energético do músculo esquelético, e dependendo da intensidade das ações musculares, existem quedas significativas nas concentrações de ambas: fosfocreatina e ATP. Parece que a elevação dos níveis da AMP livre, no músculo esquelético, é a principal responsável para o aumento da atividade da AMPK durante o exercício. Quando ocorre diminuição da concentração de ATP, AMPK atua para inativar as vias consumidoras e ativar as vias regeneradoras de ATP. O efeito do cálcio para aumentar a captação de glicose dos músculos esqueléticos parece ser via CaMK, $\mathrm{PKC}$, ou ambas, as quais são importantes intermediárias na transdução do sinal celular. CaMK são uma família de proteínas que fosforila substratos importantes na transcrição, secreção, regulação dos canais íons, e morfogênese. NO também é crucial para a regulação da captação de glicose durante o exercício. E a sua ativação deve ser resultado de um ou mais 
processos a seguir, ou de sua combinação: aumento dos níveis de cálcio intracelular, ativação de AMPK, aumento das espécies reativas de oxigênio (ROS) (JESSEN et al, 2005; McCONNELL et al, 2005).

Outro possível candidato envolvido na sinalização da captação de glicose estimulada pelo exercício é a bradicinina, um hormônio não peptídico, liberado localmente, pelos músculos esqueléticos em ação. A bradicinina media efeitos fisiológicos, como dor, inflamação, permeabilidade vascular, hipotensão, formação de edema, e contração do músculo liso (JESSEN et al, 2005; McCONNELL et al, 2005).

Após uma sessão de atividade física, a utilização de glicose pelos músculos continua elevada para restaurar as concentrações de glicogênio muscular. Quando o estímulo do exercício cessa, o fluxo sangüíneo torna-se mais lento, mas o transporte de glicose permanece elevado e os músculos que estavam ativos estão mais sensíveis à ação da insulina (RUDERMAN et al, 2002).

\subsection{Respostas agudas de portadores de DM1 ao exercício}

\subsubsection{Metabolismo da Glicose}

Os níveis sangüíneos de glicose são regulados espontaneamente em não portadores de diabetes, tanto em repouso quanto em exercício, por meio de mecanismos neurais e hormonais (sistema neuroendócrino) (McARDLE et al, 2001). 
Existe uma contra-regulação entre a secreção de insulina e a concentração de glicose sangüínea (McARDLE et al).

Durante o repouso, o aumento da concentração de glicose sangüínea após uma refeição é acompanhado por aumento da insulinemia e redução dos níveis de glucagon. Isto induz ao aumento da captação de glicose pelas células, redução dos níveis de glicose circulantes e inibição da secreção de insulina. Quando ocorre queda dos níveis de glicose, há aumento da liberação de hormônios com ação antagônica à insulina (epinefrina e noraepinefrina, cortisol, glucagon) os quais estimulam a glicogenólise (conversão dos estoques de glicogênio em glicose) e gliconeogênese (síntese de glicose, principalmente de lactato e aminoácidos) (GUYTON et al, 2006), aumentando a concentração de glicose sangüínea.

Durante o exercício, a estimulação do sistema nervoso simpático bloqueia a liberação de insulina, atenuando o maior declínio da concentração de glicose sangüínea e assegurando energia suficiente para o tecido neural e músculos ativos (GUYTON et al, 2006).

A glicemia de portadores de DM1 não é regulada pela presença de hiper ou hipoglicemia, o que lhes confere uma deficiência na contra-regulação da insulina, tanto em repouso quanto em exercício (SBD, 2005; RUDERMAN et al, 2002). Para eles, a realização de atividade física ou exercício não planejado, sem ajuste da dose de insulina ou da ingestão de carboidratos, somada a captação muscular de glicose facilitada e ao aumento da sensibilidade à ação da insulina, podem aumentar o risco de hipoglicemia. E, o contrário, a redução acentuada da dose de insulina e uma maior ingestão de carboidratos podem exacerbar a hiperglicemia, que se não corrigida, 
pode desencadear o aumento da formação de corpos cetônicos e cetoacidose (RUDERMAN et al, 2002; PEIRCE, 1999; WASSERMAN et al, 1994).

A avaliação da variação glicêmica de portadores de DM1, durante a prática de tipos diferentes de exercícios, padronizando suas intensidades e ajustes de doses de insulina, pode ser útil para a orientação destes pacientes quanto à prática de atividade física.

\subsubsection{Cardiopulmonares}

Com o aumento da atividade física, eleva-se a demanda por oxigênio para dar suporte à ressíntese de ATP pela via aeróbia. Isto requer um incremento na oferta de oxigênio aos músculos ativos pelo sistema cardiovascular, resultando em aumento da ventilação pulmonar e da freqüência cardíaca. (RUDERMAN et al, 2002)

Durante o exercício aeróbio, a vasodilatação intramuscular, causada pelo incremento do metabolismo muscular, mais o aumento da pressão arterial e a redução da resistência vascular periférica, promovem uma elevação significativa do fluxo sangüíneo (GUYTON et al, 2006; McARDLE et al, 2001). Este é então redistribuído para ofertar nutrientes aos músculos ativos. Concomitante a isto ocorre: liberação de hormônios contra-reguladores (adrenalina, glucagon, cortisol e hormônio de crescimento-GH) que estimularão a glicólise hepática, elevando a oferta energética; diminuição da secreção de insulina; e aumento da captação de glicose pelos músculos ativos, principalmente pela via independente da ação da insulina (SIGAL et al, 2004; MARLISS \&VRANIC, 2002; SIGAL et al, 1999; PEIRCE, 1999). A 
freqüência cardíaca, a pressão arterial e o fluxo sangüíneo apresentam relação linear com a intensidade do exercício e retornam aos níveis de repouso ao término do esforço. (NEGRÃO et al, 2005)

Enquanto o exercício dinâmico aumenta o fluxo sangüíneo, o exercício resistido promove uma compressão vascular que aumenta a resistência periférica total e reduz a perfusão muscular. Esta redução do fluxo sangüíneo é diretamente proporcional ao percentual de força máxima executada. E a magnitude da resposta pressórica está relacionada à intensidade do esforço e à quantidade de massa muscular ativada (McARDLE et al, 2001).

Desconhecemos dados na literatura sobre as respostas do sistema cardiovascular, de portadores de DM1, submetidos a exercícios resistidos e a sua comparação com os dados daqueles submetidos a exercícios aeróbios.

\subsection{Respostas crônicas de portadores de DM1 ao exercício}

\subsubsection{Metabolismo da Glicose}

O treinamento aeróbio estimula o aumento: do número de capilares das fibras musculares, do número e tamanho das mitocôndrias, do número de transportadores de glicose (GLUT 4) e das enzimas envolvidas nas reações de oxidação de substratos (RUDERMAN et al, 2002) 
O treinamento de exercícios resistidos aumenta a força muscular, devido a maior recrutamento neural e aumento da massa muscular. Inicialmente o ganho de força é por meio dos ajustes neurais, mudanças no sistema nervoso central e periférico, que melhoram a coordenação do recrutamento da unidade motora e a sinalização neural geral (FRY 2004; DESCHENES et al, 2002; RUDERMAN et al, 2002; FLECK et al, 1999, ENOKA, 1997). O treinamento deste tipo de exercício também aumenta o número de capilares das fibras musculares e promove a transformação das fibras IIB para IIA, que são mais oxidativas e responsivas à ação da insulina quando comparadas às do tipo IIB (DESCHENES et al, 2002).

Existe na literatura uma grande controvérsia em relação à melhora do controle glicêmico, analisado por meio da hemoglobina glicada (HbA1c), de portadores de DM1 submetidos ao treinamento físico. Alguns autores relataram melhora (ADA, 2004; ANDREWS et al, 2002; FLOOD et al, 2002; KOIVISTO et al, 1986), outros não observaram nenhuma mudança (KHAWALI et al, 2003; FUCHSJÄGERMAYRL, 2002; LAAKSONEN et al, 2000; RAILE et al, 1999, LEHMANN et al, 1997), mas ressaltam outros benefícios, independente da melhora do controle glicêmico. Alguns autores sugerem que a melhora está associada ao ajuste da insulina e alimentação para acomodar a atividade física (FLOOD et al, 2002; WASSERMAN et al, 1994). 


\subsubsection{Cardiopulmonares}

O treinamento de exercícios aeróbios, geralmente resulta em aumento da ventilação pulmonar máxima, que somado ao incremento do fluxo sangüíneo pulmonar máximo, elevam a perfusão dos pulmões, resultando numa maior e mais eficiente área para trocas gasosas. O peso e o volume cardíacos também aumentam. Existe um incremento no enchimento das câmaras, um maior alongamento das fibras musculares cardíacas, que em conjunção ao aumento da espessura da parede ventricular, resultará no incremento da força contrátil que pode ser gerada pelo coração durante a sístole. Com isto, a freqüência cardíaca de repouso é reduzida pelo treinamento aeróbio e sua melhora é proporcional à apresentada pelo condicionamento físico, o que demonstra aumento da eficiência cardíaca por meio do treinamento. (RUDERMAN et al, 2002)

O treinamento de exercícios resistidos promove um aumento da espessura da parede ventricular cardíaca, mas não de sua câmara, estimulando poucas mudanças na freqüência cardíaca, no volume sistólico, no débito cardíaco, na resistência vascular periférica, na pressão arterial ou no $\mathrm{VO}_{2}$ máximo, como o treinamento de exercícios aeróbios (NEGRÃO et al, 2005; RUDERMAN et al, 2002).

Estudos evidenciam que o treinamento de exercícios aeróbios tem um grande impacto sobre os fatores de risco de doenças cardiovasculares (ACSM, 2002; IV DIRETRIZES BRASILEIRAS DE HIPERTENSÃO ARTERIAL， 2002; MINISTÉRIO DA SAÚDE, 1995). E para portadores de diabetes, este tipo de treinamento melhora a função endotelial vascular, reduz a dose diária de insulina, (FUCHSJÄGER-MAYRL et al, 2002), melhora o perfil lipídico (KHAWALI et al, 
2003; LAAKSONEN et al, 2000; LEHMANN et al, 1997), o condicionamento físico, a sensibilidade à ação da insulina e o bem-estar psicológico (NEGRÃO et al, 2005; ADA, 2006, ADA, 2004; RUDERMAN et al, 1995). Além disso, a atividade física promove um efeito benéfico em termos de longevidade e qualidade de vida. Moy e colaboradores (1993) mostraram que o nível de atividade física de portadores de DM1 era inversamente relacionado à ocorrência de complicações do diabetes e ao risco de mortalidade e que o número de homens sedentários mortos foi três vezes maior que o número de homens ativos mortos, o que para eles demonstrou um efeito benéfico em termos de longevidade em pacientes diabéticos. Os autores relatam que estes efeitos não são mantidos na ausência do exercício. 


\subsection{Recomendações para a prática segura de exercícios por portadores de diabetes mellitus tipo 1}

A American Diabetes Association, a American College of Sports Medicine, a American Heart Association, entre outros, recomendam a prática de exercícios aeróbios, com pesos e alongamentos (IV DIRETRIZES BRASILEIRAS DE HIPERTENSÃO ARTERIAL, 2002; HORNSBY, 1994). Alguns dos benefícios específicos destes exercícios são: redução dos fatores de risco para o desenvolvimento de doenças cardiovasculares, manutenção ou ganho de força muscular e de mobilidade articular. Os estímulos diferentes se traduzem em respostas agudas e crônicas também diferentes e muito necessárias no cotidiano.

Recentemente, cada vez mais estudos sugerem que os programas de treinamento de resistência, realizados apropriadamente, podem ser seguros e efetivos para portadores de diabetes (ADA, 2006; SIGAL et al, 2004; RUDERMAN et al, 1995). Outros trabalhos têm demonstrado a importância da aquisição de força na reabilitação, promoção e manutenção de saúde, e prevenção de doenças crônicodegenerativas; e o mais importante, com segurança cardiovascular e músculoesquelética (SANTAREM, 2002; WINETT et al, 2001; POLLOCK et al, 2000; FEIGENBAUM \& POLLOCK, 1999; MCCARTNEY, 1999; SOUKUP et al, 1993; SMUTOK et al, 1993).

Antes de iniciar um programa de exercícios, o portador de diabetes deve realizar avaliação médica, identificando a presença de complicações macro e microvasculares, liberando ou não para a prática de atividade física. A presença de complicações não contra-indica a participação do paciente em programa regular de 
atividade física, porém esta deve ser adaptada às complicações existentes (ADA, 2004).

Se o paciente deseja realizar atividades físicas de intensidade moderada a alta, a Associação Americana de Diabetes (ADA) recomenda a realização de um teste de esforço, monitorado pelo eletrocardiograma para avaliar a resposta do sistema cardiovascular frente ao esforço físico, com base nos seguintes critérios (ADA, 2004):

- $\quad$ Idade $>35$ anos ou idade $>25$ anos e

DM2 > 10 anos de duração

DM1 > 15 anos de duração

- Presença de algum fator de risco para doença arterial coronariana;

- Presença de doença microvascular (retinopatia proliferativa ou nefropatia incluindo microalbuminúria);

- Doença vascular periférica;

- Neuropatia autonômica.

Independente da idade e da intensidade do exercício que o paciente vai desenvolver, a realização do teste deve ser levada em consideração, porque o diabetes é um fator de risco para o desenvolvimento de doenças cardiovasculares e o exercício pode induzir efeitos adversos em pacientes com diabetes (RUDERMANN et al, 1995). Além disto, o teste de esforço fornece informações relevantes da resposta cardíaca do paciente frente ao esforço, e necessário para prescrever um programa de exercícios aeróbios individualizado. 
A Associação Americana de Diabetes (ADA, 2004) recomenda que sejam observadas as seguintes considerações em relação aos níveis glicêmicos para a realização de atividade física:

- glicemia $>300 \mathrm{mg} / \mathrm{dL}=>$ cautela;

- glicemia $>250 \mathrm{mg} / \mathrm{dL}$ e presença de cetona => evitar o exercício;

- glicemia $<100 \mathrm{mg} / \mathrm{dL}=>$ ingerir $15 \mathrm{~g}$ a $20 \mathrm{~g}$ de carboidrato.

Estas recomendações devem ser ajustadas à realidade e necessidades individuais de cada pessoa. Pois podem resultar em respostas diferentes até para um mesmo indivíduo, dependendo do tipo, horário, duração e intensidade da atividade, como também do tipo de insulina, horários e locais de aplicação, entre outras variáveis.

É crucial orientar o paciente a monitorizar a glicemia ao longo do período que segue a sessão de treino, quando os estoques depletados durante o exercício estão sendo recuperados (RUDERMAN et al, 2002). A sensibilidade à ação da insulina fica aumentada até 48 horas após uma sessão, devido ao efeito agudo do exercício, aumentando o risco de hipoglicemia (NEGRÃO et al, 2005).

O conhecimento da fisiologia do exercício, da fisiopatologia do diabetes e, principalmente das respostas do paciente aos exercícios, fornecem a base para o desenvolvimento de uma prescrição de exercícios individualizada e segura. 


\subsection{Microalbuminúria induzida pelo exercício}

A microalbuminúria é um dos marcadores mais precoce de lesão renal e disfunção endotelial. A atividade física pode aumentar agudamente a excreção urinária de proteína, decorrente da elevação da pressão glomerular e do aumento da filtração de albumina através da membrana basal glomerular, para o espaço urinário. Estas duas alterações são resultantes do aumento da pressão intravascular nas artérias e arteríolas renais (LANE et al, 2002).

Trabalhos publicados recentemente têm demonstrado que o aumento da microalbuminúria induzida pelo exercício (TUOMINEN et al, 1998) e a perda do descenso noturno da pressão arterial (LURBE et al, 2002) podem ser bons preditores da nefropatia diabética, ocorrendo antes mesmo do aparecimento da microalbuminúria em repouso. A microalbuminúria induzida pelo exercício precede a microalbuminúria em repouso e pode ser reversível com a melhora do controle glicêmico (GARG et al, 1990), podendo ser usado como um teste para identificar portadores de diabetes tipo 1 normoalbuminúricos que são susceptíveis ao desenvolvimento de microalbuminúria (LANE et al, 2002; TUOMINEN et al, 1998; O’BRIEN et al, 1995).

No entanto, permanece controverso se a microalbuminúria induzida pelo exercício em indivíduos portadores de diabetes é maior, menor ou similar aos não portadores (BERTOLUCI et al, 1993; TORFFVIT et al, 1991) e se as diferentes intensidades do exercício influenciam a taxa de microalbuminúria induzida pelo exercício (LANE et al, 2002; BERTOLUCI et al, 1993). 


\subsection{Sistema de monitorização contínua da glicose (CGMS)}

O CGMS (Continuous Glucose Monitoring System) é um sistema de sensor estilo holter que monitoriza contínua e automaticamente os valores de glicose no fluido do tecido subcutâneo, dentro da faixa de 40 a $400 \mathrm{mg} / \mathrm{dL}$, por um período usual de até 3 dias.

O sensor de glicose é um eletrodo pequeno, estéril e flexível, contendo a enzima glicose oxidase. Ele é inserido abaixo da pele do paciente, realiza leituras a cada 10 (dez) segundos e registra a média dos sinais a cada 5 (cinco) minutos, estabelecendo 288 leituras de glicose a cada 24 horas. Estes dados são armazenados em sua memória e podem ser transferidos para um computador pessoal para análise e interpretação com ajuda de um software.

O CGMS é calibrado com a inserção dos valores de glicemia capilar, obtidos por glicosímetro portátil, no mínimo 4 vezes ao dia.

Alguns trabalhos demonstram uma boa correlação entre os valores de glicemia medidos pelo glicosímetro e os valores de glicose intersticial obtidos pelo CGMS (GROSS et al, 2000a,b; REBRIN et al, 1998). Recentemente foi publicado na literatura um estudo piloto, com 5 portadores de diabetes tipo 1, avaliando a eficácia do CGMS antes, durante e após 1 sessão de exercício de alta intensidade, evidenciando uma correlação forte entre estes dois métodos (ISCOE, 2006). O CGMS reporta valores de glicose, em média $5.4 \mathrm{mg} / \mathrm{dL}$ menores do que os medidos por glicosímetros (MASTROTOTARO, 1999). 
A análise detalhada da variabilidade da glicose durante a prática de exercícios por portadores de DM1 pode ser útil para a orientação destes pacientes. Desta forma eles podem obter os benefícios da prática regular de exercício, reduzindo a freqüência dos eventos adversos (hipoglicemia, hiperglicemia e cetoacidose), comumente associados à realização de exercícios por portadores de DM1. O CGMS pode representar uma ferramenta útil para esta análise detalhada, caso mostre-se acurado durante a prática de tipos diferentes de exercícios. 
2. Objetivos 


\section{Objetivo principal:}

Analisar a variação da glicose de portadores de DM1, submetidos às sessões de exercício aeróbio, exercícios resistidos e teste ergoespirométrico, utilizando o Sistema de Monitorização Contínua da Glicose (CGMS) e o glicosímetro portátil para monitorização da glicemia capilar.

\section{Objetivos secundários:}

Analisar a acurácia do CGMS e as respostas agudas e crônicas às sessões de exercícios aeróbio, resistidos e teste ergoespirométrico por portadores de DM 1.

\section{Respostas agudas às sessões de exercícios:}

- Pressão arterial sistólica e diastólica.

- Freqüência cardíaca.

- Freqüência e resolução de hipoglicemias (glicemia $<$ ou $=50 \mathrm{mg} / \mathrm{dL}$ ).

- Redução de doses de insulinas basal e bolus para atividade física. 
Respostas crônicas às sessões de exercícios:

- Controle glicêmico (HbA1c).

- Perfil lipídico: colesterol total, triglicérides, HDL, LDL, VLDL.

- Dose de insulina basal diária.

- Microalbuminúria em repouso e microalbuminúria induzida pelo exercício.

- Dados antropométricos (DEXA).

- Avaliação da capacidade funcional cardiorrespiratória (Testes ergoespirométricos). 


\subsection{Casuística}

Portadores de DM1 (anti-GAD positivo e, ou também, níveis indetectáveis de peptídeo C), atendidos no Ambulatório de Diabetes do serviço de Endocrinologia do Hospital das Clínicas da Faculdade de Medicina da USP (HC-FMUSP) foram convidados a participar deste estudo, desde que não apresentassem os critérios de exclusão relatados abaixo e pesquisados em seus prontuários. Os participantes foram previamente informados e esclarecidos sobre os procedimentos do protocolo de pesquisa e assinaram um termo de consentimento, aprovado pela comissão de ética do Hospital das Clínicas e responderam o questionário sobre o nível de atividade física (HALLAL et al, 2005). Os pacientes foram distribuídos aleatoriamente nos grupos de exercício aeróbio ou resistido. Àqueles sedentários iniciaram o programa de imediato e aqueles que se encontravam engajados em algum tipo de atividade física sistematizada ou espontânea ficaram de 30 a 40 dias sem realizá-la (destreinamento).

Os critérios de exclusão utilizados foram:

- Presença de complicações crônicas

- Nefropatia diabética

- Microalbuminúria de repouso $>30 \mathrm{mg} / \mathrm{g}$ de Creatinina

○ Retinopatia diabética

- Exame de fundo de olho, realizado por oftalmologista. 
- Doença arterial coronariana

- ECG durante o teste ergoespirométrico

- Presença de disfunção tireoideana não compensada

○ T3, T4, T4L e TSH

- $\quad H b A 1 c>9,5 \%$

A Figura 4 é uma apresentação resumida do delineamento deste estudo, descrito detalhadamente a seguir.

Início do estudo
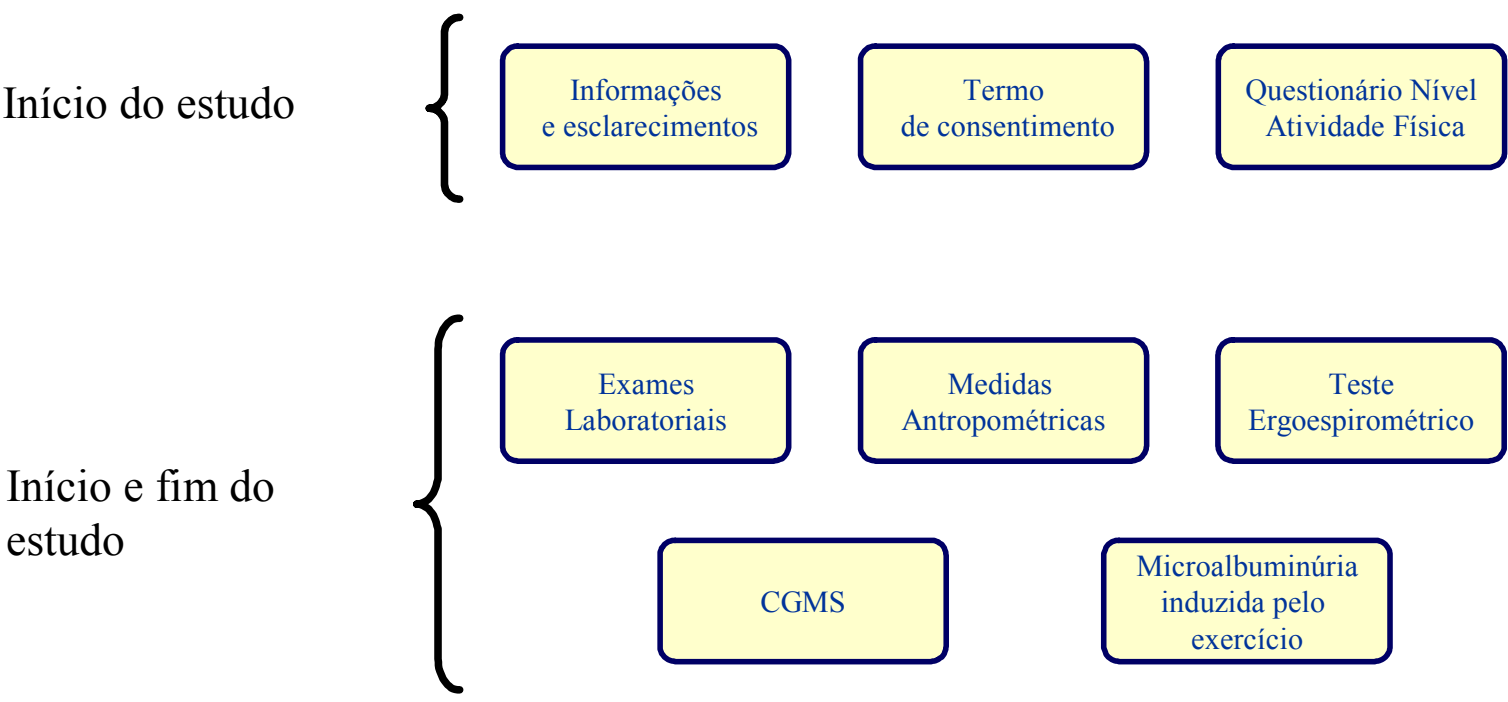

Antes, durante e

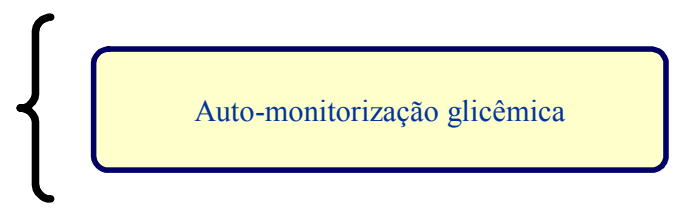
após o estudo

Figura 4. Delineamento do estudo. 


\subsection{Métodos}

No início e fim do período de treinamento (40 semanas) foram realizados exames laboratoriais, medidas antropométricas, teste ergoespirométrico, monitorização contínua da glicose e avaliação da microalbuminúria induzida pelo exercício, com os métodos e valores de referência descritos abaixo. Estes exames foram realizados entre o $5^{\circ}$ e o $15^{\circ}$ dia do ciclo menstrual, tanto no início, como no fim do período de treinamento.

\subsubsection{Exames Laboratoriais}

Tabela 1. Métodos e valores de referências dos exames laboratoriais.

\begin{tabular}{lll}
\hline \multicolumn{1}{c}{ EXAMES } & \multicolumn{1}{c}{ MÉTODO } & VARIAÇÃO NORMAL \\
\hline Glicose & $\begin{array}{l}\text { enzimático colorimétrico } \\
\text { automatizado }\end{array}$ & 70 a $100 \mathrm{mg} / \mathrm{dL}$ \\
HbA1c & HPLC (CLAE) & 4,1 a $6,0 \%$ \\
Microalbuminúria & Nefelometria & $<30 \mathrm{mg} / \mathrm{g}$ de Creatinina \\
Colesterol total & $\begin{array}{l}\text { enzimático colorimétrico } \\
\text { automatizado } \\
\text { enzimático colorimétrico }\end{array}$ & $<200 \mathrm{mg} / \mathrm{dL}$ \\
Triglicérides & $\begin{array}{l}\text { automatizado } \\
\text { enzimático colorimétrico } \\
\text { automatizado }\end{array}$ & $>50 \mathrm{mg} / \mathrm{dL} *$ \\
HDL & $\begin{array}{l}\text { enzimático colorimétrico } \\
\text { automatizado } \\
\text { enzimático colorimétrico }\end{array}$ & $<100 \mathrm{mg} / \mathrm{dL} *$ \\
LDL & $\begin{array}{l}\text { automatizado } \\
\text { VLDL }\end{array}$ &
\end{tabular}

* Valores recomendados para portadores de diabetes (ADA, 2007). 


\subsubsection{Medidas antropométricas}

Peso e altura: o peso corporal $(\mathrm{kg})$ e a altura $(\mathrm{cm})$ foram aferidos utilizando uma balança mecânica e um estadiômetro da marca Filizola, modelo 31 - São Paulo, Brasil.

Circunferência da cintura: foi medida no ponto médio entre a crista ilíaca e a última costela.

Índice de Massa Corpórea (IMC): foi calculado como o peso do paciente (kg), dividido pela sua altura $(\mathrm{m})$ elevada ao quadrado.

Composição Corporal: foi avaliada pelo Dexa (Dual Energy X-Ray Absorptiometry) modelo Hologic QDR 4500 series Bone Densitometers, o qual estima o conteúdo mineral ósseo (BMC) e a densidade mineral óssea (BMD) em $\mathrm{g} / \mathrm{cm}^{2}$.

\subsubsection{Aferição de freqüência cardíaca e pressão arterial antes e após o exercício}

Antes e após as sessões de exercícios, foram aferidas a freqüência cardíaca e a pressão arterial (sistólica e diastólica). A freqüência cardíaca foi mensurada por método palpatório da artéria radial. E a pressão arterial sistólica e diastólica foi mensurada utilizando estetoscópio por método auscultatório. 


\subsubsection{Teste Ergoespirométrico}

\subsubsection{Avaliação eletrocardiográfica e da pressão arterial}

Foi realizado, inicialmente, um eletrocardiograma em repouso, em eletrocardiógrafo (Cardio Control Workstation, versão 1.3.1.216), com o registro das doze derivações padrão (D1, D2, D3, aVR, aVL, aVF, V1, V2, V3, V4, V5, V6). Foram aferidas a freqüência cardíaca e a pressão arterial de repouso, pelo método auscultatório, com o paciente na posição sentada. Em seguida, o teste foi realizado em cicloergômetro eletromagnético (Cardio Control), seguindo protocolo de rampa com aumento de carga a cada minuto, mantendo-se a velocidade de 60 rotações por minuto, até a exaustão. Os incrementos de carga foram calculados pela carga máxima predita menos $10 \%$ e dividida por 10 minutos.

Durante o teste, os pacientes foram monitorados pelo eletrocardiograma e sua freqüência cardíaca foi registrada ao final de cada minuto e no $1 \mathrm{o}, 2^{\circ}, 4^{\circ}$ e $6^{\circ}$ minutos do período de recuperação. E a pressão arterial foi medida nos 30 segundos finais a cada 2 estágios do exercício e no $1^{\circ}, 2^{\circ}, 4^{\circ}$ e $6^{\circ}$ minutos do período de recuperação.

Qualquer alteração eletrocardiográfica observada excluía o paciente do estudo.

\subsubsection{Avaliação da capacidade funcional cardiorrespiratória}

A avaliação da capacidade funcional cardiorrespiratória foi determinada por meio da medida direta do consumo de oxigênio máximo $\left(\mathrm{VO}_{2} \max \right)$. Durante o teste, 
o ar expirado foi coletado e analisado a cada ciclo respiratório pelo analisador de gases computadorizado (Medical Graphics Corporation - MGC, modelo CAD/Net 2001).

A partir das análises de ventilação pulmonar (VE) e das concentrações de oxigênio $\left(\mathrm{O}_{2}\right)$ e dióxido de carbono $\left(\mathrm{CO}_{2}\right)$ expirados, foram calculados o consumo de oxigênio $\left(\mathrm{VO}_{2}\right)$ e a produção de dióxido de carbono $\left(\mathrm{VCO}_{2}\right)$.

$\mathrm{O}$ consumo máximo de oxigênio $\left(\mathrm{VO}_{2} \max \right)$ foi considerado o consumo de $\mathrm{O}_{2}$ obtido no pico do exercício, quando o paciente não conseguia mais manter a velocidade de 60 rotações por minuto no cicloergômetro.

Os critérios mais utilizados para caracterizar um teste máximo são: a) a ocorrência do platô no $\mathrm{VO}_{2}$, isto é a manutenção do valor do $\mathrm{VO}_{2}$ mesmo com incrementos na carga de trabalho; b) RQ (razão de troca respiratória $-\mathrm{VCO}_{2} / \mathrm{VO}_{2}$ ) > 1,10 (ACSM, 2001).

\subsubsection{Determinação do Limiar Anaeróbio e do Ponto de Compensação} Respiratória

O Limiar Anaeróbio (LA) e o Ponto de Compensação Respiratória (PCR) foram obtidos no teste ergoespirométrico e foram utilizados na prescrição da intensidade das sessões de exercício aeróbio.

O LA foi determinado no minuto de exercício em que o paciente apresentou: menores valores do equivalente ventilatório de $\mathrm{O} 2$ (VE/VO2) e pressão parcial final 
de $\mathrm{O} 2$ (PetO2) antes destes iniciarem um aumento progressivo, e incremento não linear da razão de troca respiratória (RER).

O PCR foi determinado no minuto de exercício em que o paciente apresentou: o menor valor do equivalente ventilatório de $\mathrm{CO} 2$ (VE/VCO2), antes deste iniciar um aumento progressivo, e o maior valor da pressão parcial final de CO2 (PetCO2), antes desta começar a diminuir.

\subsubsection{Sistema de Monitorização Contínua da Glicose (CGMS)}

Foi utilizado o sistema de monitorização contínua da glicose (Medtronic MiniMed() e o seu software (MiniMed.Solutions ${ }^{\mathrm{TM}}$ CGMS Sensor MMT-7310, versão 3.0C - 3.0.128) conforme o seguinte protocolo:

- Colocação do CGMS e realização do teste ergoespirométrico, após a calibração inicial do CGMS.

A colocação foi realizada no período da manhã e o teste no período da tarde.

O cateter foi inserido na região abdominal.

- Realização da sessão de exercícios com o CGMS

- Dia livre com o CGMS

- Realização da sessão de exercícios com o CGMS e retirada do aparelho A retirada ocorreu cerca de 30 minutos após o término da sessão. 


\subsubsection{Protocolo de Microalbuminúria induzida pelo exercício}

Ao chegar ao local de treino, o paciente verificava a glicemia capilar, e esta deveria apresentar valores entre $100 \mathrm{mg} / \mathrm{dL}$ e $160 \mathrm{mg} / \mathrm{dL}$ para a realização da coleta de urina. Após a monitorização da glicemia capilar, o paciente desprezava a urina e, em seguida, consumia $500 \mathrm{~mL}$ de água, imediatamente antes do início da sessão de exercícios (GARG et al, 1995).

A coleta de urina simples era obtida ao final da sessão de exercícios e entregue no laboratório central do HC-FMUSP.

\subsubsection{Monitorização da glicemia capilar com glicosímetro}

Os pacientes que participaram desta pesquisa já realizavam a monitorização da glicemia capilar com o glicosímetro Accu-Chek, Roche Diagnóstica.

Foram realizadas glicemias capilares antes, durante (se necessário) e após as sessões de exercícioe ingestão de carboidrato, na forma de gel de glicose (11g), baseado nos critérios da Associação Americana de Diabetes (ADA, 2004), com adaptações. 


\section{Glicemia capilar:}

\section{$<100 \mathrm{mg} / \mathrm{dL}$}

O paciente deveria ingerir o gel de glicose (11g de carboidrato):

1 unidade do gel se glicemia $<100 \mathrm{mg} / \mathrm{dl}$

2 unidades do gel se glicemia $<$ ou $=70 \mathrm{mg} / \mathrm{dl}$

Aguardar cerca de 20 minutos, medir a glicemia novamente e repetir a ingestão do gel, se necessário.

\section{$>250 \mathrm{mg} / \mathrm{dL}$ e presença de cetona}

Quando a glicemia era maior que $250 \mathrm{mg} / \mathrm{dL}$, o paciente realizava um teste de urina para verificar a presença de cetona (Combur ${ }^{10}$ Test-Roche).

Com o teste positivo, ele era dispensado da sessão e orientado a realizar seu controle metabólico.

\section{$>250 \mathrm{mg} / \mathrm{dL}$ sem presença de cetona}

Sem presença de cetona, o paciente iniciava a sessão e verificava a glicemia após 30 minutos, se aumentasse ele era dispensado e orientado.

Ao final de cada sessão de exercício a glicemia capilar era avaliada. Na presença de glicemia $<100 \mathrm{mg} / \mathrm{dL}$, ele ingeria 1 ou mais gel de glicose, sendo liberado apenas com glicemia superior a $100 \mathrm{mg} / \mathrm{dL}$. 


\subsubsection{Avaliações Clínicas}

Foram realizadas avaliações clínicas dos participantes do estudo no início e no fim da pesquisa. Durante o período de treinamento, o paciente foi avaliado sempre que eram percebidas alterações glicêmicas (hipoglicemias ou hiperglicemias) persistentes. Nestes atendimentos foram realizados os ajustes necessários na insulinoterapia.

\subsubsection{Ajuste de doses de insulina}

Os pacientes convidados a participar do projeto faziam uso de insulinoterapia intensiva previamente, em esquema basal/bolus. Realizavam os ajustes necessários da insulina de ação rápida ou ultra-rápida de acordo com o nível glicêmico e a quantidade de carboidratos a ser ingerida. Utilizavam fator de correção (queda aproximada da glicemia após administração de $1 \mathrm{U}$ de insulina de ação rápida ou ultra-rápida), para corrigir as alterações glicêmicas pré-prandiais (DE WITT et al, 2003). O fator de correção, bem como a relação carboidrato/insulina foram ajustados individualmente, pela equipe médica, de acordo com o controle glicêmico, analisado por meio de 4 glicemias capilares ao dia.

Foram disponibilizados nos locais de treino: glicosímetros, fitas reagentes para a verificação de glicemias capilares e cetonúria, bem como géis de glicose.

A sessão de exercícios foi realizada cerca de $2 \mathrm{~h}$ após o almoço. No dia de exercício o paciente foi orientado quanto ao ajuste de dose de insulina: 
1) Insulina Basal

Se o paciente utilizasse menos de 20 unidades de insulina de ação intermediária $(\mathrm{NPH})$ antes do café da manhã, ele teria que diminuir lunidade. Se utilizasse mais de 20 unidades, ele reduziria 2 unidades.

2) Insulina tipo bolus

O paciente reduziu em $50 \%$ a insulina ultra-rápida (calculada a partir da contagem de carboidratos e glicemia pré-prandial) administrada na refeição anterior ao exercício, neste caso, o almoço. Se mesmo assim, ele apresentasse 2 ou mais glicemias $<100 \mathrm{mg} / \mathrm{dL}$ no início, meio ou fim do exercício, ele reduziria em 75\% a insulina rápida ou ultra-rápida (RABASA-LHORET et al, 2001).

\subsubsection{Programa de Treinamento de Exercício Aeróbio (A)}

O programa foi realizado em 40 sessões (cerca de 4 meses), com exceção da primeira semana, denominada familiarização, onde o paciente realizou o movimento sem cargas com a finalidade de aprendê-lo e se ajustar ao aparelho.

Sua freqüência foi de três vezes por semana em dias alternados.

Horário: período pós-prandial do almoço (aproximadamente 2 horas após o início da refeição).

Com a duração de $1 \mathrm{~h}$ de exercício aeróbio por dia, em cicloergômetro.

A intensidade do exercício foi baseada no teste ergoespirométrico, variando entre o Limiar Anaeróbio e o Ponto de Compensação Respiratória.

A progressão do exercício baseou-se na freqüência cardíaca durante o mesmo.

Descrição da sessão: 
Aquecimento: 5 minutos de alongamento;

50 minutos de exercício aeróbio;

5 minutos de relaxamento (NEGRÃO et al, 2001).

\subsubsection{Programa de Treinamento de Exercícios Resistidos ou com pesos (R)}

O programa foi realizado em 40 sessões (cerca de 4 meses), com exceção da primeira semana, denominada familiarização, onde o paciente realizou o movimento sem cargas com a finalidade de aprendê-lo e se ajustar ao aparelho.

Sua freqüência foi de três vezes por semana em dias alternados.

Horário: período pós-prandial do almoço (aproximadamente 2 horas após o início da refeição).

Com a duração de $1 \mathrm{~h}$ por dia, foram realizados 9 (nove) exercícios em aparelhos com sistemas de alavancas e pesos, ativando os principais grupos musculares do corpo: press peitoral, remada, elevações laterais, rosca de bíceps, press de tríceps, leg press, extensões lombares, flexões abdominais e flexões plantares, realizados de 3 (pequenos grupos musculares) a 5 (grandes grupos musculares) séries, de 8 a 12 repetições.

O paciente foi supervisionado e solicitado durante o exercício a: realizar a técnica correta de execução dos exercícios, não bloquear a respiração e relatar sua escala de percepção de esforço, a qual deveria encontrar-se de 13 a 15, correpondendo à intensidade moderada ( Figura 5) (POLLOCK et al, 2000). 
As cargas foram aumentadas sempre que foi possível realizar mais repetições, do que o limite superior da faixa programada para o exercício. Assim, cada treino é um teste de carga sub-máxima.

Descrição da sessão:

Primeiras séries (12 repetições): movimentos lentos e alongados; cerca de $50 \%$ da carga da última série;

Segundas séries (10 repetições): cerca de 70\% da última série;

Últimas séries (8 repetições): carga efetiva de treinamento (KRAEMER \& RATAMESS, 2004).

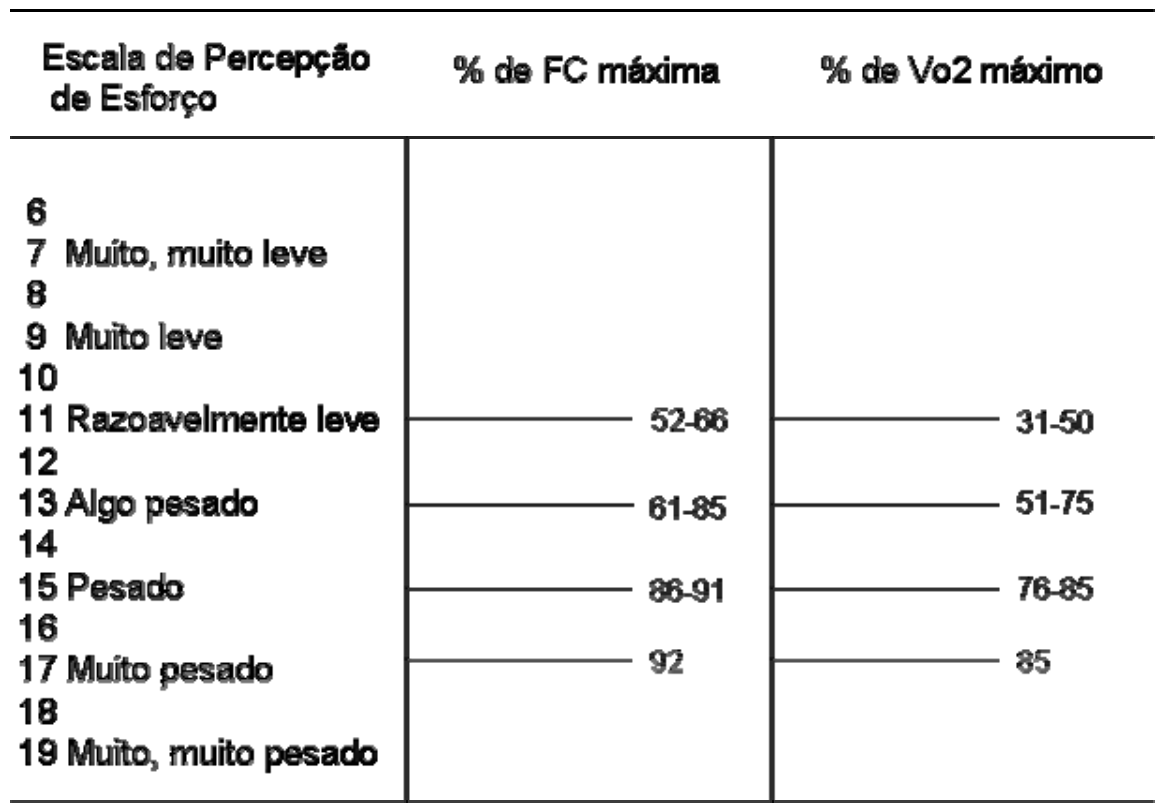

Figura 5. Escala de percepção de esforço de Borg.

Adaptada de McArdle et al, 2001.

Ambos os treinamentos foram realizados sob a orientação e presença da pósgraduanda. 


\subsubsection{Metodologia estatística}

A técnica multivariada de Modelo Linear Geral para medidas repetidas foi utilizada para comparação dos efeitos dos tratamentos para cada uma das variáveis de interesse. O efeito foi estimado a partir da variação Antes e Após os exercícios. A fórmula geral usada para todas as variáveis foi:

\section{EFEITO = MEDIDA (APÓS) - MEDIDA (ANTES)}

Intervalos de confiança de Bonferroni foram ajustados para detecção da significância dos efeitos dos treinamentos (comparando com Zero) e entre os treinamentos (avaliando se tem pontos em comum).

A técnica de Regressão Linear foi aplicada para ajustar as curvas de decaimento das variações de glicemia capilar com o passar das sessões. Três tipos de curvas foram ajustadas: linear, logarítmica e quadrática. Também foi aplicada para ajuste do modelo envolvendo os dois tipos de medições feitas durante os exercícios: glicemia capilar e CGMS.

O teste T-Student foi usado para testar a significância dos parâmetros do modelo de regressão ajustado para os dados de glicose medidos pelos métodos glicosímetro portátil e CGMS.

O teste T-Student para dados pareados foi usado para comparação dos níveis médios de microalbuminúria nas condições de repouso e de exercício. 
Correlação de Pearson foi utilizada para avaliação da associação entre as medidas efetuadas com os dois tipos de equipamentos. 
O estudo incluiu 16 portadores de DM1, sendo 10 do sexo feminino (F) e 6 do sexo masculino (M), com idades variando entre 16 e 45 anos. Dois ( $1 \mathrm{~F}$ e $1 \mathrm{M})$ destes foram excluídos no início do protocolo porque não conseguiram realizar o teste ergoespirométrico: um por elevação da pressão arterial e a outra por queixa de crise asmática durante o teste. Outros 4 pacientes não concluíram o programa de treinamento por problemas pessoais $(3 \mathrm{~F}$ e $1 \mathrm{M})$. E, finalmente 10 pacientes $(6 \mathrm{~F}$ e 4 M) finalizaram o programa de treinamento.

As características clínicas dos pacientes que concluíram o estudo estão descritas na tabela 2. Não houve diferenças significativas entre os pacientes dos grupos A e R, em relação à idade, tempo de diagnóstico, IMC e dose total diária de insulina basal, no início do programa de treinamento. 
Tabela 2 - Características clínicas dos portadores de DM1.

\begin{tabular}{|c|c|c|c|c|c|c|}
\hline Paciente & Exercício & Sexo & $\begin{array}{l}\text { Idade } \\
\text { (anos) }\end{array}$ & $\begin{array}{c}\text { Tempo de } \\
\text { Diagnóstico } \\
\text { (anos) }\end{array}$ & $\begin{array}{l}\text { DTDIB } \\
\text { (u/dia) }\end{array}$ & $\begin{array}{c}\text { IMC } \\
\left(\mathrm{kg} / \mathrm{cm}^{2}\right)\end{array}$ \\
\hline 1 & $\mathrm{~A}$ & $\mathrm{~F}$ & 23 & 7 & 1,19 & 25 \\
\hline 2 & A & $\mathrm{F}$ & 31 & 11 & 0,38 & 21 \\
\hline 3 & A & $\mathrm{F}$ & 16 & 6 & 0,60 & 18 \\
\hline 4 & A & $\mathrm{M}$ & 17 & 8 & 0,40 & 25 \\
\hline 5 & $\mathrm{R}$ & $\mathrm{F}$ & 32 & 4 & 0,20 & 18 \\
\hline 6 & $\mathrm{R}$ & $\mathrm{F}$ & 21 & 18 & 0,23 & 25 \\
\hline 7 & $\mathrm{R}$ & $\mathrm{F}$ & 26 & 10 & 0,59 & 24 \\
\hline 8 & $\mathrm{R}$ & M & 29 & 4 & 0,25 & 22 \\
\hline 9 & $\mathrm{R}$ & M & 45 & 27 & 0,41 & 23 \\
\hline 10 & $\mathrm{R}$ & $\mathrm{M}$ & 17 & 8 & 0,46 & 26 \\
\hline
\end{tabular}

$\mathrm{DTDIB}=$ dose total diária de insulina basal; $\mathrm{A}=$ exercício aeróbio; $\mathrm{R}=$ exercício resistido; $\mathrm{F}=$ feminino; $\mathrm{M}=$ masculino; $\mathrm{IMC}=$ índice de massa corpórea. 


\subsection{Variação da Glicose}

\subsubsection{Variação aguda da glicemia capilar (GC)}

A glicemia capilar foi mensurada com o glicosímetro portátil antes e após cada uma das sessões de exercícios. O impacto dos diferentes tipos de exercícios sobre a glicemia capilar foi avaliado através do cálculo da variação da GC antes e após os exercícios, num total de 40 sessões consecutivas por paciente. A variação foi calculada da seguinte maneira:

\section{VARIAÇÃO GC = GC (Após) - GC (Antes)}

Na tabela 3 apresentamos as variações médias observadas, elas foram obtidas com base na aplicação da técnica de Modelos Lineares Gerais para Medidas Repetidas.

Tabela 3 - Variação da glicemia capilar nas sessões de exercícios segundo o tipo.

\begin{tabular}{lllll}
\hline Grupo & $\begin{array}{l}\text { Variação } \\
\text { Média } \\
(\mathbf{m g} / \mathbf{d L})\end{array}$ & $\begin{array}{l}\text { Desvio } \\
(\mathbf{m g} / \mathbf{d L})\end{array}$ & $\begin{array}{l}\text { I.C. 95\% } \\
\text { Limite } \\
\text { inferior } \\
(\mathbf{m g} / \mathbf{d L})\end{array}$ & $\begin{array}{l}\text { Limite } \\
\text { superior } \\
(\mathbf{m g} / \mathbf{d L})\end{array}$ \\
\hline Aeróbio & $-66,92$ & 10,03 & $-90,05$ & $-43,79$ \\
Resistido & $-36,58$ & 8,19 & $-55,46$ & $-16,69$ \\
\hline
\end{tabular}


O resultado do teste comparativo das variações médias teve estatística $\mathrm{F}=5,490$ com $\mathrm{p}=0,047$, indicando ser significativa a diferença observada. Os exercícios aeróbios promoveram uma queda maior na GC $(67 \mathrm{mg} / \mathrm{dL})$, quando comparada à queda causada pelos exercícios resistidos $(37 \mathrm{mg} / \mathrm{dL})$.

$\mathrm{Na}$ figura 6 apresentamos graficamente o resultado das variações observadas nas 40 sessões de treinamento. Os resultados são apresentados por tipo de exercício (Grupo).

Variação Aguda da Glicose (GC)

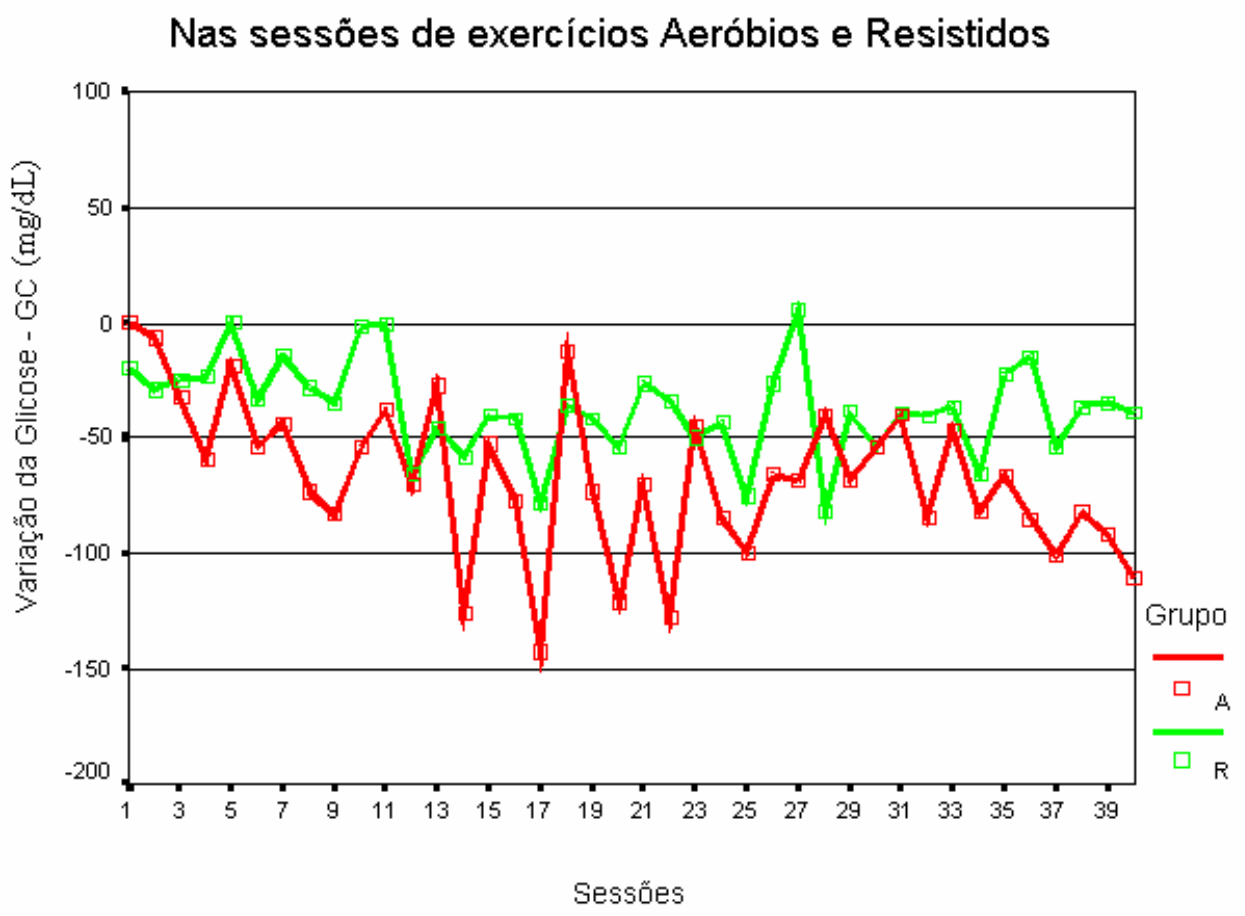

Figura 6 - Evolução da variação da glicemia capilar com as sessões de exercícios.

Para cada tipo de exercício ajustamos curvas para descrever o comportamento das variações de glicemia capilar em função do número de sessões realizadas. $\mathrm{Na}$ 
figura 7 apresentamos os resultados dos ajustes conseguidos com base na técnica de Regressão Linear.

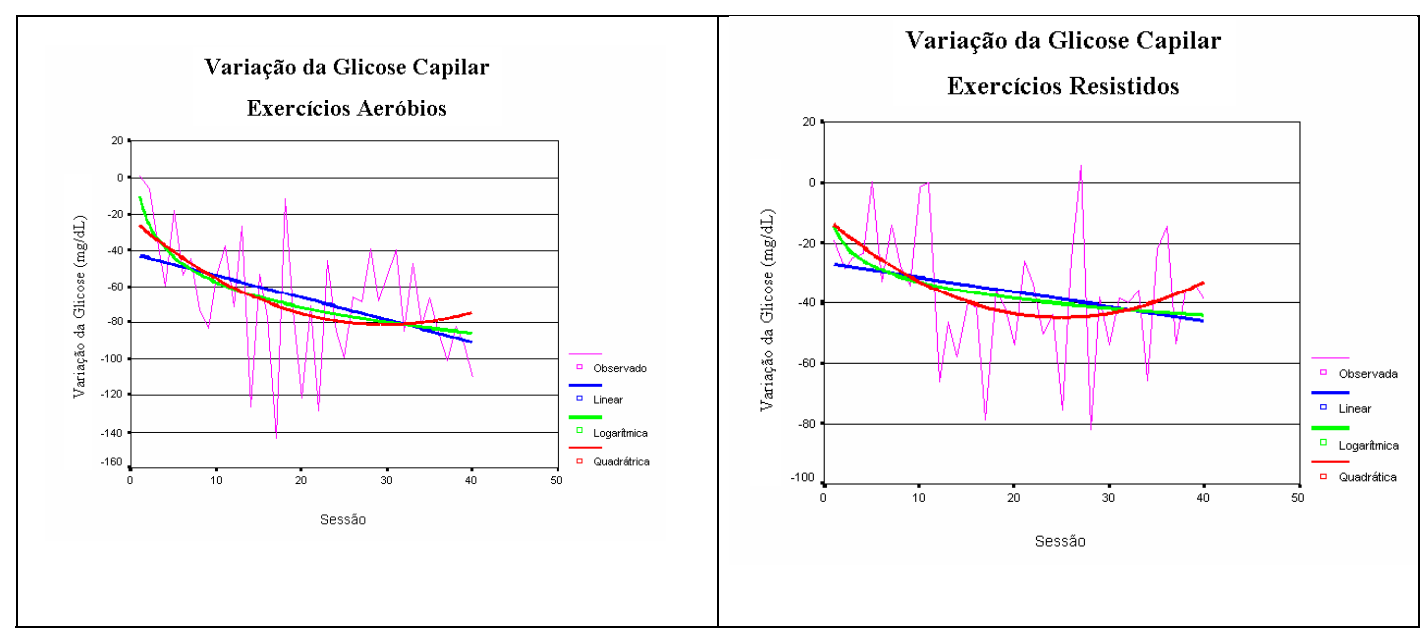

Figura 7 - Ajustes de curvas para a variação da GC em função do número de sessões de exercício realizadas.

Na tabela 4 apresentamos os valores dos parâmetros da equação linear ajustada para cada tipo de exercício (Grupo). Evidenciamos que o exercício aeróbio promove uma queda inicial na $\mathrm{GC}$, durante o período de treinamento, mais rápida que o resistido e que a taxa de decréscimo da GC com o número de sessões do exercício aeróbio é 2,5x maior que a do exercício resistido.

Tabela 4 - Parâmetros das equações de reta ajustada para a queda da GC.

\begin{tabular}{|c|c|}
\hline Aeróbio & Resistido \\
\hline$R=0,431, p=0,005$ & $R=0,276, p=0,085$ \\
\hline Constante $=\mathbf{- 4 1 , 5 5}$ & Constante $=\mathbf{- 2 6 , 5 2}$ \\
\hline Taxa $=\mathbf{- 1 , 2 4}$ por sessão & Taxa $=\mathbf{- 0 , 4 9}$ por sessão \\
\hline
\end{tabular}




\subsubsection{Variação aguda da glicose utilizando o Sistema de Monitorização Contínua da Glicose (CGMS)}

Foi utilizada a Técnica de Modelos Lineares Gerais (MLG), para medidas repetidas, para a avaliação do comportamento das medições, feitas com o Sistema de Monitorização Contínua da Glicose durante a realização dos dois tipos de exercícios (grupos), nos períodos Inicial e Final de treinamento e considerando as duas condições de redução de dose de insulina ultra-rápida (UR): 50 e 75\%.

A significância dos efeitos dessas variáveis pode então ser testada. Os resultados estão na tabela 5 e ilustrados pelas figuras 8 a 10 .

Tabela 5 - Testes do MLG para as medidas de glicose feitas com o CGMS durante os exercícios.

\begin{tabular}{|c|c|c|c|}
\hline E F E I TOS & Wilk's $\lambda$ & $\mathbf{p}$ & Interpretação \\
\hline Glicose no Tempo & 0,477 & $\mathbf{0 , 0 5 1}$ & Queda significativa \\
\hline Tipo de exercício (A e R) & 0,728 & 0,644 & $\begin{array}{l}\text { Mesmo perfil nos dois } \\
\text { tipos de exercício }\end{array}$ \\
\hline $\begin{array}{l}\text { Período de treinamento } \\
\text { (Início e Fim) }\end{array}$ & 0,631 & 0,329 & $\begin{array}{l}\text { Mesmo perfil nos dois } \\
\text { tipos de exercício }\end{array}$ \\
\hline Esquema UR (50 e 75\%) & 0,510 & $\mathbf{0 , 0 8 4}$ & $\begin{array}{l}\text { Há indícios de diferença } \\
\text { no comportamento }\end{array}$ \\
\hline
\end{tabular}

As figuras 8 a 10, mostradas a seguir ilustram os resultados e principalmente servem de apoio para as interpretações da tabela 5. 


\section{Médias corrigidas e glicose - CGMS \\ (durante os exercícios)}

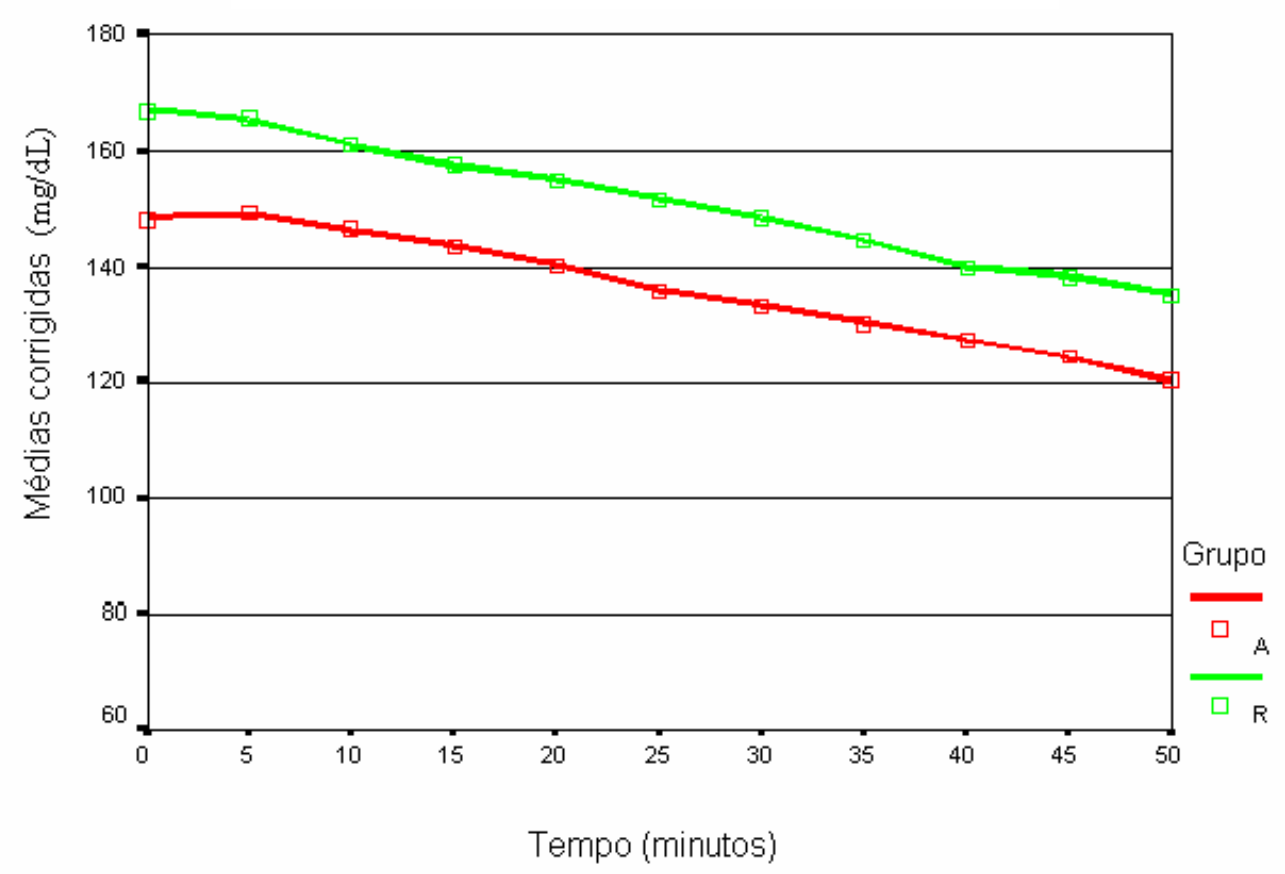

Figura 8. Comportamento da Glicose avaliado durante os exercícios com o CGMS.

A tendência de decaimento linear das concentrações de glicose em função do tempo de exercício foi significativa, $\mathrm{F}=15,127$ com $\mathrm{p}=0,001$.

$\mathrm{O}$ efeito do período de treinamento também foi similar nos testes efetuados durante a realização dos exercícios. A diferença entre os níveis médios das curvas não foi evidenciado, com base no número de pacientes avaliado (Figura 9). Uma casuística maior poderá evidenciar a diferença dos níveis médios de glicose. 
Médias corrigidas e glicose - CGMS

(durante os exercícios)

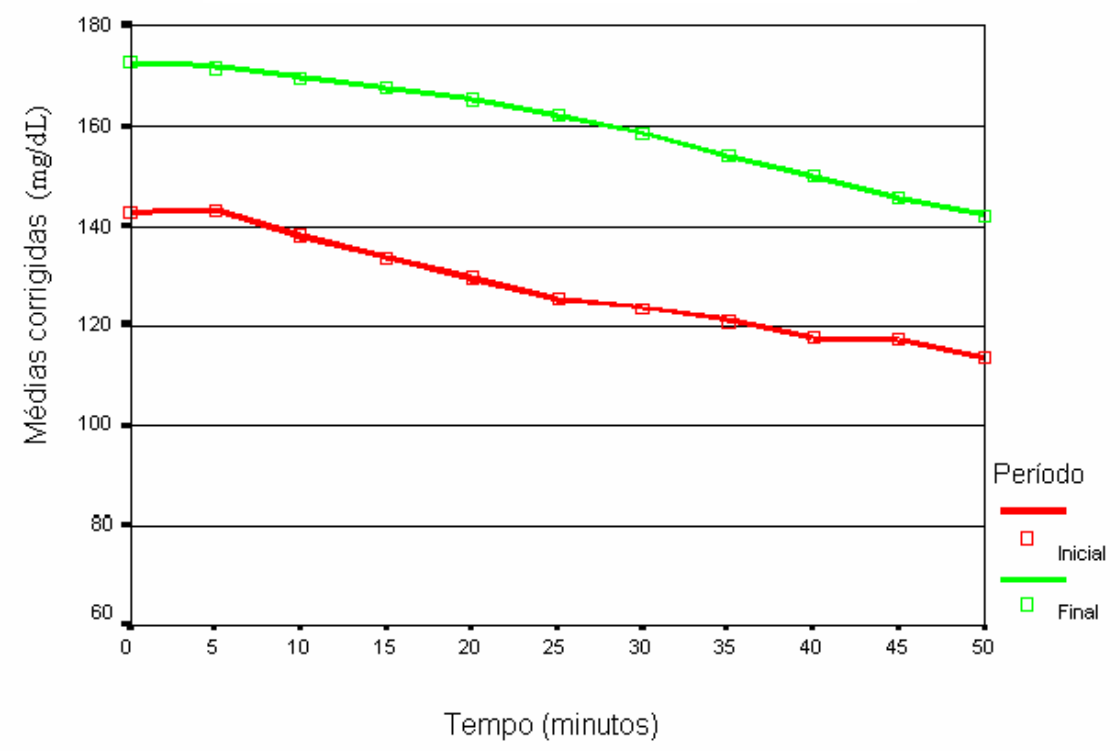

Figura 9. Evolução da glicose (CGMS) durante os exercícios, segundo o período de treinamento.

Médias corrigidas e glicose - CGMS

(durante os exercícios)

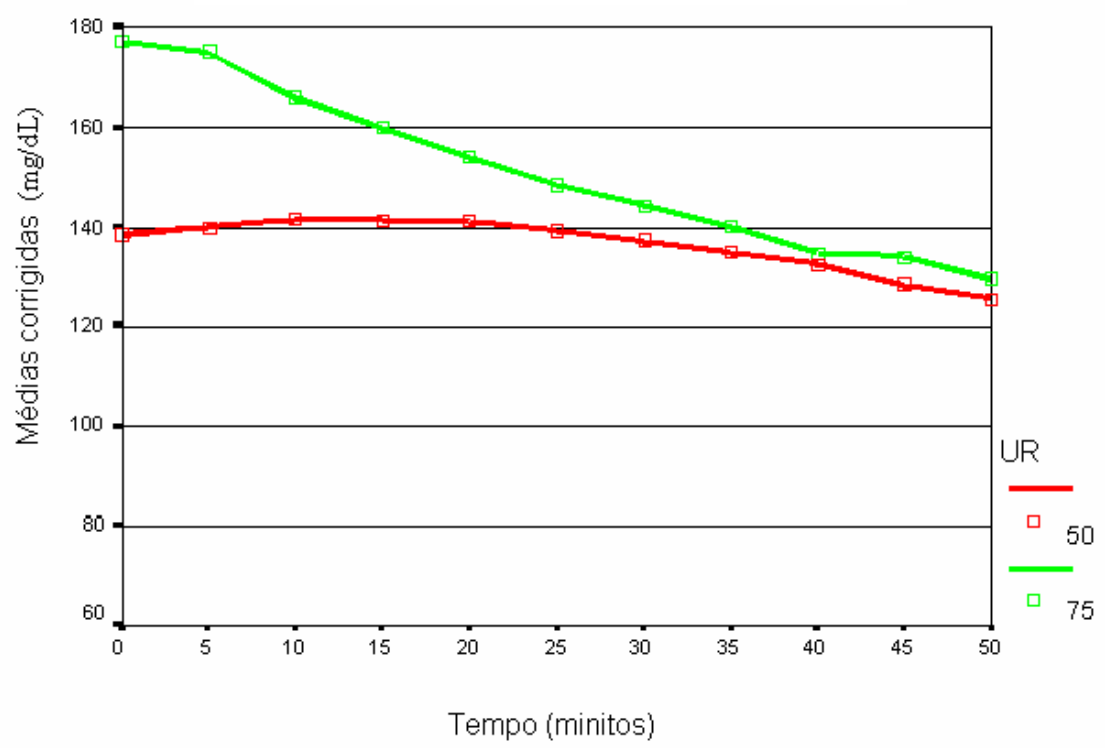

Figura 10. Evolução da Glicose (CGSM) segundo os esquemas

UR $50 \% \times 75 \%$ 
Conforme apontado na tabela 5, há indícios de comportamento diferenciado para os dois esquemas, enquanto observamos uma queda constante com redução de $75 \%$ de UR, no esquema com redução de $50 \%$ de UR o comportamento da glicose, praticamente ficou estável durante a realização dos exercícios (Figura10).

Vale observar que essa conclusão já conta com a eliminação dos efeitos do tipo de exercício e do período de treinamento.

\subsection{Acurácia do CGMS}

\subsubsection{Avaliação do Sistema de Monitorização Contínua da Glicose (CGMS) e GC para medidas de glicose durante a realização de exercícios físicos}

Nessa avaliação foram considerados os seguintes dados: tipo de exercício (grupo), período de treinamento (Início/Fim), esquema de redução de insulina UR (50 x 75\%), tempo de execução dos exercícios (minutos), pressão arterial sistólica (PAS) e pressão arterial disatólica (PAD), freqüência cardíaca e as duas medidas de glicose baseadas em GC e CGMS.

Um modelo de Regressão linear múltipla foi ajustado para a previsão das concentrações de glicose GC em função das medidas efetuadas com o CGMS. O processo de adequação do modelo consiste em ajustar um modelo saturado, contendo todas as variáveis e ir retirando as variáveis, uma a uma, de acordo com a 
significância das mesmas, até que tenhamos um modelo final com somente variáveis com contribuição significativa para explicar as variações da glicemia medidas com o glicosímetro.

Na tabela 6 apresentamos os resultados do ajuste do modelo saturado.

Tabela 6 - Resultados do ajuste do modelo saturado para GC em função do CGMS

\begin{tabular}{lllllll}
\hline & \multicolumn{7}{l}{ Coeficientes } & $\begin{array}{l}\text { Coeficientes } \\
\text { padronizados }\end{array}$ & T & P \\
Variáveis no Modelo & B & Desvio & Beta & & \\
\hline (Constante) & 111,456 & 40,075 & & 2,781 & 0,007 \\
CGMS (mg/dL) & 0,813 & 0,041 & 0,944 & 19,903 & $<0,001$ \\
Grupo (A e R) & $-18,145$ & 7,450 & $-0,142$ & $-2,436$ & 0,018 \\
PAS (mmHg) & $-0,587$ & 0,293 & $-0,104$ & $-2,005$ & 0,049 \\
PAD (mmHg) & 0,064 & 0,467 & 0,008 & 0,137 & $\mathbf{0 , 8 9 1}$ \\
FC (bpm) & $-0,233$ & 0,189 & $-0,073$ & $-1,233$ & 0,222 \\
Tempo (min) & 0,059 & 0,090 & 0,033 & 0,656 & 0,514 \\
UR (50 e 75\%) & 0,530 & 0,307 & 0,102 & 1,728 & 0,089 \\
Período & de & $-15,563$ & 7,452 & $-0,126$ & $-2,089$ & 0,041 \\
treinamento (I/F) & & & & & \\
\hline
\end{tabular}

Esse primeiro ajuste indica que há variáveis com contribuição não significativa para explicar as variações das dosagens de glicose, a menos significativa foi a PAD (maior valor de p). Na tabela 7 apresentamos a seqüência das variáveis não significativas que foram retiradas do modelo de ajuste aos dados de dosagens de glicose com o GC e CGMS. 
Tabela 7 - Seqüência de variáveis com contribuição não significativas.

\begin{tabular}{lll}
\hline Passo & Variável removida & P \\
\hline 1 & PAD (mmHg) & 0,891 \\
2 & Tempo de exercício (min) & 0,499 \\
3 & Freqüência cardíaca (bpm) & 0,286 \\
4 & Esquema UR (50 e 75\%) & 0,095 \\
& Período de treinamento & \\
5 & (Início e Fim) & 0,121 \\
\end{tabular}

Temos então que, a PAD, o tempo de exercício, a freqüência cardíaca, o esquema de redução de insulina UR e o período de treinamento não influenciaram significativamente as dosagens de glicose durante a realização dos exercícios. As variáveis que apresentaram influências significativas estão no modelo final ajustado e cujos resultados estão na tabela 8 , a seguir.

Tabela 8 - Resultados do modelo final ajustado para as dosagens de glicose durante os exercícios.

\begin{tabular}{|c|c|c|c|c|c|}
\hline \multirow[b]{2}{*}{$\begin{array}{l}\text { Variáveis } \\
\text { Modelo }\end{array}$} & \multicolumn{2}{|c|}{ Coeficientes } & \multirow{2}{*}{$\begin{array}{l}\text { Coeficientes } \\
\text { padronizados } \\
\text { Beta }\end{array}$} & \multirow{2}{*}{$\mathbf{T}$} & \multirow{2}{*}{$\mathbf{p}$} \\
\hline & B & Desvio & & & \\
\hline (Constante) & 91,356 & 29,138 & & 3,135 & 0,002 \\
\hline $\begin{array}{l}\text { CGMS } \\
(\mathrm{mg} / \mathrm{dL})\end{array}$ & 0,796 & 0,038 & 0,925 & 21,126 & $<\mathbf{0 , 0 0 1}$ \\
\hline Grupo (A e R) & $-12,744$ & 5,687 & $-0,100$ & $-2,241$ & 0,028 \\
\hline PAS (mmHg) & $-0,499$ & 0,251 & $-0,088$ & $-1,988$ & 0,051 \\
\hline
\end{tabular}


O coeficiente de explicação do modelo final foi de $r^{2}=86,6 \%$, as concentrações de glicose medidas pelo CGMS foram as que mais se associaram às medidas de GC, em seguida o tipo de exercício e por fim a PAS.

Na tabela 9 apresentamos as equações dos modelos finais ajustados para os dois grupos.

Tabela 9 - Equações dos modelos preditivos de dosagens de glicose (GC) em função das observadas com o CGMS nos dois grupos de exercício.

\begin{tabular}{ll}
\hline Aeróbio & Resistido \\
\hline $\mathrm{GC}=91,356+0,796 \mathrm{CGMS}-0,499 * \mathrm{PAS}$ & $\mathrm{GC}=78,612+0,796 \mathrm{CGMS}-0,499 * \mathrm{PAS}$ \\
\hline
\end{tabular}

Outro indicador da qualidade do modelo é o grau de aderência entre os valores previstos pelo modelo contra os efetivamente observados. Na figura 11 apresentamos esses dados. Devemos observar que a explicação do modelo foi de 97,63\%. 


\section{Diagrama de dispersão: previsto $x$ real}

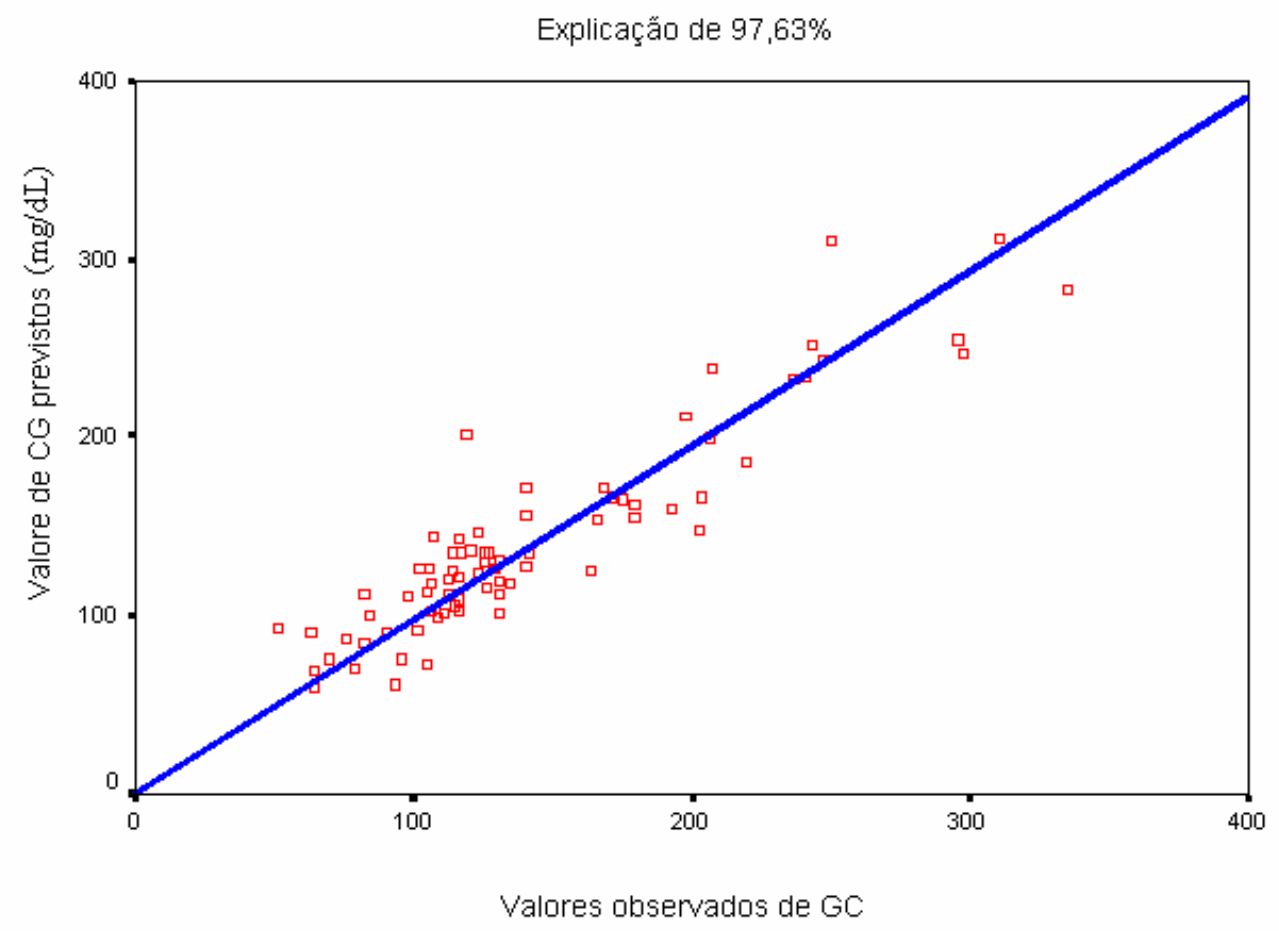

Figura 11. Valores previstos de GC x valores observados de GC durante o exercício

4.2.2 Correlação entre as médias de glicose obtidas pelo glicosímetro (GC) e CGMS durante o teste ergoespirométrico (TE).

Analisamos a correlação entre os dados obtidos pelo CGMS e pelo glicosímetro, durante o teste ergoespirométrico e tivemos os seguintes resultados:

- a correlação é significativa $(\mathrm{p}<0,001)$, positiva e direta $(\mathrm{r}=+0,925)$;

- o modelo obtido foi: $[\mathrm{GC}]=0,95 \times$ [CGSM];

- o teste do coeficiente angular teve estatística igual a $\mathrm{t}=16,892$ com $\mathrm{p}<0,001$; 
- o intervalo de confiança com 95\% para o coeficiente é [0,837 ---- 1,063$]$, que contém a unidade, ou seja, praticamente os métodos se equivalem quanto as medidas efetuadas, pois o teste do coeficiente linear apontou que o mesmo pode ser considerado igual a zero.

$\mathrm{Na}$ figura 12 apresentamos a reta ajustada, o intervalo de confiança para o modelo e os dados efetivamente observados.

\section{Diagrama de dispersão das medidas de glicose pelo glicosímetro e CGMS}

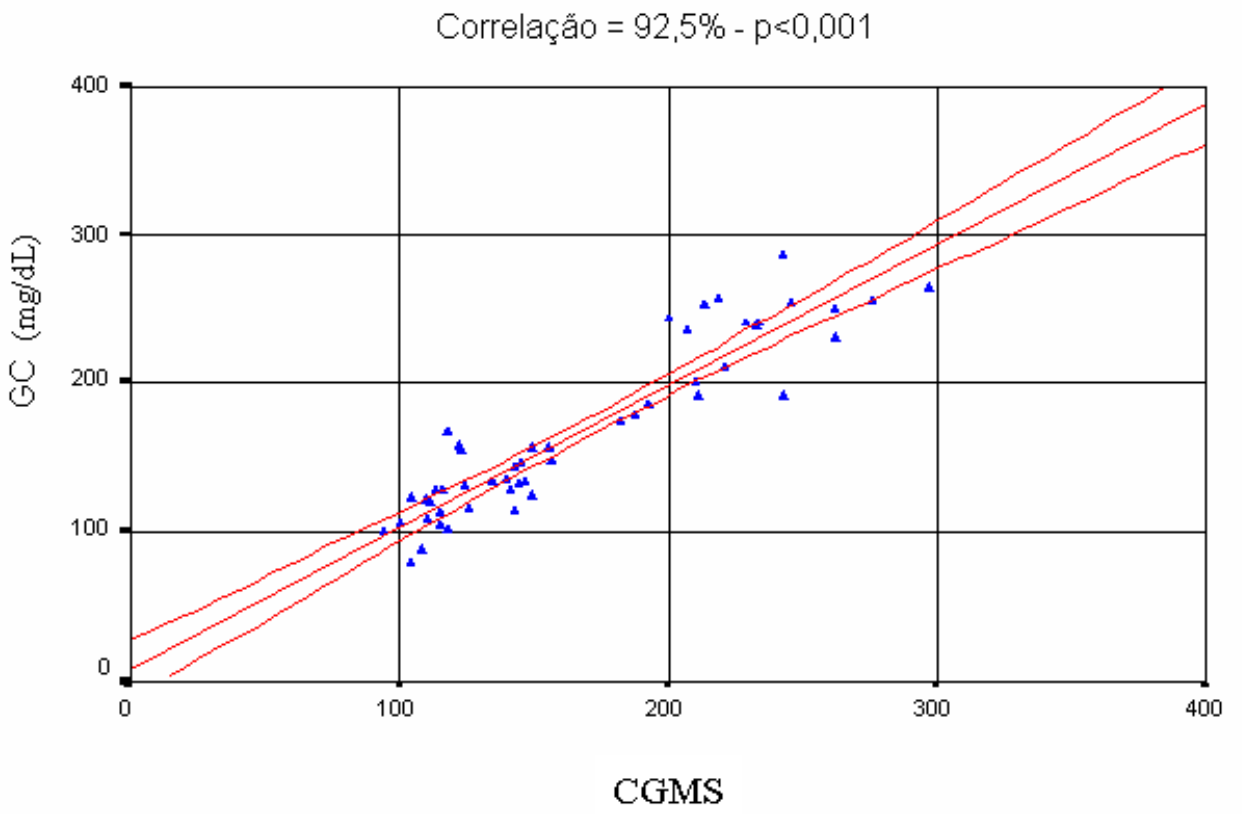

Figura 12. Correlação entre as medidas de glicose obtidas pelo glicosímetro e CGMS, durante o teste ergoespirométrico. 


\subsection{Análise temporal do comportamento da glicose durante os exercícios}

O modelo ajustado considerando o tipo de exercício e o tempo de exercício teve como resultado a ausência de diferença significativa entre os dois tipos de exercício (grupos), a estatística observada foi igual a $\mathrm{F}=0,752$ com $\mathrm{p}=0,386$. As curvas tiveram o mesmo perfil (comportamento quadrático) diferindo somente no nível. A tabela 10 apresenta os níveis médios associados aos grupos.

Tabela 10 - Níveis médios de glicose por grupo - CGMS .

95\% Intervalo de Confiança

GRUPO Média Desvio

Limite Inferior Limite Superior

\begin{tabular}{lllll}
$\mathbf{A}$ & 140,161 & 5,535 & 129,276 & 151,046 \\
$\mathbf{R}$ & 146,215 & 4,255 & 137,848 & 154,582 \\
\hline
\end{tabular}

Nessas condições o ajuste final do modelo foi feito com base em todos os dados, independentemente do tipo de exercício. Os dados do ajuste estão na tabela 11 .

Tabela 11 - Variáveis dependentes: CGMS.

\begin{tabular}{ccrrr}
\hline & Média & \multicolumn{2}{c}{ Desvio } & \multicolumn{2}{c}{$\begin{array}{c}\text { 95\% Intervalo de Confiança } \\
\text { LEMPO }\end{array}$} & & Limite Inferior & Limite Superior \\
\hline $\mathbf{0}$ & 154,371 & 11,185 & 132,378 & 176,365 \\
$\mathbf{5}$ & 154,486 & 11,185 & 132,492 & 176,480 \\
$\mathbf{1 0}$ & 152,686 & 11,185 & 130,692 & 174,680 \\
$\mathbf{1 5}$ & 150,457 & 11,185 & 128,463 & 172,451 \\
$\mathbf{2 0}$ & 148,457 & 11,185 & 126,463 & 170,451 \\
$\mathbf{2 5}$ & 145,286 & 11,185 & 123,292 & 167,280 \\
$\mathbf{3 0}$ & 142,429 & 11,185 & 120,435 & 164,422 \\
$\mathbf{3 5}$ & 138,971 & 11,185 & 116,978 & 160,965 \\
$\mathbf{4 0}$ & 135,314 & 11,185 & 113,320 & 157,308 \\
$\mathbf{4 5}$ & 132,286 & 11,185 & 110,292 & 154,280 \\
$\mathbf{5 0}$ & 128,886 & 11,185 & 106,892 & 150,880 \\
\hline
\end{tabular}


Foram ajustados modelos lineares e exponenciais, ambos com coeficiente de explicação inferior ao modelo quadrático, daí a escolha do mesmo. O modelo matemático estabelecido para a predição do nível de glicose, relacionado ao tempo de exercício é:

Glicose $=155,28-0,247 * \mathbf{T}-0,00587 * \mathbf{T}^{2}$

Explicação $=99,66 \% \quad \mathrm{p}<0,001$

$\mathrm{T}=$ tempo em minutos.

Como as características individuais dos grupos pesquisados se refletem na constante do modelo, ajustamos o mesmo para vários valores iniciais (constantes), visto que o comportamento de decaimento será o mesmo (Figura 13) e as curvas podem ser vistas na figura 14 .

\section{Modelo para qualquer condição de Glicose Inicial}

\begin{tabular}{|c|c|c|c|c|c|c|c|c|c|}
\hline Glicose Inicial & 100 & 110 & 120 & 130 & 140 & 150 & 160 & 170 \\
\hline Tempo & \multicolumn{9}{|c|}{ M O D E L O } \\
\hline $\mathbf{0}$ & 100 & 110 & 120 & 130 & 140 & 150 & 160 & 170 \\
\hline $\mathbf{5}$ & 99 & 109 & 119 & 129 & 139 & 149 & 159 & 169 \\
\hline $\mathbf{1 0}$ & 97 & 107 & 117 & 127 & 137 & 147 & 157 & 167 \\
\hline $\mathbf{1 5}$ & 95 & 105 & 115 & 125 & 135 & 145 & 155 & 165 \\
\hline $\mathbf{2 0}$ & 93 & 103 & 113 & 123 & 133 & 143 & 153 & 163 \\
\hline $\mathbf{2 5}$ & 90 & 100 & 110 & 120 & 130 & 140 & 150 & 160 \\
\hline $\mathbf{3 0}$ & 87 & 97 & 107 & 117 & 127 & 137 & 147 & 157 \\
\hline $\mathbf{3 5}$ & 84 & 94 & 104 & 114 & 124 & 134 & 144 & 154 \\
\hline $\mathbf{4 0}$ & 81 & 91 & 101 & 111 & 121 & 131 & 141 & 151 \\
\hline $\mathbf{4 5}$ & 77 & 87 & 97 & 107 & 117 & 127 & 137 & 147 \\
\hline $\mathbf{5 0}$ & 73 & 83 & 93 & 103 & 113 & 123 & 133 & 143 \\
\hline $\mathbf{5 5}$ & 69 & 79 & 89 & 99 & 109 & 119 & 129 & 139 \\
\hline $\mathbf{6 0}$ & 64 & 74 & 84 & 94 & 104 & 114 & 124 & 134 \\
\hline $\mathbf{6 5}$ & 59 & 69 & 79 & 89 & 99 & 109 & 119 & 129 \\
\hline $\mathbf{7 0}$ & 54 & 64 & 74 & 84 & 94 & 104 & 114 & 124 \\
\hline $\mathbf{7 5}$ & 48 & 58 & 68 & 78 & 88 & 98 & 108 & 118 \\
\hline $\mathbf{8 0}$ & 43 & 53 & 63 & 73 & 83 & 93 & 103 & 113 \\
\hline $\mathbf{8 5}$ & 37 & 47 & 57 & 67 & 77 & 87 & 97 & 107 \\
\hline $\mathbf{9 0}$ & 30 & 40 & 50 & 60 & 70 & 80 & 90 & 100 \\
\hline
\end{tabular}


Figura 13. Generalização do modelo para qualquer condição de glicose inicial.

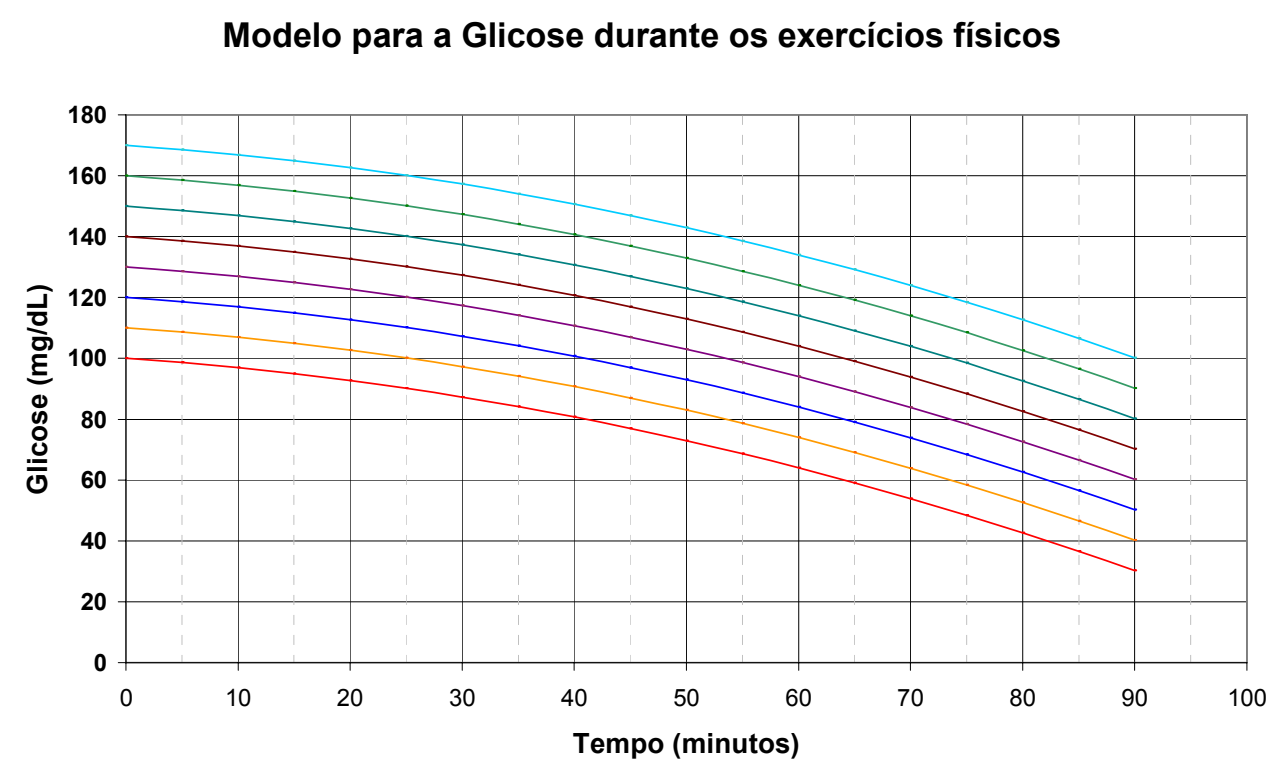

Figura 14. Curvas modelo para determinação do comportamento da glicose durante sessões de exercício.

\subsection{Freqüência cardíaca}

Na tabela 12 apresentamos o efeito dos exercícios aeróbios e resistidos sobre a freqüência cardíaca dos pacientes.

Tabela 12 - Efeito dos treinamentos sobre a freqüência cardíaca.

\begin{tabular}{lllll}
\hline Grupo & $\begin{array}{l}\text { Média } \\
(\mathbf{b p m})\end{array}$ & $\begin{array}{l}\text { Desvio } \\
\text { padrão } \\
(\mathbf{b p m})\end{array}$ & $\begin{array}{l}\text { I.C. 95\% } \\
\text { Limite } \\
\text { inferior } \\
(\mathbf{b p m})\end{array}$ & $\begin{array}{l}\text { Limite } \\
\text { superior } \\
(\mathbf{b p m})\end{array}$ \\
\hline Aeróbio & $+42,6$ & 5,1 & 30,408 & 54,792 \\
Resistido & $+4,7$ & 3,7 & $-3,896$ & 13,346 \\
\hline
\end{tabular}


O resultado da aplicação da técnica de Modelo Linear Geral para Medidas Repetidas apontou diferença significativa entre os efeitos dos treinamentos sobre a FC. A estatística observada foi igual a $F=35,971$ com $p=0,001$. Os intervalos de confiança construídos com base na técnica de Bonferroni identificaram que o efeito do exercício resistido sobre a FC não foi significativo. Em relação ao exercício aeróbio, há um aumento significativo na FC (43bpm) após os exercícios.

\subsection{Pressão arterial}

\subsubsection{Pressão Arterial Sistólica (PAS)}

Na tabela 13 apresentamos o efeito dos exercícios aeróbio e resistidos sobre a pressão arterial sistólica dos pacientes. Foi avaliada nesse caso a variação observada antes e após os exercícios. A diferença foi calculada da seguinte maneira:

$$
\text { VARIAÇÃO = PAS (Após) - PAS (Antes) }
$$

Tabela 13 - Efeito dos treinamentos sobre a pressão arterial sistólica.

\begin{tabular}{lllll}
\hline & $\begin{array}{l}\text { Variação } \\
\text { média } \\
(\mathbf{m m H g})\end{array}$ & $\begin{array}{l}\text { Desvio } \\
\text { padrão } \\
(\mathbf{m m H g})\end{array}$ & $\begin{array}{l}\text { I.C. 95\% } \\
\text { Limite } \\
\text { inferior } \\
(\mathbf{m m H g})\end{array}$ & $\begin{array}{l}\text { Limite } \\
\text { superior } \\
(\mathbf{m m H g})\end{array}$ \\
\hline Aeróbio & 12,9 & 1,64 & 9,1 & 16,9 \\
Resistido & 0,4 & 1,16 & $-2,3$ & 3,2 \\
\hline
\end{tabular}


O resultado da aplicação da técnica de Modelo Linear Geral para Medidas Repetidas apontou diferença significativa entre os efeitos dos exercícios sobre a PAS. A estatística observada foi igual a $F=38,711$ com $p<0,001$. Os intervalos de confiança de Bonferroni identificaram que o efeito do exercício resistido sobre a PAS não foi significativo. Após o exercício aeróbio, há um aumento significativo na PAS (13 mmHg).

$\mathrm{Na}$ figura 15 apresentamos o comportamento da PAS para os dois tipos de exercício durante o período de treinamento.

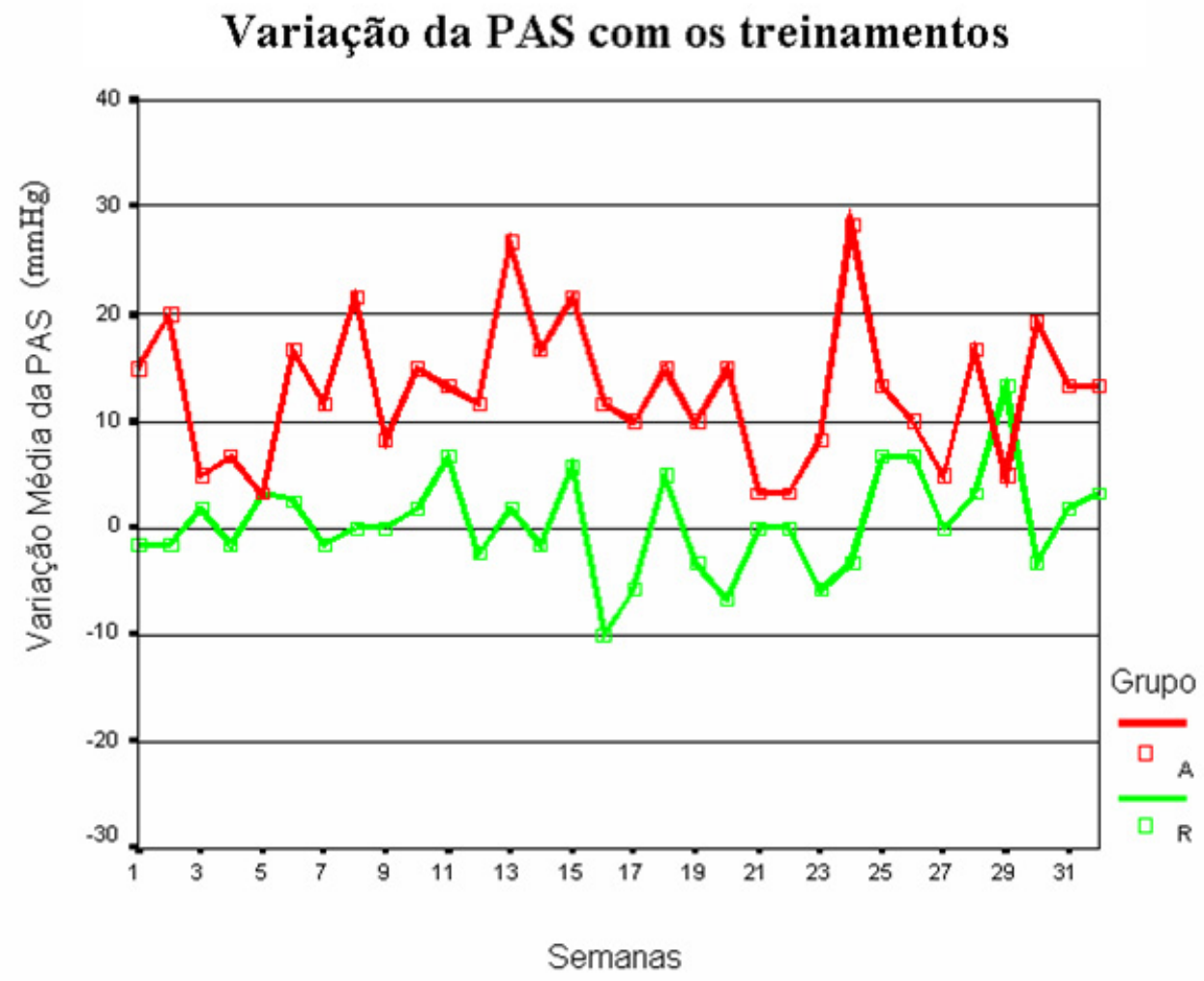

Figura 15. Evolução da variação da pressão arterial sistólica com os treinamentos. 


\subsubsection{Pressão Arterial Diastólica (PAD)}

Na tabela 14 apresentamos o efeito dos exercícios aeróbio e resistidos sobre a pressão arterial diastólica dos pacientes. Foi avaliada nesse caso a variação observada antes e após os exercícios. A diferença foi calculada da seguinte maneira:

$$
\text { VARIAÇÃO = PAD (Após) - PAD (Antes) }
$$

Tabela 14 - Efeito dos treinamentos sobre a pressão arterial diastólica.

\begin{tabular}{lllll}
\hline & $\begin{array}{l}\text { Variação } \\
\text { média } \\
\mathbf{( m m H g )}\end{array}$ & $\begin{array}{l}\text { Desvio } \\
\text { padrão } \\
(\mathbf{m m H g})\end{array}$ & $\begin{array}{l}\text { I.C. 95\% } \\
\text { Limite } \\
\text { inferior } \\
(\mathbf{m m H g})\end{array}$ & $\begin{array}{l}\text { Limite } \\
\text { superior } \\
(\mathbf{m m H g})\end{array}$ \\
\hline Aeróbio & $-2,22$ & 1,06 & $-4,66$ & 0,21 \\
Resistido & 0,94 & 0,86 & $-1,05$ & 2,93 \\
\hline
\end{tabular}

Não foi evidenciada diferença significativa no comportamento da PAD após ambos os treinamentos. A estatística do teste foi igual a $\mathrm{F}=0,908$ com $\mathrm{p}=0,612$.

Veja que em ambos os intervalos de confiança o valor NULO está incluso.

Na figura 16 apresentamos o comportamento da PAD para os dois tipos de exercício durante o período de avaliação. 


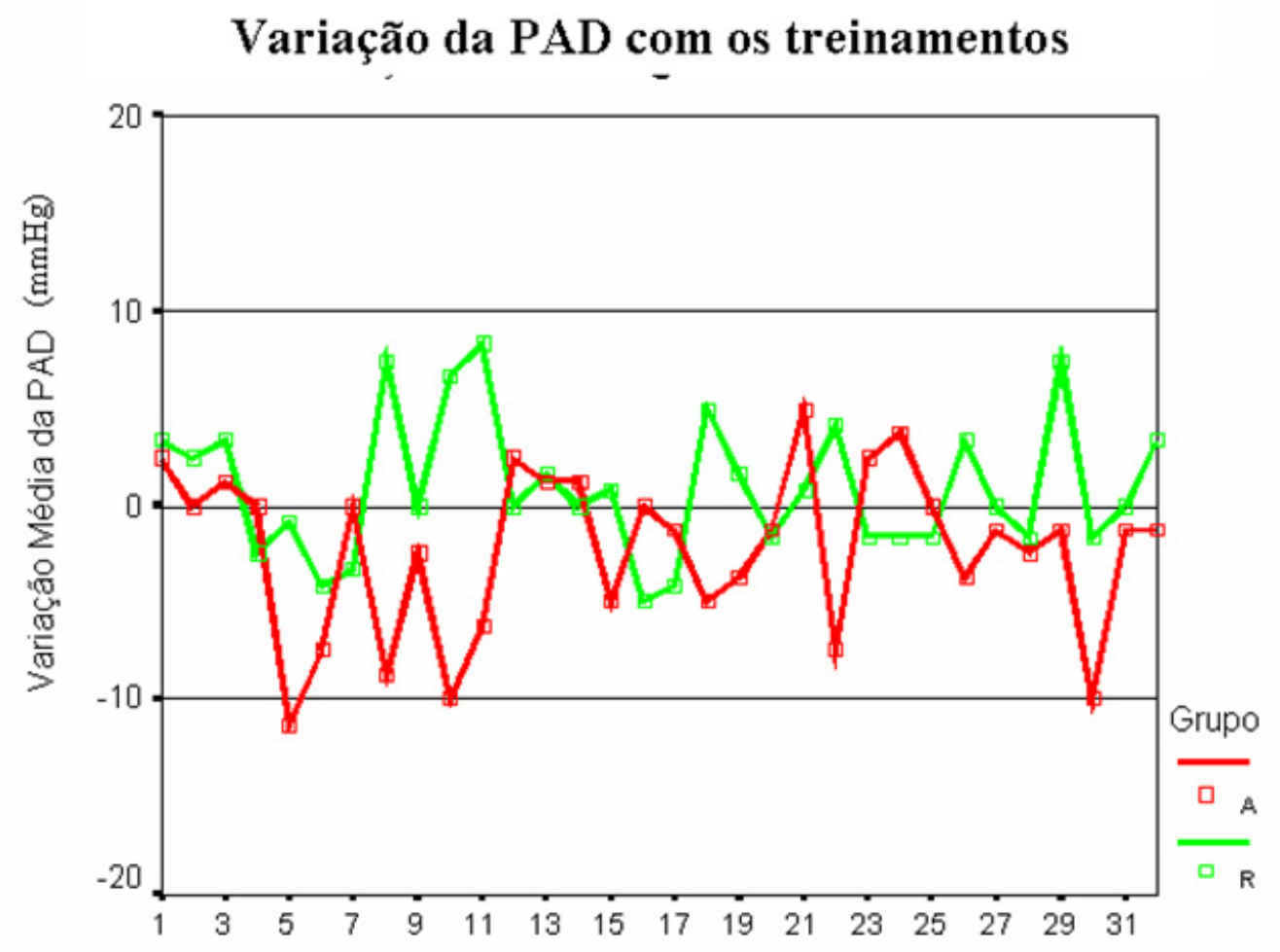

Semanas

Figura 16. Evolução da variação da Pressão Arterial Diastólica com os treinamentos.

\subsection{Freqüência e resolução de hipoglicemias}

Consideramos como hipoglicemia valores de glicemia capilar menores ou iguais a $50 \mathrm{mg} / \mathrm{dL}$.

\subsubsection{Freqüência de consumo de gel durante os exercícios}

Para essa variável avaliamos os efeitos do tipo de treinamento (grupo) e período de treinamento $(\mathrm{I} / \mathrm{F})$. A técnica de Modelo Linear Geral também foi utilizada para 
essa análise. Nas tabelas 15 e 16 apresentamos as médias observadas considerando o período de treinamento e o efeito do tipo de exercício (grupo), respectivamente.

Tabela 15 - Freqüência média de consumo de gel segundo o período de treinamento.

\begin{tabular}{lllll}
\hline & $\begin{array}{l}\text { Freqüência } \\
\text { Média } \\
\text { Período } \\
\text { treinamento }\end{array}$ & $\begin{array}{l}\text { Desvio } \\
\text { padrão } \\
\text { (Unidade) }\end{array}$ & I.C. 95\% & Limite inferior \\
\hline I & 22,6 & 3,62 & 14,80 & $\begin{array}{l}\text { Limite } \\
\text { superior }\end{array}$ \\
F & 13,8 & 4,61 & 3,87 & 23,80 \\
\hline
\end{tabular}

O teste comparativo das médias teve estatística $F=2,243$ com $p=0,158$, apontando indícios de comportamento diferenciado para os períodos de treinamento. Com um número maior de pacientes esse fato poderá ser comprovado.

Tabela 16 - Freqüência média de consumo de gel segundo o grupo.

\begin{tabular}{lllll}
\hline & $\begin{array}{l}\text { Freqüência } \\
\text { Média }\end{array}$ & $\begin{array}{l}\text { Desvio } \\
\text { padrão }\end{array}$ & $\begin{array}{l}\text { I.C. 95\% } \\
\text { Limite } \\
\text { inferior }\end{array}$ & $\begin{array}{l}\text { Limite } \\
\text { superior }\end{array}$ \\
\hline Aerúbio & 19,8 & 4,29 & 10,53 & 29,07 \\
Resistido & 16,7 & 3,89 & 8,24 & 25,05 \\
\hline
\end{tabular}

O teste comparativo das médias teve estatística $\mathrm{F}=0,304$ com $\mathrm{p}=0,591$, indicando não haver indícios de efeito significativo do tipo de exercício (Grupo) sobre a freqüência de consumo de gel.

$\mathrm{Na}$ figura 17, apresentamos graficamente o resultado observado que ilustra o achado estatístico. 
Freqüência de consumo de Gel

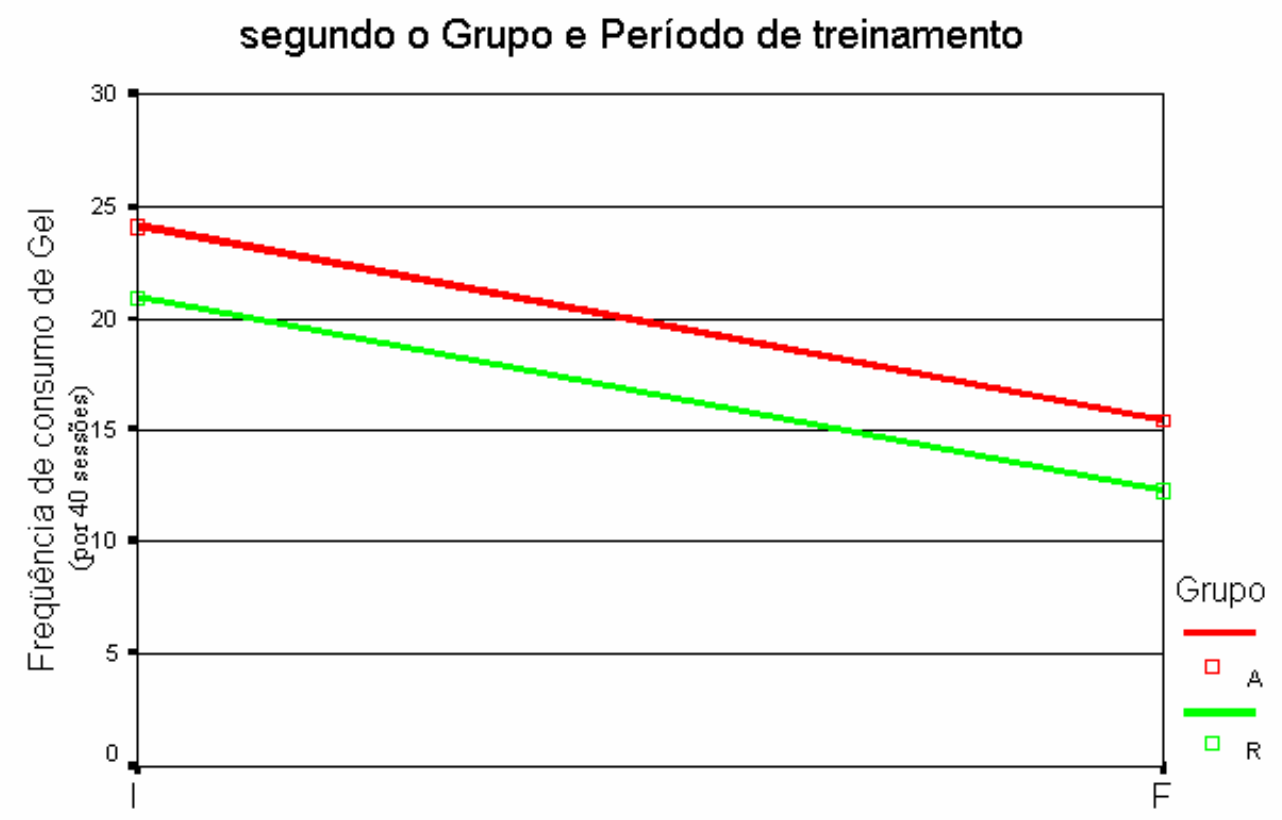

Período de treinamento

Figura 17. Freqüência média de consumo de gel durante os exercícios por grupo e período de treinamento.

O comportamento dos grupos foi similar havendo somente indícios de queda no período Final de treinamento.

\subsubsection{Quantidade consumida de gel durante os exercícios}

Avaliamos os efeitos do tipo de treinamento (A e R) e período de treinamento (I/F). A técnica de Modelo Linear Geral também foi utilizada para essa análise. Nas 
tabelas 17 e 18 apresentamos as médias observadas, considerando o período de treinamento e o efeito do tipo de exercício (grupo), respectivamente.

Tabela 17 - Quantidade média de consumo de Gel segundo o período de treinamento.

\begin{tabular}{|c|c|c|c|c|c|}
\hline $\begin{array}{l}\text { Período } \\
\text { treinamento }\end{array}$ & de & $\begin{array}{l}\text { Quantidade } \\
\text { Média }\end{array}$ & $\begin{array}{l}\text { Desvio } \\
\text { padrão }\end{array}$ & $\begin{array}{l}\text { I.C. } 95 \% \\
\text { Limite inferior }\end{array}$ & $\begin{array}{l}\text { Limite } \\
\text { superior }\end{array}$ \\
\hline I & & 30,6 & 4,58 & 20,70 & 40,48 \\
\hline $\mathbf{F}$ & & 18,8 & 5,84 & 6,23 & 31,44 \\
\hline
\end{tabular}

O teste comparativo das médias teve estatística $F=2,513$ com $p=0,137$ apontando haver indícios comportamento diferenciado para os Períodos de treinamento. Com um número maior de pacientes esse fato poderá ser comprovado.

Tabela 18 - Quantidade média de consumo de gel segundo o grupo.

\begin{tabular}{lllll}
\hline & $\begin{array}{l}\text { Quantidade } \\
\text { Média }\end{array}$ & $\begin{array}{l}\text { Desvio } \\
\text { padrão }\end{array}$ & $\begin{array}{l}\text { I.C. 95\% } \\
\text { Limite } \\
\text { inferior }\end{array}$ & $\begin{array}{l}\text { Limite } \\
\text { superior }\end{array}$ \\
\hline Aeróbio & 28,2 & 5,43 & 16,43 & 39,89 \\
Resistido & 21,3 & 4,92 & 10,63 & 31,90 \\
\hline
\end{tabular}

O teste comparativo das médias teve estatística $\mathrm{F}=0,908$ com $\mathrm{p}=0,358$ indicando não haver indícios de efeito significativo do tipo de exercício (Grupo) sobre a quantidade consumida de gel durante os exercícios. Na figura 18 apresentamos graficamente o resultado observado, ela ilustra o achado estatístico. 


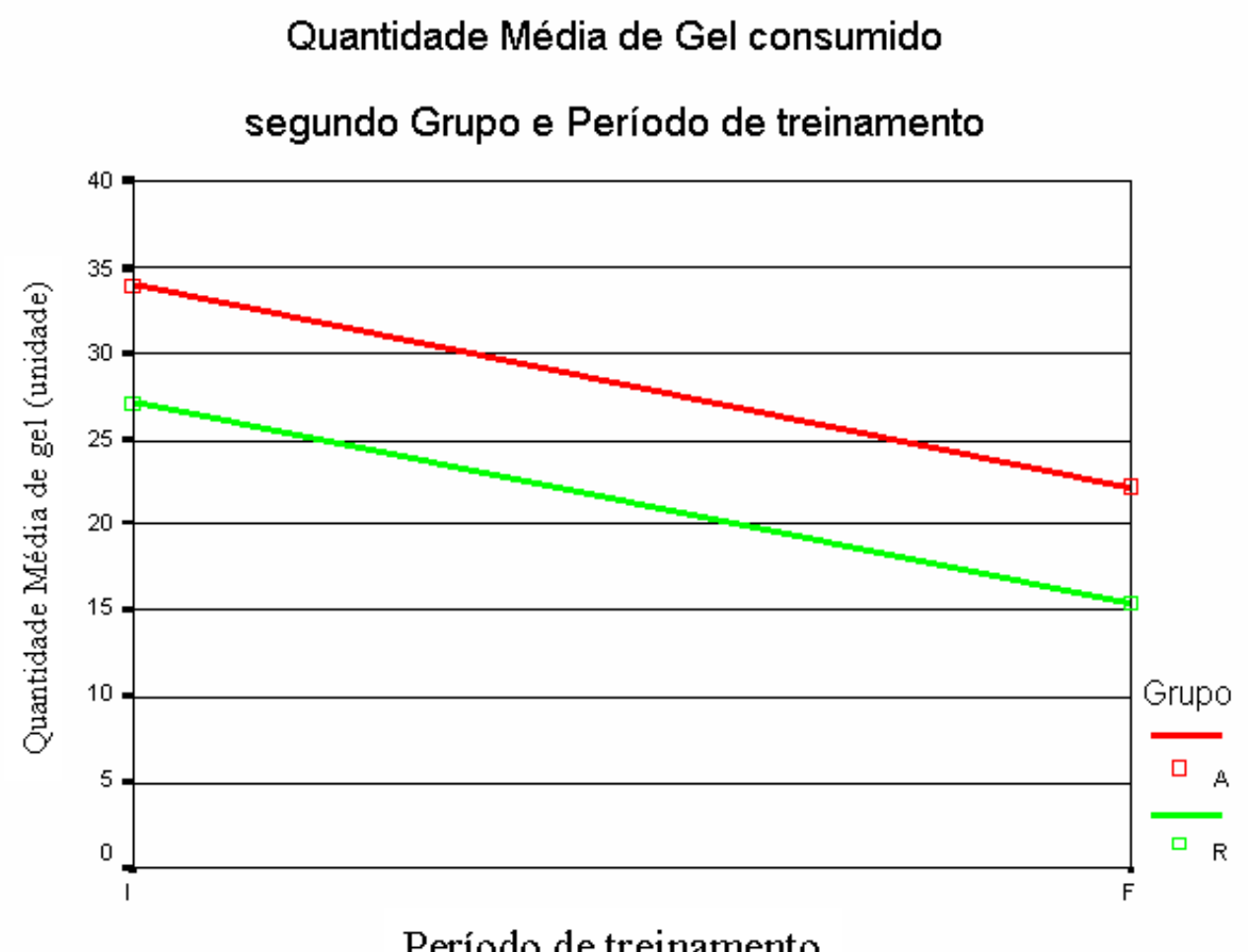

Período de treinamento

Figura 18. Consumo médio de gel durante os exercícios por Grupo e período de treinamento.

Também para a quantidade de gel consumida, os perfis são iguais para os dois grupos, há indícios de queda da quantidade no período final de treinamento.

\subsubsection{Freqüência de hipoglicemia durante os exercícios}

Também para essa variável avaliamos os efeitos do tipo de treinamento (grupo) e período de treinamento (I/F). A técnica de Modelo Linear Geral também foi 
utilizada para essa análise. Nas tabelas 19 e 20 apresentamos as médias observadas considerando o período de treinamento e o efeito do tipo de exercício (grupo), respectivamente.

Tabela 19 - Freqüência de hipoglicemia segundo o período de treinamento.

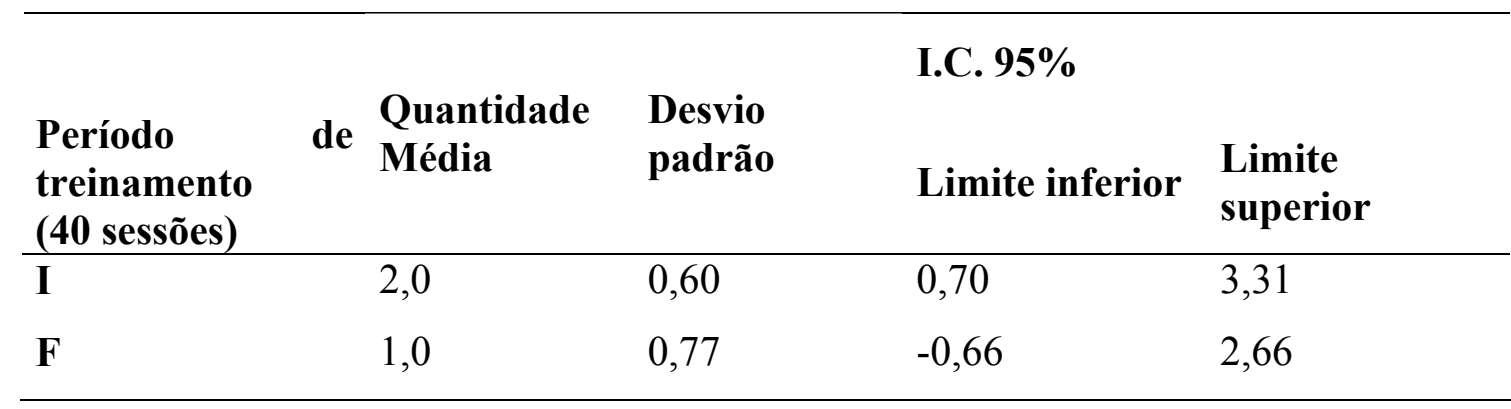

$\mathrm{O}$ teste comparativo das médias teve estatística $\mathrm{F}=1,050$ com $\mathrm{p}=0,324$ apontando não haver indícios de comportamento diferenciado da freqüência de hipoglicemia nos dois períodos de treinamento.

Tabela 20 - Freqüência de hipoglicemia segundo o grupo.

\begin{tabular}{lllll}
\hline & $\begin{array}{l}\text { Quantidade } \\
\text { Média }\end{array}$ & $\begin{array}{l}\text { Desvio } \\
\text { padrão }\end{array}$ & $\begin{array}{l}\text { I.C. 95\% } \\
\text { Limite } \\
\text { inferior }\end{array}$ & $\begin{array}{l}\text { Limite } \\
\text { superior }\end{array}$ \\
\hline Aeróbio & 1,5 & 0,71 & $-0,04$ & 3,04 \\
Resistido & 1,5 & 0,65 & 0,10 & 2,90 \\
\hline
\end{tabular}

O teste comparativo das médias teve estatística $\mathrm{F}=0,00$ com $\mathrm{p}=1,00$, indicando não haver efeito do tipo de exercício (Grupo) sobre a freqüência de hipoglicemia durante os exercícios. Na figura 19 apresentamos de forma gráfica o resultado dos testes. 
Freqüência de episódios de Hipoglicemia segundo Grupo e Periodo de treinamento

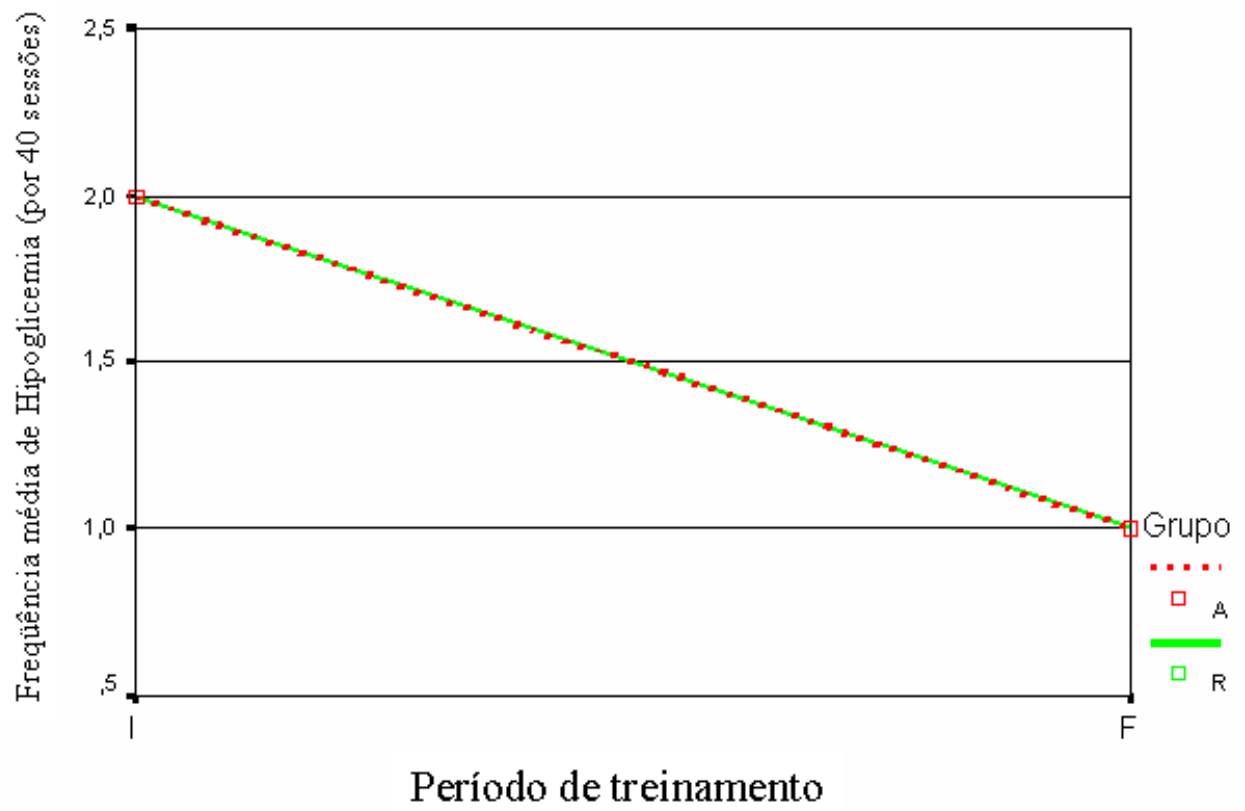

Figura 19. Freqüência média de hipoglicemia durante os exercícios, segundo o grupo e o período de treinamento.

Avaliando conjuntamente os esquemas de redução de $50 \%$ e $75 \%$ de UR, constatamos haver indícios de influência.

4.6.4 Freqüência de hipoglicemia e esquema de redução de dose de insulina UR de $50 \% \times 75 \%$

$\mathrm{Na}$ tabela 21 apresentamos as freqüências médias de hipoglicemia segundo o esquema de redução de $50 \%$ ou $75 \%$ de insulina UR. 
Tabela 21 - Freqüência de hipoglicemia durante exercícios e esquemas de redução de insulina UR.

\begin{tabular}{lllll}
\hline & $\begin{array}{l}\text { Freqüência } \\
\text { Média }\end{array}$ & Desvio & $\begin{array}{l}\text { I.C. 95\% } \\
\text { Limite } \\
\text { inferior }\end{array}$ & $\begin{array}{l}\text { Limite } \\
\text { superior }\end{array}$ \\
\hline $\mathbf{5 0} \%$ & 0,92 & 0,574 & $-0,382$ & 2,215 \\
$\mathbf{7 5} \%$ & 1,83 & 0,614 & 0,445 & 3,221 \\
\hline
\end{tabular}

A estatística do teste teve valor igual a $F=1,190$ com $p=0,304$, indicando não haver indícios de diferença para os diferentes esquemas. A avaliação conjunta com o grupo de treinamento indicou haver indícios de influência do tipo de treinamento (grupo), em conjunto com o esquema de redução de UR na freqüência de hipoglicemia. A estatística observada para o grupo foi igual a $\mathrm{F}=2,213 \mathrm{com} \mathrm{p}=0,161$. A figura 20 ilustra esse resultado.

Freqüência Média de Hipoglicemia segundo esquema $50 \% \times 75 \%$ e Grupo

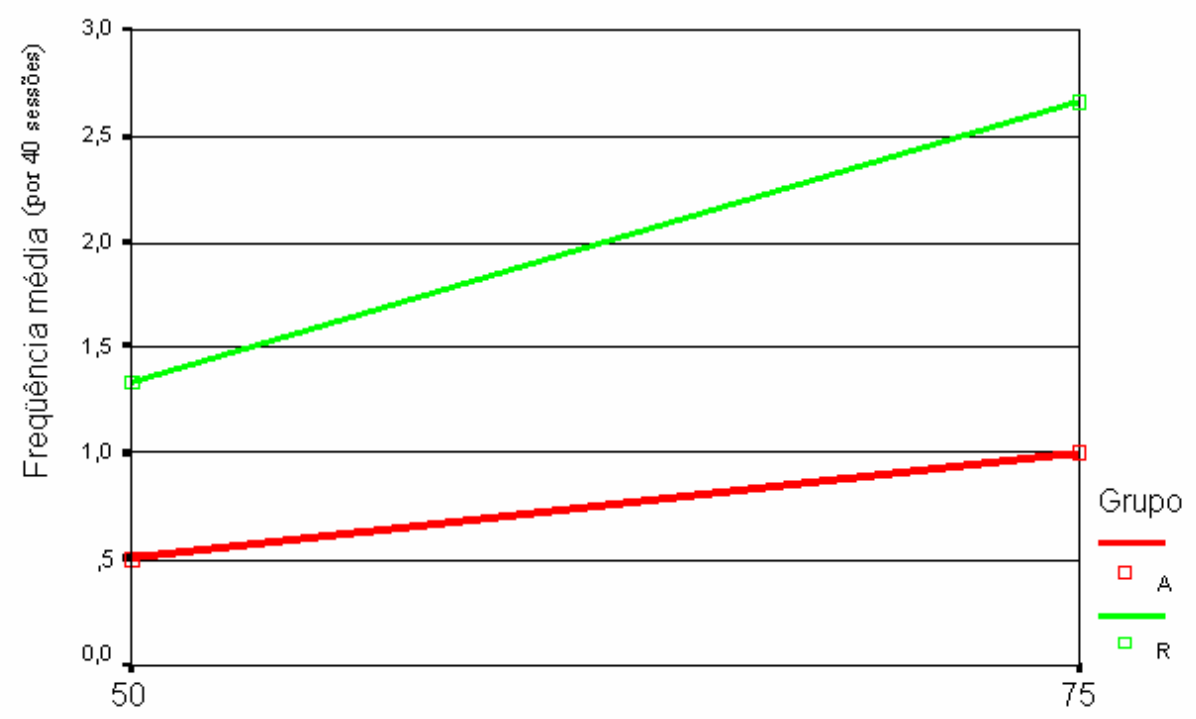

UR

Figura 20. Freqüência média de hipoglicemia segundo o grupo e esquema de redução de UR. 
Há indícios que o treinamento Resistido tenha freqüência de hipoglicemia superior ao aeróbio com redução de UR de 75\%. A confirmação desse indício deverá ser feita com um maior número de pacientes avaliados.

4.6.5 Quantidade consumida de gel por grupo e esquema de redução de insulina UR

Na tabela 22 apresentamos o consumo médio de gel durante os exercícios, segundo o tipo de exercício (grupo) e esquema de redução de insulina UR (50 ou $75 \%)$.

Tabela 22. Quantidade média consumida de gel segundo o grupo e esquema UR

\begin{tabular}{|c|c|c|c|c|}
\hline UR & $\begin{array}{l}\text { Quantidade } \\
\text { Média }\end{array}$ & Desvio & $\begin{array}{l}\text { I.C. } 95 \% \\
\text { Limite } \\
\text { inferior }\end{array}$ & $\begin{array}{l}\text { Limite } \\
\text { superior }\end{array}$ \\
\hline $50 \%$ & 24,29 & 5,75 & 11,28 & 37,31 \\
\hline $75 \%$ & 23,50 & 6,15 & 9,59 & 37,41 \\
\hline
\end{tabular}

Como resultado do ajuste do modelo conjunto para avaliar a influência do grupo e do esquema de UR, tivemos que a quantidade consumida de gel durante os exercícios pode ser considerada independente do grupo e do esquema UR. As estatísticas dos testes foram iguais a $\mathrm{F}=0,001$ com $\mathrm{p}=0,987$ para o Grupo e $\mathrm{F}=0,009$ com $p=0,927$ para o esquema UR. 


\section{Respostas Crônicas}

\subsection{Controle glicêmico (HbA1c)}

Foram feitas avaliações no Início e ao Final dos treinamentos. O controle glicêmico foi avaliado por meio da HbAlc, nesses dois períodos e foi comparado com base no ajuste de um Modelo Linear Geral Univariado tomando como fatores intervenientes o período de treinamento (I/F) e o tipo de exercício (Grupo A ou R). Na tabela 23 apresentamos as médias observadas considerando esses dois fatores e o teste estatístico utilizado foi ANOVA. Observamos que nem o período de treinamento $(p=0,682)$, nem o tipo de exercício $(p=0,765)$ apresentou associação com a variável de controle glicêmico, $\mathrm{HbA1c}$.

\subsection{Colesterol Total (CT)}

O colesterol total foi avaliado no início e ao final dos treinamentos, para os dois grupos de exercício, aeróbio e resistido. As médias de colesterol total observadas estão na tabela 23. O colesterol total não foi influenciado significativamente pelos treinamentos $(p=0,221)$. O período também não influenciou o colesterol total $(\mathrm{p}=0,420)$. 


\subsection{HDL}

O colesterol HDL foi avaliado no início e ao final dos treinamentos, para os dois grupos de exercício, aeróbio e resistido. As médias de HDL observadas estão na tabela 23. O HDL não foi influenciado significativamente pelo período de treinamento $(\mathrm{p}=0,672)$, nem pelo tipo de exercício $(\mathrm{p}=0,450)$.

\subsection{Triglicérides}

O triglicérides foi avaliado no início e ao final dos treinamentos, para os dois grupos de exercício, aeróbio e resistido. As médias de TG observadas estão na tabela 23. O triglicérides não foi influenciado significativamente pelo período de treinamento $(\mathrm{p}=0,710)$, nem pelo tipo de exercício $(0,560)$.

\subsection{LDL}

O colesterol LDL foi avaliado no início e ao final dos treinamentos para os dois grupos de exercício, aeróbio e resistido. As médias de LDL observadas estão na tabela 23. O LDL não foi influenciado significativamente pelo período de treinamento $(\mathrm{p}=0,285)$, nem pelo tipo de exercício $(\mathrm{p}=0,471)$. 


\subsection{VLDL}

O VLDL foi avaliado no início e ao final dos treinamentos para os dois grupos de exercício, aeróbio e resistido. As médias de VLDL observadas estão na tabela 23. O VLDL não foi influenciado significativamente pelo período de treinamento $(p=0,718)$, nem pelo tipo de exercício $(p=0,638)$.

Vale observar com relação a esses parâmetros que todos apresentaram uma pequena variação positiva. Um número maior de pacientes ou um período maior de acompanhamento poderá auxiliar no teste de significância dos mesmos, caso ela exista.

Na figura 21 apresentamos os gráficos de cada uma das variáveis pesquisadas no controle glicêmico e Perfil lipídico.

Tabela 23 - Médias dos parâmetros de controle glicêmico e perfil lipídico em função do grupo e período.

\begin{tabular}{lcccccc}
\hline & $\begin{array}{c}\text { HbA1c } \\
(\%)\end{array}$ & $\begin{array}{c}\text { CT } \\
(\mathbf{m g} / \mathbf{d L})\end{array}$ & $\begin{array}{c}\text { TG } \\
(\mathbf{m g} / \mathbf{d L})\end{array}$ & $\begin{array}{c}\text { HDL } \\
(\mathbf{m g} / \mathbf{d L})\end{array}$ & $\begin{array}{c}\text { LDL } \\
(\mathbf{m g} / \mathbf{d L})\end{array}$ & $\begin{array}{c}\text { VLDL } \\
(\mathbf{m g} / \mathbf{d L})\end{array}$ \\
\hline AERÓBIO & & & & & & \\
Início & 7,3 & 138 & 55 & 49 & 77 & 11 \\
Fim & 7,2 & 137 & 71 & 52 & 71 & 14 \\
RESISTIDO & & & & & & \\
Início & 7,2 & 145 & 67 & 55 & 76 & 13 \\
Fim & 7,7 & 162 & 65 & 59 & 90 & 13 \\
\hline
\end{tabular}




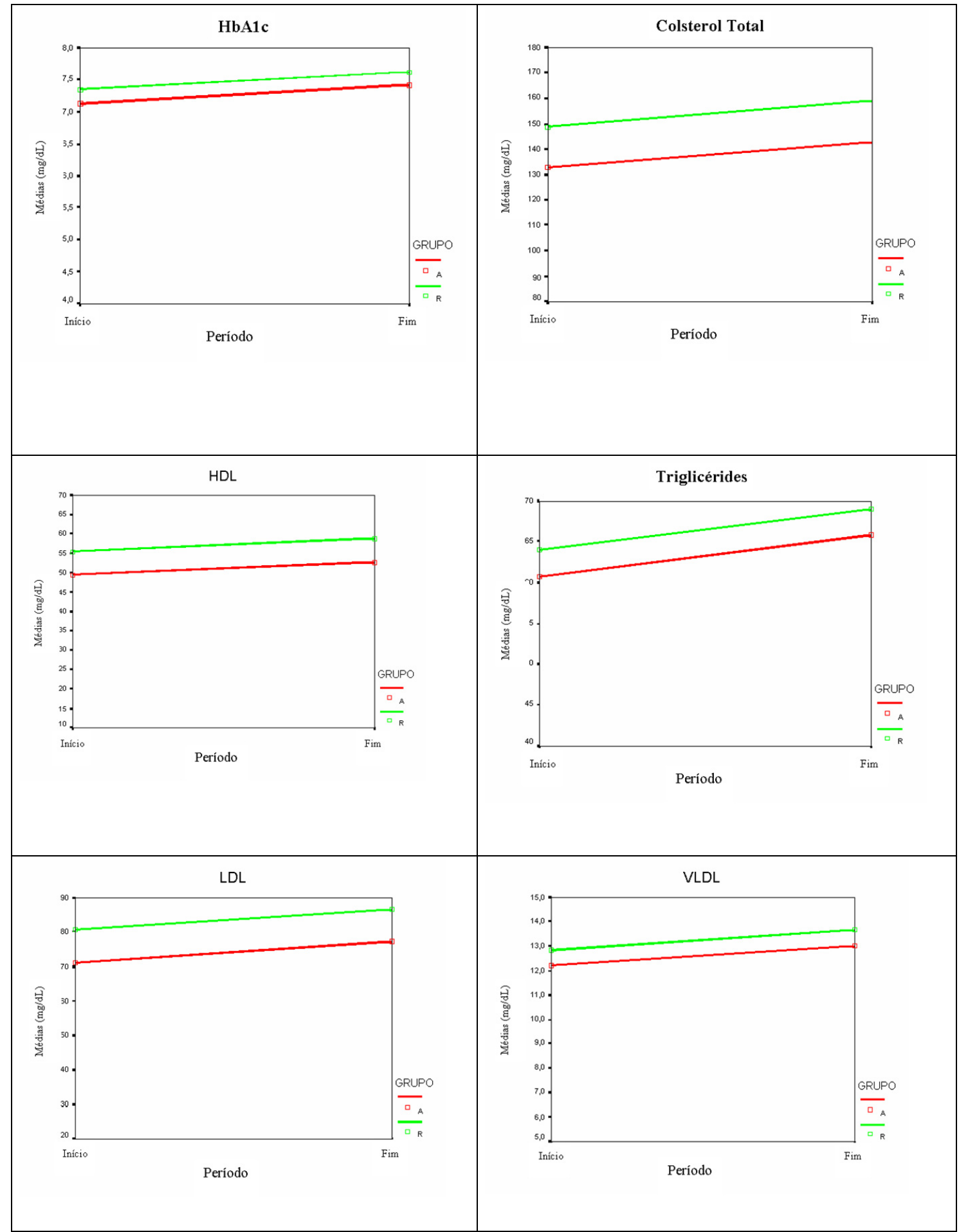

Figura 21. Evolução dos parâmetros de controle glicêmico e perfil lipídico. 


\subsection{Dose total diária de insulina basal (DTDIB)}

Foi ajustado um MLG tendo como variável resposta a DTDIB (u/dia) e como variáveis explicativas: grupo $50 \% \times 75 \%$ e período de treinamento. O resultado do ajuste está apresentado na tabela 24. A análise da DTDIB/ $/ \mathrm{kg} / \mathrm{dia}(\mathrm{u} / \mathrm{kg} / \mathrm{dia})$ não será apresentada porque sua correlação com a unidade/dia (u/dia) é superior a 95\%.

Tabela 24 - Modelo para a DTDIB - testes dos parâmetros.

\begin{tabular}{lll}
\hline Fonte de variação & F & p \\
\hline Modelo & 1,121 & 0,370 \\
Intercepto & 53,857 & $<0,001$ \\
GRUPO & 3,242 & 0,091 \\
UR 50x75\% & 0,216 & 0,648 \\
PERIODO & 0,005 & 0,945 \\
\hline
\end{tabular}

Como podemos observar, há indícios de que o tipo de exercício (grupo) tenha associação significativa com a dose total diária de insulina. Na tabela 25 apresentamos as médias corrigidas para os dois tipos de exercício, aeróbio e resistido. 
Tabela 25 - Médias corrigidas de DTDIB, segundo o grupo.

\begin{tabular}{|c|c|c|c|c|}
\hline \multirow[b]{2}{*}{ Grupo } & \multirow[b]{2}{*}{ Média } & \multirow[b]{2}{*}{ desvio } & \multicolumn{2}{|c|}{ 95\% Confidence Interval } \\
\hline & & & $\begin{array}{l}\text { Limite } \\
\text { inferior }\end{array}$ & $\begin{array}{l}\text { Limite } \\
\text { superior }\end{array}$ \\
\hline Aeróbio & 36,03 & 5,64 & 24,08 & 47,98 \\
\hline Resistido & 23,06 & 5,16 & 12,13 & 33,99 \\
\hline
\end{tabular}

O exercício Resistido promoveu uma menor média de dose total diária de insulina basal se comparado com o grupo de exercício aeróbio. O nível descritivo desse teste foi igual a 9,1\% indicando que com um número maior de pacientes será possível constatar essa redução.

\subsubsection{A redução das doses de insulina NPH}

Foi ajustado um MLG tendo como variável resposta a NPH e como variáveis explicativas: Grupo (A e R), redução da insulina UR 50\%x75\% e Período de treinamento (I ou F), o resultado do ajuste está apresentado na tabela 26. 
Tabela 26 - Modelo para a NPH no exercício - testes dos parâmetros.

\begin{tabular}{lll}
\hline Fonte de variação & F & P \\
\hline Modelo & 0,511 & 0,681 \\
Intercepto & 46,367 & $<0,001$ \\
GRUPO & 0,483 & 0,497 \\
UR & 0,408 & 0,532 \\
PERIODO & 0,007 & 0,936 \\
\hline
\end{tabular}

Não foram significativas as diferenças observadas entre as médias para os grupos, para os esquemas de redução de UR (50x75\%) e para o período de treinamento (I x F), ou seja, a redução foi uniforme e independente dessas variáveis.

\subsection{Microalbuminúria}

\subsubsection{Microalbuminúria em repouso}

A microalbuminúria dos pacientes foi avaliada em duas condições: repouso e exercício, elas foram também avaliadas no Início e Final dos treinamentos. Nas tabelas 27 e 28 apresentamos as médias na condição de repouso e respectivos testes estatísticos de significância para os fatores grupo e período. 
Tabela 27 - Médias de microalbuminúria em repouso.

\begin{tabular}{lllll}
\hline Grupo & Período & Média & Desvio & N \\
\hline \multirow{2}{*}{ Aeróbio } & Inicio & 15,773 & 6,408 & 4 \\
& Final & 16,800 & 9,227 & 4 \\
& Total & 16,286 & 7,375 & 8 \\
& Inicio & 12,547 & 5,588 & 6 \\
Resistido & Final & 10,250 & 6,314 & 6 \\
& Total & 11,398 & 5,810 & 12 \\
& Inicio & 13,837 & 5,815 & 10 \\
& Final & 12,870 & 7,872 & 10 \\
\hline \multirow{2}{*}{ Total } & Total & 13,354 & 6,754 & 20 \\
& & & & \\
\hline
\end{tabular}

Os testes de significância para os fatores grupo e período de treinamento foram obtidos através do ajuste de um MLG Univariado.

Tabela 28 - ANOVA para o modelo ajustado para a microalbuminúria em repouso

\begin{tabular}{lll}
\hline Fonte de variação & F & p \\
\hline Modelo & 1,358 & 0,284 \\
Intercepto & 83,687 & $<0,001$ \\
GRUPO & 2,609 & 0,125 \\
PERIODO & 0,106 & 0,748 \\
\hline
\end{tabular}


Para a microalbuminúria em repouso, o período de treinamento não influenciou significativamente as médias, quanto ao tipo de exercício (grupo), há indícios de associação com o mesmo. Um maior número de pacientes, ou um maior período de acompanhamento poderá confirmar esse indício. As médias foram:

- Aeróbio: 16,3 \pm 7,4 mg/g de Creatinina

- Resistido: 11,4 \pm 5,8 mg/g de Creatinina

\subsubsection{Microalbuminúria induzida pelo exercício}

Nas tabelas 29 e 30 apresentamos as médias na condição de exercício e respectivos testes estatísticos de significância para os fatores Grupo e Período.

Tabela 29 - Médias de microalbuminúria em exercício.

\begin{tabular}{ccccc}
\hline Grupo & Período & Média & desvio & N \\
\hline \multirow{3}{*}{ Aeróbio } & Inicio & 39,343 & 31,330 & 4 \\
& Final & 17,575 & 11,098 & 4 \\
& Total & 28,459 & 24,675 & 8 \\
& Inicio & 21,703 & 23,698 & 6 \\
Resistido & Final & 26,725 & 29,531 & 6 \\
& Total & 24,214 & 25,662 & 12 \\
& Inicio & 28,759 & 26,873 & 10 \\
Total & Final & 23,065 & 23,407 & 10 \\
& Total & 25,912 & 24,701 & 20 \\
\hline
\end{tabular}


Os testes de significância para os fatores grupo e período de treinamento foram obtidos através do ajuste de um MLG Univariado.

Tabela 30 - ANOVA para o modelo ajustado para a microalbuminúria em exercício.

\begin{tabular}{lll}
\hline Fonte de variação & F & p \\
\hline Modelo & 0,223 & 0,803 \\
Intercepto & 20,359 & 0,001 \\
GRUPO & 0,093 & 0,765 \\
PERIODO & 0,353 & 0,562 \\
\hline
\end{tabular}

Para a microalbuminúria em exercício, não foram significativas as contribuições do tipo de exercício (grupo) nem do período de treinamento (I/F).

Visando comparar as médias de microalbuminúria nas duas condições, repouso e exercício, aplicamos o teste t-Student para dados pareados, as médias observadas foram iguais a:

- Repouso: $13,35 \pm 1,51 \mathrm{mg} / \mathrm{g}$ de Creatinina

- Exercício: $25,91 \pm 5,52 \mathrm{mg} / \mathrm{g}$ de Cretinina

A estatística foi igual a $\mathrm{t}=2,515$ com $\mathrm{p}=0,021$, indicando que os níveis médios de microalbuminúria praticamente dobram na condição de exercício. Na figura 22 ilustramos esse resultado. 


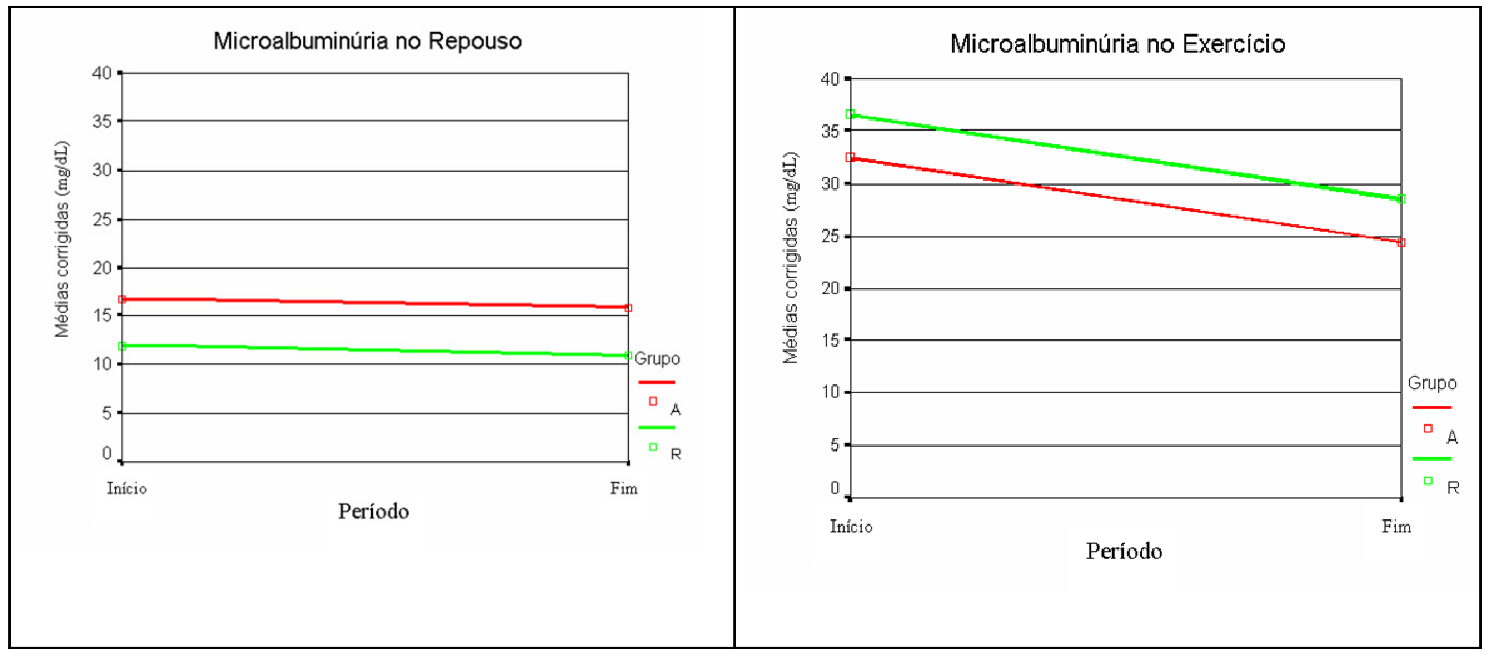

Figura 22. Evolução da microalbuminúria com os tratamentos nas condições de repouso e de exercícios

\subsection{Parâmetros Antropométricos}

\subsubsection{Altura, peso, IMC e circunferência da cintura}

Foram avaliados: Altura e Peso para cálculo do IMC, e ainda a Circunferência da Cintura, e para controle, a Idade das pacientes no início e ao final do tratamento.

Na tabela 31 apresentamos as idades das pacientes por grupo e período de treinamento. 
Tabela 31 - Médias das Idades das pacientes por grupo.

\begin{tabular}{lllll}
\hline Grupo & Período & Média & Desvio & $\mathbf{N}$ \\
\hline & Inicio & 21,75 & 6,90 & 4 \\
& Final & 22,25 & 7,41 & 4 \\
& Total & 22,00 & 6,63 & 8 \\
& Inicio & 28,33 & 9,79 & 6 \\
R & Final & 28,67 & 9,65 & 6 \\
& Total & 28,50 & 9,27 & 12 \\
& Inicio & 25,70 & 8,98 & 10 \\
& Final & 26,10 & 9,00 & 10 \\
Total & Total & 25,90 & 8,75 & 20 \\
& & & \\
\hline
\end{tabular}

Os grupos podem ser considerados homogêneos com respeito à idade, $p=0,139$.

Na tabela 32 apresentamos as médias de IMC observadas por grupo e período de treinamento. 
Tabela 32 - Médias de IMC segundo o grupo e período de treinamento.

\begin{tabular}{lllll}
\hline & Período & Média & Desvio & N \\
Grupo & Inicio & 22,401 & 3,163 & 4 \\
& Final & 22,275 & 3,406 & 4 \\
& Total & 22,338 & 3,044 & 8 \\
R & Inicio & 23,279 & 2,762 & 6 \\
& Final & 22,926 & 1,886 & 6 \\
& Total & 23,102 & 2,263 & 12 \\
& Inicio & 22,928 & 2,789 & 10 \\
Total & Final & 22,665 & 2,441 & 10 \\
& Total & 22,797 & 2,554 & 20 \\
\hline
\end{tabular}

Na tabela 33 apresentamos os resultados dos testes de significância entre essas médias. 
Tabela 33 - Testes estatísticos para o IMC em função dos grupos e período de treinamento.

\begin{tabular}{lll}
\hline Fonte de variação & \multicolumn{1}{c}{ F } & P \\
\hline Modelo & 0,221 & 0,804 \\
Intercepto & 1394,544 & $<0,001$ \\
GRUPO & 0,395 & 0,538 \\
PERIODO & 0,048 & 0,828 \\
\hline
\end{tabular}

Não foram significativas as variações do IMC entre os Grupos e nos diferentes períodos de avaliação. Podemos considerar que ficaram constantes.

Na tabela 34 apresentamos as médias de cicunferência da cintura, segundo o tratamento (grupo) e período de treinamento. 
Tabela 34 - Circunferência média da cintura dos pacientes segundo o grupo e o período.

\begin{tabular}{lllll}
\hline \multirow{2}{*}{ Grupo } & Período & Média & Desvio & N \\
\hline & Inicio & 81,250 & 8,958 & 4 \\
& Final & 79,375 & 10,950 & 4 \\
& Total & 80,313 & 9,316 & 8 \\
& Inicio & 84,167 & 4,633 & 6 \\
& Final & 81,250 & 4,666 & 6 \\
& Total & 82,708 & 4,688 & 12 \\
& Inicio & 83,000 & 6,399 & 10 \\
& Final & 80,500 & 7,280 & 10 \\
& Total & 81,750 & 6,793 & 20 \\
\hline
\end{tabular}

Na tabela 35 apresentamos os resultados dos testes estatísticos para avaliação das diferenças entre os grupos e entre os períodos de treinamento.

Tabela 35 - Teste de significância para a Circunferência da Cintura.

\begin{tabular}{lll}
\hline Fonte de variação & F & P \\
\hline Modelo & 0,611 & 0,554 \\
Intercepto & 2651,250 & $<0,001$ \\
GRUPO & 0,573 & 0,460 \\
PERIODO & 0,649 & 0,431 \\
\hline
\end{tabular}


Não foi evidenciada influência significativa dos treinamentos (grupos) e do período de treinamento sobre a circunferência da cintura.

\subsubsection{Avaliação da composição corporal (DEXA)}

$\mathrm{Na}$ tabela 36 apresentamos as estatísticas observadas através do ajuste de Modelos Lineares Gerais Univariado para as variáveis de composição corporal (DEXA). Ela apresenta os resultados da estatística F-Fisher para teste da significância dos fatores: grupo, período de treinamento e região.

Tabela 36 - Resultados dos testes de significância para a composição corporal.

\begin{tabular}{|c|c|c|c|c|c|c|}
\hline \multirow{3}{*}{$\begin{array}{l}\text { Indicador da } \\
\text { Composição } \\
\text { corporal }\end{array}$} & \multicolumn{6}{|c|}{ Fatores Pesquisados } \\
\hline & \multicolumn{2}{|l|}{ Grupo } & \multicolumn{2}{|c|}{ Período } & \multicolumn{2}{|c|}{ Região } \\
\hline & $\mathbf{F}$ & $\mathbf{p}$ & $\mathbf{F}$ & $\mathbf{p}$ & $\mathbf{F}$ & $\mathbf{p}$ \\
\hline Área $\left(\mathrm{cm}^{2}\right)$ & 5,710 & 0,036 & 0,021 & 0,887 & 399,6 & $<0,001$ \\
\hline$B M D\left(\mathrm{~g} / \mathrm{cm}^{2}\right)$ & 3,237 & 0,074 & 0,089 & 0,766 & 74,5 & $<0,001$ \\
\hline$B M C(g)$ & 7,091 & $\mathbf{0 , 0 3 2}$ & 0,028 & 0,868 & 67,9 & $<0,001$ \\
\hline$F A T(g)$ & 2,626 & 0,108 & 0,044 & 0,834 & 54,5 & $<\mathbf{0 , 0 0 1}$ \\
\hline Lean $(g)$ & 4,966 & $\mathbf{0 , 0 2 8}$ & 0,016 & 0,900 & 164,2 & $<0,001$ \\
\hline Lean $+B M C$ & 10,682 & 0,001 & 0,128 & 0,721 & 138,5 & $<0,001$ \\
\hline TOTAL $(\mathrm{g})$ & 3,488 & 0,064 & 0,016 & 0,900 & 339,6 & $<0,001$ \\
\hline$\% F A T$ & 14,088 & $<\mathbf{0 , 0 0 1}$ & 0,004 & 0,947 & 2,567 & $\mathbf{0 , 0 1 7}$ \\
\hline
\end{tabular}

Em relação aos dados da tabela 36, temos os seguintes resultados: 
$\checkmark$ O tipo de exercício, Aeróbio ou Resistido, influenciou de maneira significativa a maioria dos indicadores da composição corporal, para os que não foi possível evidenciar, há fortes indícios de influência;

$\checkmark$ O período de treinamento não influenciou significativamente os indicadores de composição corporal;

\subsection{Testes ergoespirométricos}

A associação entre os dois métodos de medição da glicose, durante o teste ergoespirométrico já foi abordada anteriormente, agora apresentaremos a avaliação conjunta dos dados avaliados nesse teste, são eles: PAS, PAD, FC, período de treinamento e tempo de exercício.

Ajustamos um Modelo Linear Geral Univariado, tomando como resposta a Glicose (GC) e como fatores explicativos: grupo, período de treinamento. Como covariadas foram avaliadas: PAS, PAD e FC. O resultado do ajuste do modelo está apresentado na tabela 37. 
Tabela 37 - Modelo para o GC no teste ergoespirométrico.

\begin{tabular}{lll}
\hline Fonte de variação & F & P \\
\hline Modelo & 3,762 & $\mathbf{0 , 0 1 3}$ \\
Intercepto & 58,024 & $<\mathbf{0 , 0 0 1}$ \\
PERIODO & 4,699 & $\mathbf{0 , 0 3 7}$ \\
GRUPO & 7,265 & $\mathbf{0 , 0 1 1}$ \\
PAS & 9,411 & $\mathbf{0 , 0 0 4}$ \\
FC & 6,871 & $\mathbf{0 , 0 1 3}$ \\
PAD & 0,471 & 0,498 \\
TEMPO & 0,477 & 0,495 \\
\hline
\end{tabular}

Como resultado, o ajuste do modelo foi significativo, ou seja, existem variáveis nele que ajudam a explicar a variação da glicose no teste. As variáveis com explicação significativa foram: período de treinamento $(\mathrm{I} / \mathrm{F})$, tipo de exercício (Grupo), PAS e FC. As variáveis PAD e tempo de exercício não apresentaram contribuição significativa para explicar as variações de glicose, já considerando as variáveis anteriores (abordagem holística do modelo).

Nas tabela 38 e 39 apresentamos as médias corrigidas associadas ao grupo e período, respectivamente. 
Tabela 38 - Médias corrigidas de GC, por grupo no teste ergoespirométrico.

\begin{tabular}{lllll}
\hline & Média corrigida & Desvio & I.C. 95\% & \\
Grupo & & $\begin{array}{l}\text { Limite } \\
\text { inferior }\end{array}$ & $\begin{array}{l}\text { Limite } \\
\text { superior }\end{array}$ \\
\hline Aeróbio & 140,99 (a) & 13,39 & 113,75 & 168,23 \\
Resistido & 187,56 (a) & 9,96 & 167,30 & 207,82 \\
(a) Modelo corrigido para: PAS $=153,2$ e $\mathrm{FC}=132,5$. & & \\
\hline
\end{tabular}

A GC do grupo submetido aos exercícios resistidos foi maior que a observada no grupo que fez exercícios aeróbios, no teste ergoespirométrico.

Tabela 39 - Médias corrigidas de GC por período no teste ergoespirométrico.

\begin{tabular}{llcll}
\hline & \multicolumn{1}{c}{$\begin{array}{l}\text { Média } \\
\text { corrigida }\end{array}$} & desvio & & \\
Período & & Limite inferior & $\begin{array}{l}\text { Limite } \\
\text { superior }\end{array}$ \\
\hline Inicial & $147,41(\mathrm{a})$ & 11,64 & 123,73 & 171,09 \\
Final & $181,14(\mathrm{a})$ & 10,72 & 159,34 & 202,94 \\
(a) Modelo corrigido para: PAS $=153,2$ e $\mathrm{FC}=132,5$. & \\
\hline
\end{tabular}

Houve um aumento significativo da GC no período final se comparado ao resultado observado no período inicial, nos testes ergoespirométricos.

A figura 23 ilustra os dados observados nas tabelas anteriores. 


\section{Médias corrigidas de Glicose - GC}

Teste ergoespirométrico

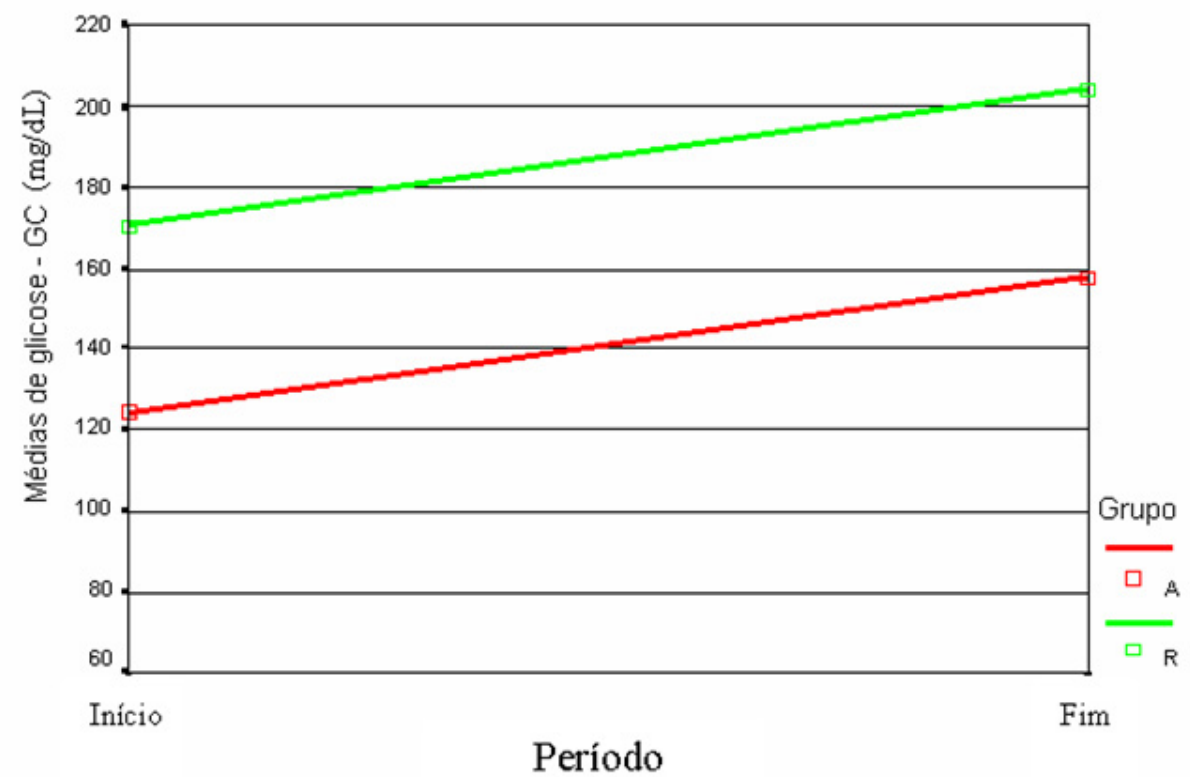

Figura 23. Evolução da GC por grupo e período de treinamento

$\mathrm{Na}$ avaliação do teste ergoespirométrico, ambos os tipos de exercícios promoveram aumento da GC.

\subsubsection{Avaliação dos dados cardiopulmonares}

Foram avaliados os seguintes parâmetros:

Protocolo (watts)/duração total do teste (min)/tempo em exercício (min)/carga máxima atingida (watts) $/ \mathrm{VO}_{2}$ máximo $(\mathrm{mL} / \mathrm{kg} / \mathrm{min}) /$ tempo total gasto para se atingir o limiar anaeróbio (min)/tempo em exercício para se atingir o limiar 
anaeróbio $(\mathrm{min}) / \mathrm{VO}_{2}$ atingido no limiar anaeróbio $(\mathrm{mL} / \mathrm{kg} / \mathrm{min}) /$ freqüência cardíaca atingida no limiar anaeróbio (bpm)/tempo total para se atingir o ponto de compensação respiratória (min)/tempo em exercício para se atingir o ponto de compensação respiratória $(\mathrm{min}) / \mathrm{VO}_{2}$ atingido no ponto de compensação respiratória $(\mathrm{mL} / \mathrm{kg} / \mathrm{min}) /$ freqüência cardíaca atingida no ponto de compensação respiratória (bpm).

Para cada uma dessas variáveis foi ajustado um Modelo Linear Geral Univariado visando avaliarmos a influência do tipo de exercício e do período de treinamento.

Os resultados dos ajustes estão apresentados na tabela 40 . 
Tabela 40 - Teste de significância para o tipo de exercício e período de treinamento na avaliação cardiopulmonar.

\begin{tabular}{|c|c|c|}
\hline \multirow{3}{*}{ Variável } & \multicolumn{2}{|c|}{ Fatores Pesquisados } \\
\hline & Tipo de & Período \\
\hline & Exercício & Treinamento \\
\hline Protocolo(Watts) & $0,526(0,478)$ & $0,039(0,846)$ \\
\hline Duração Total do Teste(min) & $0,084(0,776)$ & $0,534(0,475)$ \\
\hline Tempo em Exercício(min) & $0,553(0,467)$ & $0,615(0,444)$ \\
\hline Carga Máxima Atingida(Watts) & $3,619(0,074)$ & $0,107(0,747)$ \\
\hline $\mathrm{VO}_{2}$ máximo $(\mathrm{mL} / \mathrm{Kg} / \mathrm{min})$ & $0,464(0,505)$ & $0,350(0,562)$ \\
\hline Tempo Total gasto para se atingir o LA(min) & $0,701(0,414)$ & $0,980(0,336)$ \\
\hline Tempo em Exercício para se atingir o LA(min) & $0,144(0,709)$ & $2,038(0,171)$ \\
\hline $\mathrm{VO}_{2}$ atingido no $\mathrm{LA}(\mathrm{mL} / \mathrm{Kg} / \mathrm{min})$ & $0,318(0,580)$ & $0,197(0,663)$ \\
\hline Freqüência Cardíaca atingida no LA(bpm) & $3,549(0,077)$ & $0,502(0,488)$ \\
\hline Tempo Total para se atingir o PCR(min) & $0,508(0,486)$ & $0,322(0,578)$ \\
\hline Tempo em exercício para se atingir o PCR(min) & $0,188(0,670)$ & $0,708(0,412)$ \\
\hline $\mathrm{VO}_{2}$ atingido no $\mathrm{PCR}(\mathrm{mL} / \mathrm{Kg} / \mathrm{min})$ & $0,417(0,527)$ & $0,107(0,748)$ \\
\hline Freqüência Cardíaca atingida no PCR(bpm). & $5,336(0,034)$ & $0,628(0,439)$ \\
\hline
\end{tabular}

Foram detectadas diferenças significativas na avaliação cardiopulmonar entre os tipos de exercício (A/R) para os seguintes parâmetros: carga máxima atingida, freqüência cardíaca atingida no liminar anaeróbio e no ponto de compensação respiratória. Há indícios de influência do período de treinamento para o tempo em exercício para se atingir o limiar anaeróbio. A figura 24 apresenta o comportamento observado nos grupos e tempos de treinamento. 


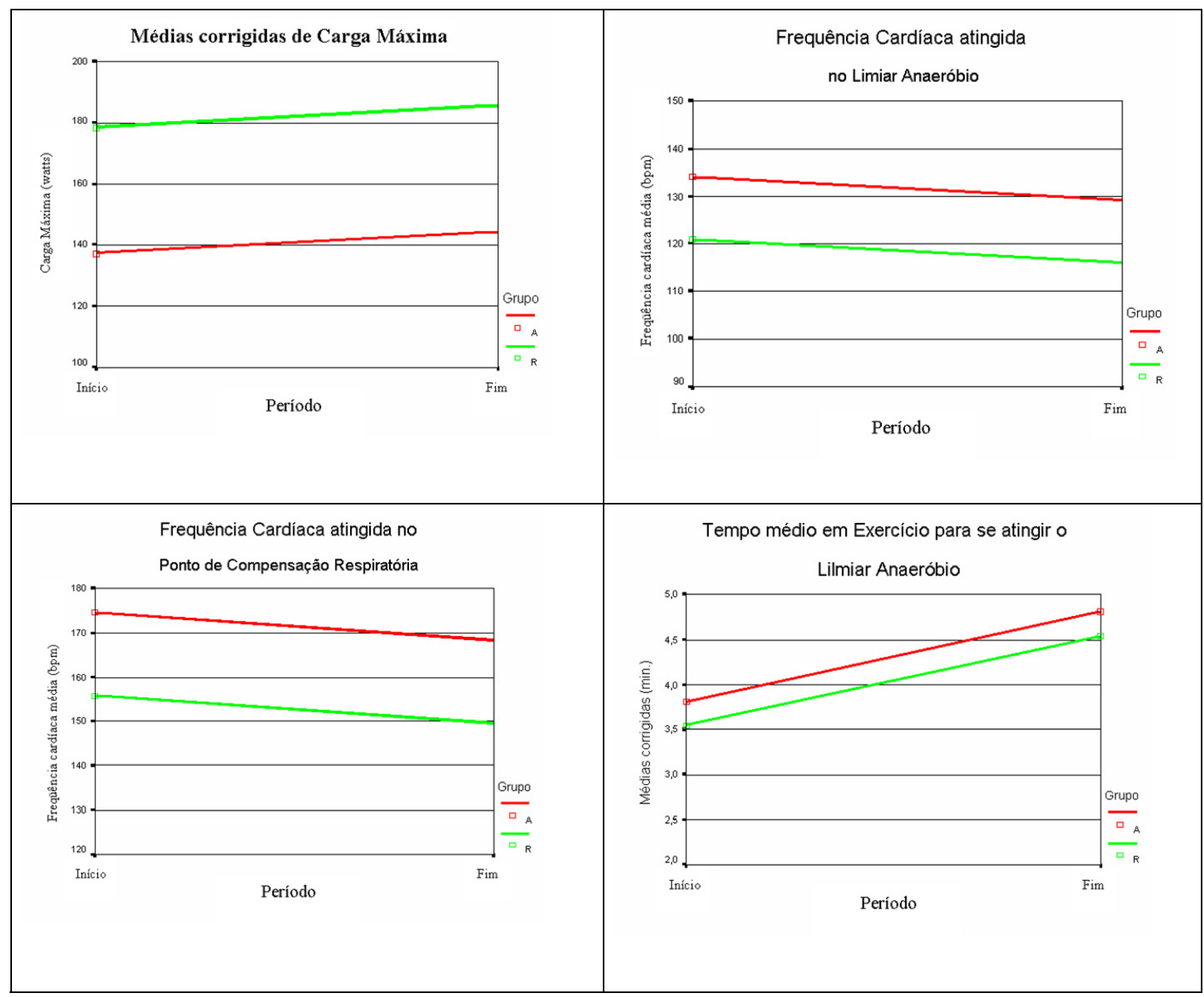

Figura 24. Comportamento das médias com diferença identificada na avaliação cardiopulmonar, para o tipo de exercício e período de treinamento

Na tabela 41 apresentamos as médias observadas para esses parâmetros nos grupos e períodos. 
Tabela 41 - Médias por Grupo e Período de treinamento observadas na avaliação cardiopulmonar.

\begin{tabular}{|c|c|c|c|c|}
\hline Variável & Fator & $\begin{array}{l}\text { Nível do } \\
\text { fator }\end{array}$ & Médias & Diferença \\
\hline Carga Máxima Atingida(Watts) & Grupo & $\begin{array}{l}\text { Aeróbio } \\
\text { Resistido }\end{array}$ & $\begin{array}{l}140,6 \\
182,1\end{array}$ & 41,5 \\
\hline $\begin{array}{l}\text { Freqüência Cardíaca atingida no } \\
\text { LA (bpm) }\end{array}$ & Grupo & $\begin{array}{l}\text { Aeróbio } \\
\text { Resistido }\end{array}$ & $\begin{array}{l}131,6 \\
118,3\end{array}$ & 13,3 \\
\hline $\begin{array}{l}\text { Freqüência Cardíaca atingida no } \\
\text { PCR (bpm) }\end{array}$ & Grupo & $\begin{array}{l}\text { Aeróbio } \\
\text { Resistido }\end{array}$ & $\begin{array}{l}171,5 \\
152,7\end{array}$ & 18,8 \\
\hline $\begin{array}{l}\text { Tempo em Exercício para se } \\
\text { atingir o LA(minutos) }\end{array}$ & Período & $\begin{array}{l}\text { Inicial } \\
\text { Final }\end{array}$ & $\begin{array}{l}3: 40 \\
4: 40\end{array}$ & $1: 00 *$ \\
\hline
\end{tabular}

Os parâmetros a seguir não foram influenciados pelo tipo de exercício (grupo) nem pelo período de treinamento (I/F) na avaliação cardiopulmonar:

\begin{tabular}{|ll|}
\hline$\checkmark$ & Protocolo(Watts) \\
$\checkmark$ & Duração Total do Teste (min) \\
$\checkmark$ & Tempo em Exercício (min) \\
$\checkmark$ & $\mathrm{VO}_{2}$ máximo (mL/kg/min) \\
$\checkmark$ & $\mathrm{VO}_{2}$ atingido no LA (mL/kg/min) \\
$\checkmark$ & $\mathrm{Tempo}$ \\
$\checkmark$ & $\mathrm{Tempotal}$ para se atingir o PCR (min) \\
$\checkmark$ & $\mathrm{VO}_{2}$ atingido no PCR (mL/kg/min) \\
\end{tabular}




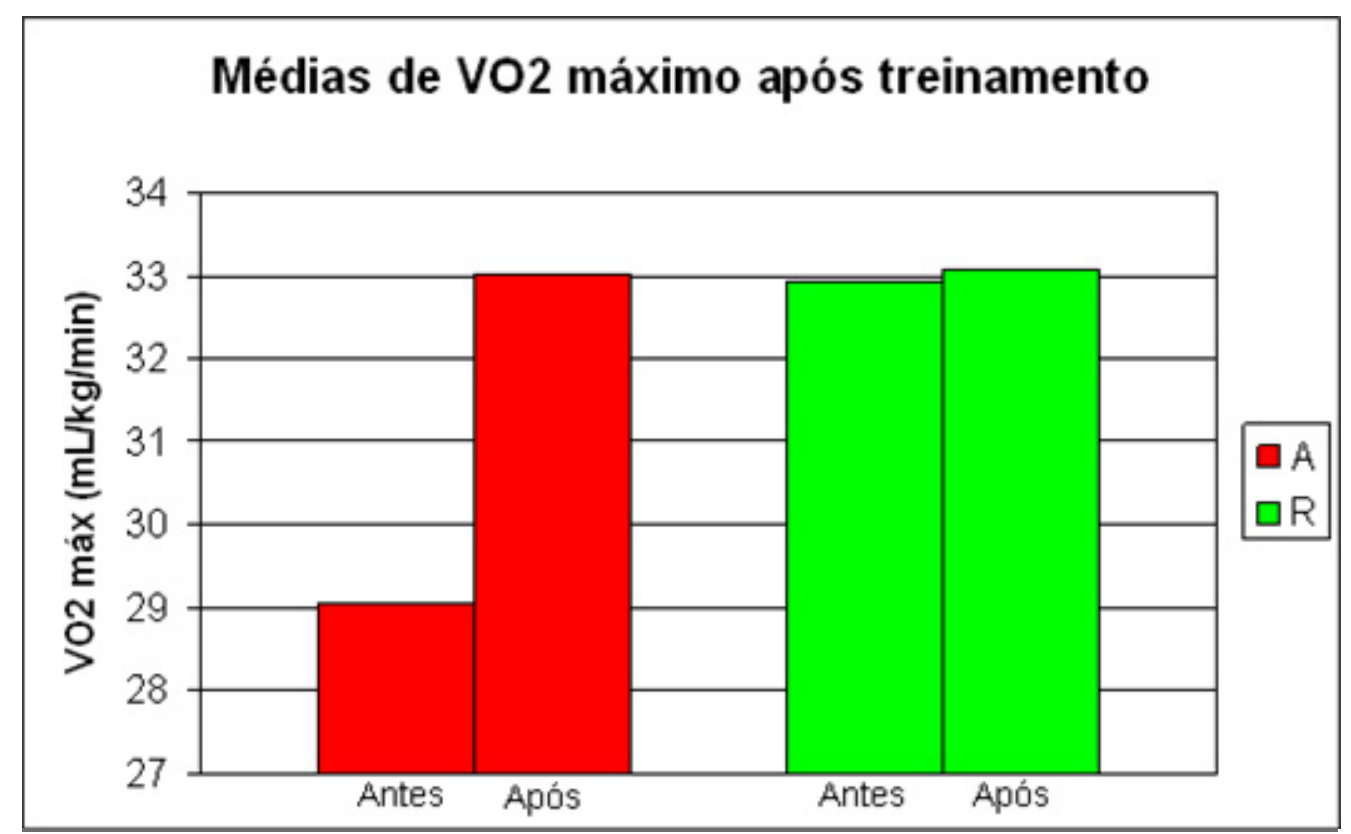

Figura 25. Média de VO2, por período

Não foram detectadas diferenças significativas na freqüência cardíaca, pressão arterial sistólica e diastólica, de repouso, quando comparados os períodos inicial e final do programa de treinamento. As figuras a seguir ilustram estes dados. 


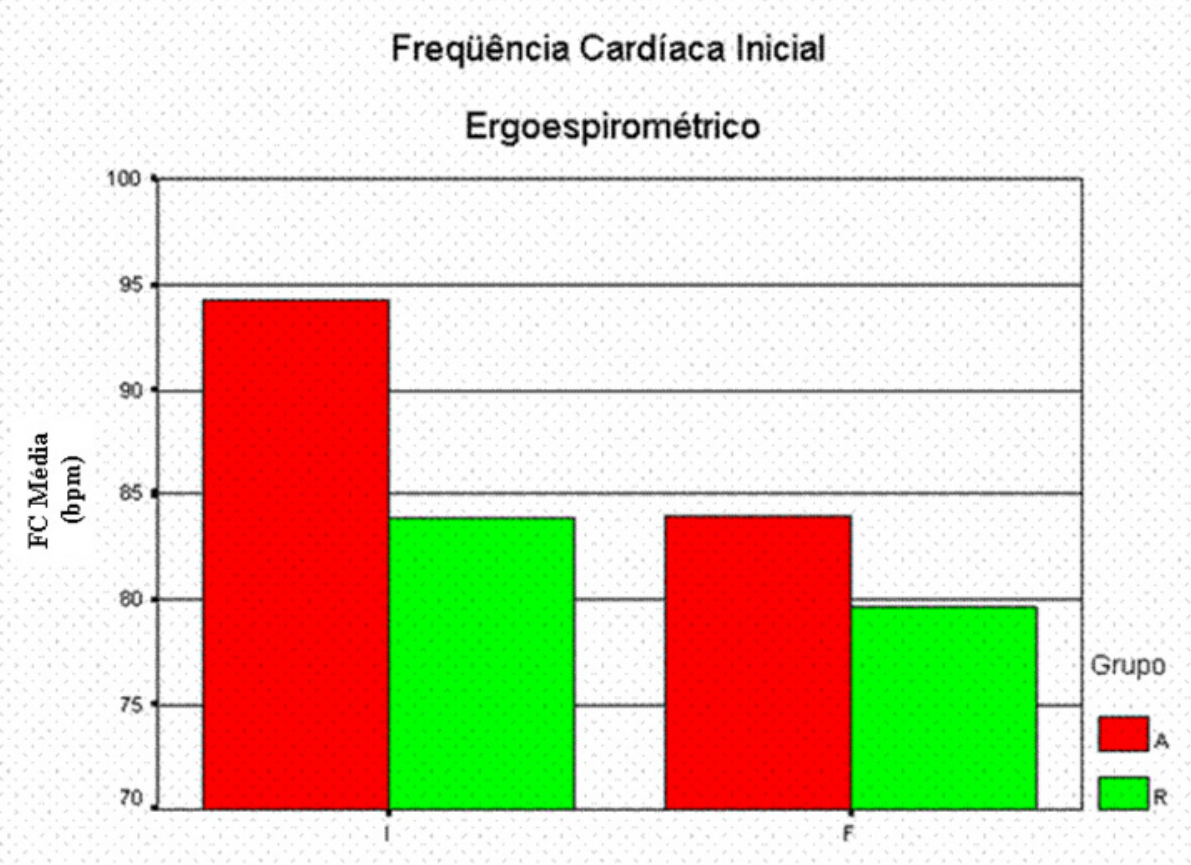

Período de Treinamento

Figura 26. FC de repouso, por grupo e período de treinamento.

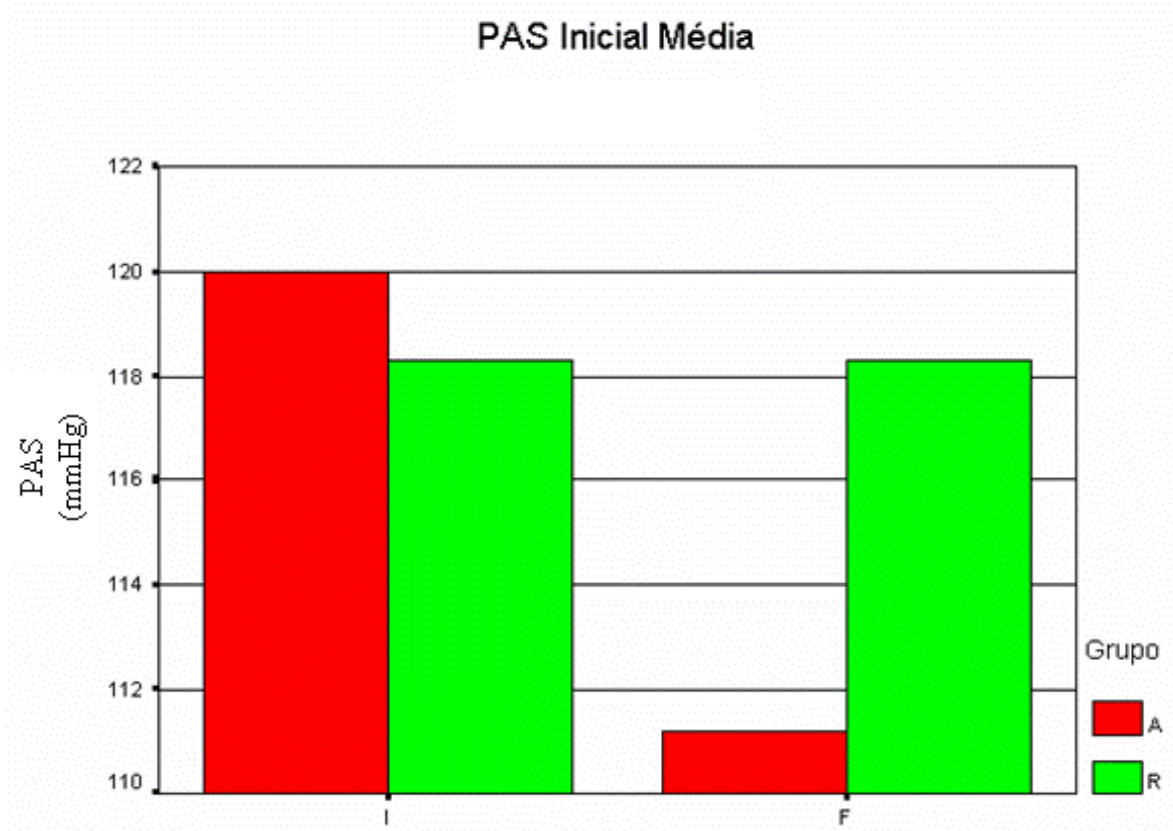

Periodo de Treinamento

Figura 27 . PAS de repouso por grupo e período de treinamento. 


\section{PAD Média Inicial}

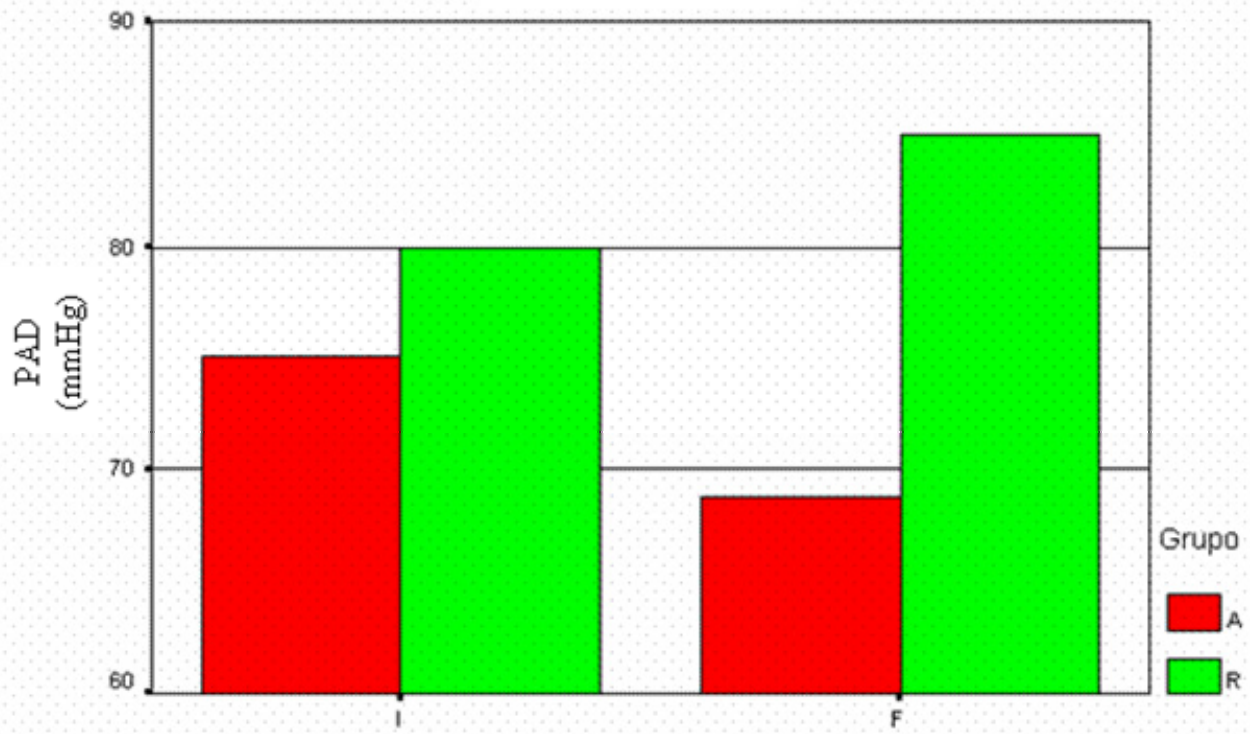

Período de Treinamento

Figura 28. PAS de repouso por grupo e período de treinamento. 


\section{Variação da glicose}

Os pacientes de nosso estudo apresentaram quedas glicêmicas diferentes em função do tipo de exercício: o grupo A $(69 \mathrm{mg} / \mathrm{dL})$ sofreu um declínio maior quando comparado ao grupo R (37mg/dL). Fato semelhante ocorreu no estudo de Ramalho e colaboradores (2006), onde portadores de DM1, que realizaram exercícios aeróbios e resistidos, também mostraram redução significativa da glicose capilar mensurada antes e depois de cada sessão de exercício, sendo que o maior decremento da glicose foi no grupo aeróbio.

Guelfi et al. (2005) também encontraram respostas diferentes quando compararam a variação glicêmica aguda de 7 portadores de DM1, durante dois tipos de exercícios também diferentes, mas ambos em cicloergômetro. Os exercícios foram realizados por 30 minutos, com e sem esforços máximos a cada 2 minutos e a intensidade foi igual a $40 \%$ do $\mathrm{VO}_{2}$ máximo. Os pacientes apresentaram maior decaimento da glicemia com o exercício que não incluiu esforços máximos, o que para os autores, pode contribuir para a manutenção dos níveis glicêmicos durante o exercício, sem a presença de hipoglicemia..

Bussau e colaboradores (2006) utilizaram um protocolo de exercício semelhante ao estudo anterior, onde 7 portadores de DM1 pedalaram por 20 minutos em cicloergômetro com ou sem esforço máximo por 10 segundos. Houve queda 
significativa dos níveis de glicose nos dois tipos de exercício, mas os pacientes que não fizeram o esforço máximo apresentaram uma queda maior em relação àqueles que o realizaram. A estabilização da glicemia visualizada no grupo com esforço máximo foi associada com elevação das catecolaminas, hormônio de crescimento e cortisol, que no outro grupo permaneceram estáveis.

Um outro estudo, promovido pelo grupo The Diabetes Research in Children Network (DirecNet) (2006), também evidenciou uma redução consistente na glicemia de portadores de DM1 após exercícios aeróbios por 75 minutos em esteira, sendo 4 períodos de 15 minutos de caminhada com intervalos de 5 minutos de repouso.

Em relação à variação glicêmica durante o teste de esforço, não houve diferença quando comparadas as glicemias do início e fim dos testes, mas sim quando comparadas as glicemias do início e fim do período de treinamento. Os testes realizados ao final do treinamento apresentaram glicemias mais elevadas que aquelas apresentadas no início do mesmo. Não sabemos por que isto ocorreu, pois os pacientes foram orientados a não reduzir a dose de insulina para a realização do teste e quando indagados pela redução, negavam sua realização. Os pacientes chegaram ao local de treino com a glicemia mais alta, o que sugere que eles podem ter aumentado a ingestão de carboidratos anterior ao teste, ou reduzido a dose de insulina prandial, como faziam habitualmente para as sessões de exercício.

A variação de glicose durante as sessões de exercício, obtida neste estudo por meio de ajustes nas doses de insulina, permitiram a realização de sessões de exercício aeróbio e resistido, sem intercorrências freqüentes. Estes ajustes, além de estimularem a prática de exercícios por portadores de diabetes tipo 1, podem proporcionar os benefícios, bem estabelecidos, do aumento da atividade física. 


\section{Sistema de Monitorização Contínua da Glicose}

Conhecemos dois trabalhos na literatura que investigaram a aplicação do CGMS e sua acurácia durante o exercício. O objetivo de um deles foi avaliar a utilidade do CGMS em 6 maratonistas com diabetes. O resultado obtido foi uma correlação boa entre as medidas do CGMS e do glicosímetro, porém inferior à encontrada em nosso estudo. Tal achado pode dever-se à intensidade maior do exercício. No entanto, obtivemos uma correlação, também superior, no teste ergoespirométrico que é um exercício de intensidade alta, mas com tempo de execução menor. Os autores concluíram que o CGMS é uma ferramenta segura e eficaz para maratonistas com diabetes (CARR et al., 2002). Outro estudo, publicado recentemente, avaliou a utilização do CGMS por 5 portadores de DM1, durante e após 60 minutos de exercício em bicicleta, com intensidade vigorosa. O CGMS também demonstrou uma correlação forte $(r=0,89, p<0,001)$ entre as mensurações obtidas por ele e pelo glicosímetro (ISCOE et al, 2006). Os estudos citados são concordantes com nossos achados em relação à acurácia do CGMS $(\mathrm{r}=0,925, \mathrm{p}<0,001)$. No entanto, não temos conhecimento de dados na literatura sobre a acurácia deste sistema durante o teste ergoespirométrico (intensidade alta e tempo de execução curto) e exercícios resistidos e aeróbio de moderada intensidade.

No presente estudo, o CGMS permitiu a identificação de decaimento linear em função do tempo de sessão, sendo semelhantes os perfis dos exercícios aeróbio e resistido. O uso da monitorização contínua da glicose, permitiu a elaboração de 
modelos matemáticos preditivos do decaimento da glicose, durante a prática de exercícios. Portanto, acreditamos que o CGMS é uma ferramenta útil para uma avaliação detalhada do comportamento da glicose de portadores de diabetes, fornecendo dados para a orientação dos mesmos quanto aos ajustes necessários para uma prática saudável de exercícios.

\section{Freqüência cardíaca e pressão arterial}

O comportamento durante as sessões de exercício aeróbio e teste ergoespirométrico, da PAS, PAD e FC foi semelhante à resposta fisiológica descrita para indivíduos não diabéticos (McARDLE et al, 2001), como no estudo de Kelleher e colaboradores (1987). Os pacientes do grupo de exercícios resistidos, não aumentaram a freqüência cardíaca e a pressão arterial em resposta ao exercício. Segundo Negrão et al (2005) há poucos estudos sobre a resposta pressórica a este tipo de exercício, associado a utilização de protocolos diferentes. Além disso, o exercício resistido parece aumentar a pressão arterial durante a execução do movimento, principalmente na sua fase concêntrica. Isto ocorre devido à oclusão vascular causada pela ação muscular, e sua magnitude depende da intensidade do exercício e do tamanho da massa muscular envolvida. Portanto, há necessidade de estudos com padronização da prescrição destes tipos de exercício, habitualmente praticado em academias, para melhor compreensão dos seus efeitos sobre os portadores de diabetes. 


\section{Hipoglicemia e redução de dose de insulina}

Há dados escassos na literatura sobre os efeitos agudos e crônicos de atividade física, exercício ou treinamento em portadores de diabetes mellitus tipo 1. A ausência de padronização na literatura, em relação a ajustes de doses de insulina, intensidade, duração e tipo de exercício, dificulta o entendimento das respostas destes pacientes à prática de atividade física e conseqüentemente a elaboração de condutas práticas.

A recomendação atual de utilização de insulinoterapia intensiva para obtenção de controle metabólico adequado, pode aumentar o risco de hipoglicemia induzida pelo exercício. Muitos autores comentam sobre a necessidade de ajuste de dose de insulina para a realização de atividades físicas, mas não oferecem exemplos de como esta conduta pode ser efetivada. A orientação fornecida, geralmente diz respeito à realização de monitorização da glicemia, ingestão de carboidratos e menos freqüentemente, redução das doses de insulina (ADA, 2004). O protocolo de redução de insulina ultra-rápida deste estudo baseou-se em publicação de Rabasa-Lhoret et al. (2001), o qual teve por objetivo avaliar e validar reduções de doses de insulina para exercícios de intensidades e durações diferentes, realizados no período pós-prandial, para minimizar o risco de hipoglicemia induzida pelo exercício em portadores de DM1. A equipe médica de diabetes do HC/FMUSP orientou a redução da dose de insulina basal (NPH) dos pacientes, nos dias de sessão de exercício, conforme descrito na metodologia, como também da dose de insulina lispro em 50 ou 75\%, na refeição que antecedia a sessão de exercícios. Estes ajustes resultaram em freqüência baixa de episódios de hipoglicemia e segurança para os pacientes realizarem o treinamento. 
Não houve redução significativa da dose total diária de insulina basal dos participantes, talvez devido à redução prévia orientada aos pacientes antes do início do protocolo. No estudo de Ramalho et al. (2006), com treinamento de exercícios aeróbios e resistidos para portadores de DM1, o ajuste de doses de insulinas ocorreu apenas na presença de hipoglicemias, durante ou após as sessões de exercícios. A redução significativa da dose total diária de insulina dos pacientes sugere que estes apresentaram uma freqüência mais elevada de hipoglicemias.

A maioria dos trabalhos que estuda a resposta glicêmica ao exercício, não realiza o ajuste de doses de insulina, apesar de descreverem sua importância para a manutenção dos níveis glicêmicos e redução de episódios de hipoglicemia.

Segundo Guelfi (2005) o maior risco de hipoglicemia está relacionado ao exercício aeróbio de intensidade moderada, sendo esta uma importante observação, pois o paciente é desencorajado a participar de atividades mais intensas para reduzirem o risco de hipoglicemia induzida pelo exercício.

O grupo The Diabetes Research in Children Network (DirecNet) Study Group (2006) concluiu que as concentrações de glicose menores que $120 \mathrm{mg} / \mathrm{dL}$ préexercício, conferem um maior risco de hipoglicemia. No presente estudo a sessão de exercícios não era iniciada, caso o paciente apresentasse glicemia inferior a 100 $\mathrm{mg} / \mathrm{dL}$, sendo disponibilizado gel (éis) de glicose e postergado o início da atividade física até que a glicemia atingisse níveis desejáveis $(>100 \mathrm{mg} / \mathrm{dL})$. O decaimento linear da glicose, observada no presente estudo, reforça a necessidade de observação dos níveis glicêmicos imediatamente antes da prática de atividades físicas, com o objetivo de reduzir o risco de hipoglicemia. 
A freqüência média de consumo $[(A=19,8)$ e $(R=16,7)]$ e a quantidade de gel $[(\mathrm{A}=28,2)$ e $(\mathrm{R}=21,3)]$ utilizada durante o período de treinamento foram similares em ambos os grupos. A freqüência de hipoglicemias foi igual em ambos os grupos $[(\mathrm{A}=1,5)$ e $(\mathrm{R}=1,5)]$ durante o treinamento, não apresentando diferenças em relação às reduções de dose de insulina UR ou período de treinamento.

No dia do teste ergoespirométrico, realizado em período pós-prandial, não houve recomendação de redução das doses de insulina, pois o teste apresenta uma curta duração (aproximadamente 10 minutos em exercício) e sua intensidade é alta (teste máximo); e nossos pacientes não apresentaram intercorrências glicêmicas, em resposta ao teste ergoespirométrico. Bertoluci et al. (1993) demonstraram queda significativa da concentração de glicose plasmática (antes $160 \mathrm{mg} / \mathrm{dL}$ e depois 102 $\mathrm{mg} / \mathrm{dL}$ ) durante testes submáximos, com duração de 20 minutos. Os pacientes do estudo foram orientados a aplicarem a dose de insulina NPH e omitirem a dose de insulina regular antes da refeição, tendo realizado o teste no período pós-prandial (café da manhã). Salientamos que o teste empregado por Bertoluci é diferente daquele aplicado em nosso estudo, visto que sua intensidade foi menor e a duração maior.

\section{Teste Ergoespirométrico}

Ao final do período de treinamento os grupos (A e R) de nosso estudo apresentaram melhoras significativas em alguns parâmetros da capacidade funcional, como: aumento da carga máxima atingida no teste e redução da freqüência cardíaca 
para se atingir os limiares ventilatórios (Limiar Anaeróbio e Ponto de Compensação Respiratória). O treinamento aeróbio para portadores de DM1 aumenta a tolerância ao exercício, como descrito por Gallen (2003), o qual afirma que as respostas ventilatórias e cardíacas a este tipo de exercício são semelhantes aos indivíduos não diabéticos. No presente estudo o consumo máximo de oxigênio $\left(\mathrm{VO}_{2}\right.$ máx $)$ não foi alterado pelos tipos de exercícios, assim como demonstrado em outros estudos (DAVIDSON et al, 2002; LAAKSONEN et al, 1999). Mas, também há evidências de melhora deste parâmetro em portadores de DM1 (FUCHSJÄGER et al, 2002), submetidos a 12 semanas de exercícios em forma de circuito (MOSHER et al, 1998). No entanto, os participantes do nosso estudo apresentaram médias iniciais de $\mathrm{VO}_{2}$ máx de $A=29,05$ e $\mathrm{R}=32,93$ e finais de $\mathrm{A}=33,02$ e $\mathrm{R}=33,06 \mathrm{ml} / \mathrm{kg} / \mathrm{min}$. A média inicial deste estudo foi similar a encontrada por Galassetti e colaboradores (2003), em sua investigação sobre exercício e DM1. Nossos pacientes apresentaram médias de $\mathrm{VO}_{2}$ máx iniciais e finais bem abaixo da média, segundo a classificação da capacidade funcional máxima para homens e mulheres, em diferentes faixas etárias (ACSM, 2001). Talvez isto possa ser explicado pela maior participação de mulheres em nosso estudo, pela falta de atividade física pregressa, bem como pela própria condição da doença, que pode influenciar suas respostas metabólicas. As mulheres apresentam níveis de VO2 máx menores quando comparadas aos homens (ACSM, 2001). 


\section{Hemoglobina glicada (HbA1c)}

Em nosso estudo não houve mudança significativa no controle glicêmico, analisado pela HbA1c. Este tema causa uma grande controvérsia. Alguns autores referem melhora do controle glicêmico (ANDREWS et al, 2002; KOIVISTO et al, 1986) e outros relatam ausência de modificação deste parâmetro (KHAWALI et al., 2003; FUCHSJÄGER-MAYRL, 2002; LAAKSONEN et al., 2000; RAILE et al., 1999, LEHMANN et al., 1997). Todos estes trabalhos referem-se ao efeito de treinamento de exercícios aeróbios, sem padronização quanto à intensidade e duração das sessões. Ramalho et al (2006) demonstraram elevação significativa da HbA1c de portadores de DM1, submetidos às sessões de exercício aeróbio (de 8,7\% para 9,8\%) e ausência de modificação no grupo de exercícios resistidos (de 8,2 para 7,6\%).

\section{Perfil Lipídico}

No presente estudo, os pacientes não apresentaram mudanças no perfil lipídico. Ramalho et al (2006) não relataram alterações do perfil lipídico dos portadores de DM1 do grupo aeróbio e resistido. Porém, outros estudos evidenciam mudanças com 12 semanas de treinamento aeróbio e com pesos em forma de circuito (MOSHER et al, 1998). Laaksonen et al (1999), relataram melhora no perfil lipídico de portadores de DM1, submetidos ao treinamento aeróbio independente das mudanças na composição corporal ou controle glicêmico. O treinamento de intensidade moderada consistiu de 12 a 16 semanas, sendo a primeira semana: 20-30 minutos de corrida, 
cerca de 50-60\% do V02máx, mesclado com caminhada (quando necessário), 3 vezes por semana e progrediu para 30-60 minutos, a 60-80\% do $\mathrm{VO}_{2}$ máximo, 4-5 vezes por semana. Portanto, a intensidade do exercício pode influenciar a resposta lipídica. E acreditamos que há necessidade da avaliação qualitativa das moléculas de lípides, para melhor compreensão do impacto da atividade física sobre o perfil lipídico.

\section{Microalbuminúria}

Outro tema que causa uma grande controvérsia na literatura, é a microalbuminúria induzida pelo exercício. Alguns autores (LANE et al, 2002; TUOMINEN et al, 1998; O'BRIEN et al, 1995) acreditam que a mesma possa ser um marcador mais precoce, da nefropatia diabética incipiente que a microalbuminúria em repouso. No entanto, ainda não foram estabelecidos na literatura, a variação normal para a microalbuminúria induzida pelo exercício e para o iccremento da mesma a partir do valor de repouso. Nossos pacientes não apresentaram mudanças na microalbuminúria de repouso e induzida pelo exercício, após o período de treinamento. Mas o valor da mesma foi duplicado após a sessão de exercício. Não conhecemos estudos que avaliaram a microalbuminúria induzida pelo exercício antes e depois de treinamento, somente de forma aguda. 


\section{Composição corporal}

O treinamento de exercícios resistidos influenciou o aumento dos seguintes parâmetros da composição corporal, avaliados pelo DEXA: área, conteúdo mineral ósseo, massa magra e reduziu o percentual de gordura. Alguns estudos não relataram mudanças na composição corporal após treinamento de exercícios (FUCHSJÄGER et al., 2002; LAAKSONEN et al., 1999). Ramalho et al. (2006) observaram redução significativa da circunferência da cintura de portadores de DM1 que realizaram o treinamento de exercício aeróbio quando comparado com o grupo de exercícios resistidos.

Compreendemos que as dificuldades encontradas para a aquisição de conhecimentos, relacionados aos efeitos crônicos de programas de treinamento de exercícios sobre portadores de diabetes tipo 1, reside na pouca disponibilidade de indivíduos jovens, para a participação em protocolos de pesquisa de período prolongado. No entanto, a redução das intercorrências glicêmicas, causadas pela ausência de orientação adequada para a prática de atividade física por estes pacientes, pode resultar em estímulo para a participação dos mesmos em programas de treinamento. Desta forma, associado à aquisição de conhecimentos podemos proporcionar os benefícios da atividade física aos portadores de diabetes tipo 1 . 
6. Conclusões 
- O protocolo para ajuste de doses de insulinas basal (NPH) e bolus (ultrarápida), empregado neste estudo, resultou em glicemias adequadas para o início e fim das sessões de exercícios por portadores de diabetes tipo 1.

- Não há necessidade de redução de dose de insulina para execução de teste máximo, no período pós-prandial, de portadores de diabetes tipo 1;

- Ambos os tipos de exercício promovem queda da glicemia, os exercícios aeróbios promovem uma queda maior que os resistidos;

- Os glicosímetros portáteis e o CGMS podem ser considerados equivalentes para efetuar as medidas de glicose dos portadores de diabetes tipo 1, durante a prática de exercícios;

- Nas medições de glicose com o CGMS, foi observada uma tendência de decaimento linear das concentrações de glicose, em função do tempo de exercício;

- Nas medições de glicose com o CGMS, durante os exercícios, foram observados perfis similares de decaimento de glicose, em função do tempo;

- Os exercícios resistidos não provocaram variação na FC, PAS e PAD;

- O exercício aeróbio provocou um aumento significativo na FC e PAS;

- Não houve diferença na freqüência de hipoglicemia entre os exercícios aeróbios ou resistidos, por portadores de diabetes tipo 1; 
- O perfil lipídico (colesterol total, colesterol LDL, colesterol HDL e triglicérides) não foi alterado pela execução de 40 sessões de exercício aeróbio ou resistido;

- Os níveis de microalbuminúria induzida pelo exercício dobraram, em relação aos níveis obtidos em repouso;

- O treinamento de exercícios resistidos aumentou a área corporal, o conteúdo mineral ósseo e massa magra e reduziu o percentual de gordura;

- Foram detectadas diferenças significativas na avaliação cardiopulmonar, entre os tipos de exercício aeróbio e resistido, para os seguintes parâmetros: carga máxima atingida, freqüência cardíaca atingida no liminar anaeróbio e no Ponto de compensação respiratória; 
IV Diretrizes de Hipertensão Arterial. Arq Bras Cardiol. 2001; 82:1-14.

American College of Sports Medicine. www. acsm.org. 2002

ACSM's Guidelines for Exercise Testing and Prescriptions. Sixth Edition. Lippinicott Willians e Wilkins. Baltimore MD. 2001; 115-133.

American Diabetes Association. Diagnosis and Classification of Diabetes Mellitus (Position Statement). Diabetes Care. 2007; 30: 42-47.

American Diabetes Association. Physical Activity/Exercise and Diabetes. Diabetes Care. 2004; 27:58-62.

Andrews RC, Holland J, Furness G, Griffiths S. Short supervised exercise programmes work in patients with diabetes. Diabetic Medicine Supplement. 2002; 19: 32-33.

Bertoluci MC, Friedman G, Schaan BD, Ribeiro, JP; Schmd H. Intensity-related exercise albuminuria in insulin dependent diabetic patients. Diabetes Research and Clinical Practice. 1993; 19:217-225.

Bevan P. Insulin Signalling. Journal of Cell Science. 2001; 114:1429-1430. 
Burton DA, Stokes K, Hall, GM. Physiological effects of exercise. Continuing Education in Anaesthesia, Critical care \& Pain. 2004; 4:185-188.

Bussau VA, Ferreira LD, Jones TW. The 10-s maximal sprint. Diabetes Care. 2006; 29:601-606.

Carr JM, Corcoran MH. Continuous glucose monitoring in marathon runners with type 1 Diabetes during the 2001 Chicago Marathon. Diabetes. 2002; 51: A244.

Carvalheira JBC, Zecchin HG, Saad MJA. Vias de sinalização da insulina. Arq Bras Endocrinol Metab. 2002; 46:419-425.

Davison GW, George L, Jackson SK, Young IS, Davies B, Bailey DM, Peters JR, Ashton T. Exercise, free radicals, and lipid peroxidation in type 1 diabetes mellitus. Free radical Biology \& Medicine. 2002;33:1543-1551.

De Witt DE, Hirsch IB. Outpatient insulin therapy in type 1 and type 2 Diabetes Mellitus. Scientific Review. JAMA. 2003; 289:2254-2264.

Deschenes MR, Kraemer WJ. Performance and physiologic adaptations to resistance training. Am J Phys Med Rehabil. 2002;81:3-16.

Enoka RM. Neural adaptations with chronic physical activity. J Biomechanics. 1997;30:447-454. 
Feigenbaum MS, Pollock ML. Prescription of resistance training for health and disease. [Clinical Sciences: Symposium: Resistance Training for Health and Disease]. Med Sci Sports Exerc.1999; 31:38-45.

Fleck SJ, Kraemer W. Fundamentos do treinamento de força muscular.1999; 2ed: Porto Alegre: Artmed.

Flood L, Constance A. Diabetes \& Exercise Safety. A J N. 2002; 102:47-55.

Fry AC. The role of resistance exercise intensity on muscle fibre adaptations. 2004; 34:663-679.

Fuchsjäger-Mayrl G, Pleiner J, Wiesinger GF, Sieder AE, Quittan, M, Nuhr MJ, Francesconi C, Seit HP, Francesconi M, Schmetterer L, Wolzt M. Exercise training improves vascular endothelial function in patients with type 1 diabetes. Diabetes Care. 2002; 25: 1795-1801.

Galassetti P, Tate D, Neill RA, Morrey S, Wasserman DH, Davis SN. Effect of antecedent hypoglycemia on counterregulatory responses to subsequent euglycemic exercise in type 1 diabetes. $2003 ; 52: 1761-1769$.

Gallen I. Exercise in type 1 diabetes. Diabetes UK. Diabetic Medicine. 2003; 20:117. 
Garg SK, Chase HP, Shapiro H, Harris S, Osberg IM. Exercise versus overnight albumin excretion rates in subjects with type 1 diabetes. Diabetes Research and Clinical Practice. 1995; 28:51-55.

Garg, SK, Chase HP, Harris S, Marshall G, Hoops S, Osberg I. Glycemic control and longitudinal testing for exercise microalbuminuria in subjects with type 1 diabetes. $\mathrm{J}$ Diabet Complications. 1990; 4:154-158.

Gross M, Bode BW, Einhorn D, Kayne DM, Reed JH, White NH, Mastrotaro, JJ. Performance evaluation of the miniMed Continuous Glucose Monitoring System during patient home use. Diabetes Technology \& Therapeutics. 2000; 2:49-56. a)

Gross M, Veer AT. Continuous glucose monitoring in previously unstudied population subgroups. Diabetes Technology \& Therapeutics. 2000; 2:27-34. b)

Guelfi KJ, Jones TW, Fournier PA. The decline in blood glucose levels is less with intermittent high-intensity compared with moderate exercise in individuals with type 1 diabetes. Diabetes Care. 2005; 28:1289-1294.

Guyton AC, Hall JE. Textbook of medical physiology. Índia: Elseveir 2006.

Hallal PC, Matsudo SM, Matsudo VKR, Araújo TL, Andrade DR, Bertoldi AD. Physical activity in adults from two brazilian areas: similarities and differences. Cad Saúde Pública, Rio de Janeiro. 2005; 21:109-118. 
Hargreaves M. Skeletal muscle metabolism during exercise in humans. Clin Exp Pharmacol Physiol. 2000; 27:225-228.

Iscoe KE, Campbell JE, Jamnik V, Perkins BA, Riddell MC. Efficacy of continuous real-time blood glucose monitoring during and after prolonged high-intensity cycling exercise: spinning with a continuous glucose monitoring ssystem. Diabetes Technol Ther. 2006; 8:627-635.

Jessen N, Goodyear LJ. Contraction signaling to glucose transport in skeletal muscle. J Appl Physiol. 2005; 99: 330-337.

Kelleher C, Ferriss JB, Ross H, O'Sullivan DJ. The pressor response to exercise and stress in uncomplicated insulin-dependent diabetes. J Hum Hypert. 1987; 1:59-64.

Khawali C.; Andriolo A.; Ferreira S.R.G. Benefícios da atividade física no perfil lipídico de pacientes com Diabetes Tipo 1. Arq Bras Endocrinol Metab. 2003; 49-54.

Koivisto VA, Yki-Jarvinen H, DeFronzo RA. Physical training and insulin sensitivity. Diabetes Metab Rev. 1986; 1:445-81.

Kraemer WJ, Ratamess NA. Fundamentals of resistance training: progression and exercise prescription. Medicine \& Science in Sports \& Exercise. 2003. 674-688. 
Laaksonen DE, Atalay M, Niskanen LK, Mustonen J, Sen CK, Lakka TA, Uusitupa MIJ. Aerobic exercise and the lipid profile in type 1 diabetic men: a randomized controlled trial. Medicine \& Science in Sports \& Exercise. 2000; 1541-1548.

Lane J, Ford T, Larson LA, Chambers W, Lane P. Does Exercise Significantly Effect Albumin Excretion in Normoalbuminuric Normotensive Patients with Type 1 Diabetes? Diabetes. 2002; 51:A249..

Lehmann R, Kaplan V, Bingisser R, Bloch KE, Spinas GA. Impact of physical activity on cardiovascular risk factors in IDDM. Diabetes Care. 1997; 20:1603-1611.

Lurbe E, Redon J, Kesani A, Pascual J, Tacons J, Alvarez V, Batlle D. Increase in nocturnal blood pressure and progression to microalbuminuria in type 1 Diabetes. $\mathrm{N}$ Engl J Med, 2002; 347: 797-805.

Machado UF, Schaan BD, Seraphim PM. Glucose transporters in the metabolic syndrome. Arq Bras Endocrinol Metabol. 2006; 50:177-189.

Marliss EB, Vranic M. Intense exercise has unique effects on both insulin release and its roles in glucorregulation. Implications for Diabetes. Diabetes. 2002; 51: 271-283.

Mastrototaro J. The MiniMed Continuous Glucose Monitoring System (CGMS). Journal of Pediatric Endocrinology \& Metabolism. 1999; 12:751-758. 
McArdle WD, Katch FI, Katch VL. Exercise Physiology - Energy, Nutrition, and Human Performance. USA: Lippincott Williams \& Wilkins. 2001.

McCartney N. Acute responses to resistance training and safety. Med Sci Sports Exerc. 1999; 31:31-37.

McConell GK, Kingwell, BA. Does nitric oxide regulate skeletal muscle glucose uptake during exercise? Exercise and Sport Sciences Reviews. 2005; 35-41. MINISTÉRIO DA SAÚDE. Plano de reorganização da atenção à hipertensão arterial e ao diabetes mellitus. Campanha Nacional de Detecção de Suspeitos de Diabetes Mellitus. Relatório Técnico. 2001

MINISTÉRIO DA SAÚDE. Orientações Básicas sobre Atividade Física e Saúde para Profissionais das Áreas de Educação e Saúde. Brasília. 1995

Mosher PE, Nash MS, Perry AC, LaPerriere AR, Goldberg R. Aerobic circuit exercise training: effect on adolescentes with well-controlled insulin-dependent diabetes mellitus. Arch Phys Med Rehabil. 1998; 79:652-657.

Moy CS, Songer TJ, LaPorte RE, Dorman JS, Kriska AM, Orchad TJ, Becker DJ, Drash AL. Insulin-dependent diabetes mellitus, physical activity, and death. Am J Epidemiol. 1993: 137:74-81.

Negrão CE, Barreto ACP. Cardiologia do Exercício. Barueri, SP: Manole 2005. 
Negrão CE, Rondon MU, Tinucci T, Alves MJ, Roveda F, Braga AM, Reis SF, Nastari L, Barreto AC, Krieger EM, Middlekauff HR. Abnormal neurovascular control during exercise is linked to heart failure severity. Am J Physiol Heart Circ Physiol. 2001: 280:H1286-92.

O'Brien SF, Watts GF, Powrie JK, Shaw KM. Exercise testing as a long-term predictor of the development of microalbuminuria in normoalbuminuric IDDM patients. Diabetes Care: 1995; 18:1602-1605.

Peirce NS. Diabetes and Exercise. Br J Sports Med. 1999; 33:161-173.

Pollock ML, Franklin BA, Balady GJ, Chaitman BL, Jerome L, Fletcher B, Limacher M, Piña IL, Stein RA, Williams M, Bazzare T. Resistance exercise in individuals with and without cardiovascular disease: an advisory from the committee on exercise, rehabilitation, and prevention, council on clinical cardiology, American Heart Association [AHA Science Advisory]. Position paper endorsed by the American College of Sports Medicine. Circulation. 2000; 101: 828-833.

Rabasa-Lhoret RR, Bourque J, Ducros F, Chiasson JL. Guidelines for premeal insulin dose reduction for postprandial exercise of diferent intensities and durations in type 1 diabetic subjects treated intensively with a basal-bolus insulin regimen (Ultralente-Lispro). Diabetes Care. 2001, 24:625-630. 
Raile K, Kapellen T, Schweiger A, Hunkert F, Nietzschmann U, Dost A, Kiess W. Physical activity and sports in children and adolescents with type 1 diabetes. Diabetes Care, 1999; 22:1904-1905.

Ramalho AC, Lima ML, Nunes F, Cambuí Z, Barbosa C, Andrade A, Viana A, Martins M, Abrantes V, Aragão C, Temístocles M. The effect of resistance versus aerobic training on metabolic control in patients with type-1 diabetes mellitus. Diabetes Res Clin Pract. 2006;72:271-6.

Rea S, James DE. Moving Glut 4: the biogenesis and trafficking of Glut 4 storage vesicles. Diabetes. 2005; 46:1667-1677.

Rebrin K, Steil GM, Antwerp V, Mastrototaro JJ. Reability of Intestitial Glucose Sensors in Humans. Diabetologia. 1998:41:880.

Rose AJ, Richter EA. Skeletal muscle glucose uptake during exercise: how is it regulated? Physiology. 2005; 20:260-270.

Ruderman N, Devlin JT. The Health Professional's Guide to Diabetes and Exercise. Clinical Education Series. American Diabetes Association. 1995.

Saltiel AR, Kahn CR. Insulin signalling and the regulation of glucose and lipid metabolism. Nature. 2001; 414:799-806. 
Santarém JM. Atualização em exercícios resistidos: segurança cardiovascular. www.saudetotal.com/exresist.htm 2002

Shepherd PR, Kahn B. Mechanisms of disease: glucose transporters and insulin action - implications for insulin resistance and diabetes mellitus [Review Articles]. The New England Journal of Medicine. 1999; 341:248-257.

Sigal RJ, Kenny GP, Wasserman DH, Castaneda-Sceppa C. Physical Activity/Exercise and Type 2 Diabetes. Diabetes Care 2004; 27:2518-2539.

Sigal RJ, Fisher SJ, Halter JB, Vranic M, Marliss EB. Glucoregulation during and after Intense Exercise: Effects of $\beta$-Adrenergic Blockad in Subjects with Type 1 Diabetes Mellitus. The Journal of Clinical Endocrinology \& Metabolism 1999; 84:3961-3971.

Smutok MA, Reece C, Kokkinos PF, Farmer C, Dawson P, Shulman R, Devane-Bell J, Patterson J, Charabogos C, Goldberg AP, Hurley BF. Aerobic versus strength training for risk factor intervention in middle-aged men at high risk for coronary heart disease. Metabolism: Clinical \& Experimental. 1993; 42:177-184.

Soukup JT, Kovaleski JE. A review of the effects of resistance training for individuals with diabetes mellitus. Diabetes Educ. 1993;19:307-12. 
The diabetes research in children network (direcnet) study group. The effects of aerobi c exercise on glucose and counterregulatory hormone concentrations in children with type 1 diabetes. Diabetes Care. 2006; 29:20-25.

Thompson PD, Buchner D, Piña IL, Balady GJ; Williams MA, Marcus BH, Berra K, Blair SN, Costa F, Franklin B, Fletcher GF, Gordon NF, Pate RR, Rodriguez BL, Yancey AK, Wenger NK. Exercise and physical activity in the prevention and treatment of atherosclerotic cardiovascular disease. A statement from the council on clinical cardiology (subcommittee on exercise, rehabilitation, and prevention) and the council on nutrition, physical activity, and metabolism (subcommittee on physical activity). Circulation 2003; 107: 3109-3116.

Torffvit O, Castenfors J, Agardh CD. A st udy of exercise-induced microalbuminuria in type 1 (insulin-dependent) diabetes mellitus. Scand J Urol. Neph. 1991; 25:39-43.

Tuominen JA, Ebeling P, Koivisto VA. Long-TermLisinopril Therapy Reduces Exercise-Induced Albuminuria in Normoalbuminuric Normotensive IDDMPatients. Diabetes Care. 1998; 21:1345-1348.

Wasserman DH, Zinman B. Exercise in Individuals with IDDM. Diabetes Care; 1994; 17:924-937.

Winett RA, Carpinelli RN. Potential Health-Related Benefits of Resistance Training. Preventive Medicine. 2001;33:503-513. 


\section{HOSPITAL DAS CLÍNICAS \\ DA}

FACULDADE DE MEDICINA DA UNIVERSIDADE DE SÃO PAULO

\section{TERMO DE CONSENTIMENTO LIVRE E ESCLARECIDO}

(Instruções para preenchimento no verso)

\section{I - DADOS DE IDENTIFICAÇÃO DO SUJEITO DA PESQUISA OU RESPONSÁVEL LEGAL}

1. NOME DO PACIENTE

DOCUMENTO DE IDENTIDADE $\mathrm{N}^{\circ}$ :

SEXO : $\quad M$ $\mathrm{F}$

DATA NASCIMENTO:

ENDEREÇO

/ $/$

$\mathrm{N}^{\circ}$

APTO:

BAIRRO:

CIDADE :

CEP: TELEFONE: DDD ( ...) .

2. RESPONSÁVEL LEGAL

NATUREZA (grau de parentesco, tutor, curador etc.)

DOCUMENTO DE IDENTIDADE SEXO: $M$

$\mathrm{F}$

DATA NASCIMENTO.: / /

ENDEREÇO:

$\mathrm{N}^{\mathrm{o}}$

APTO

BAIRRO

CIDADE:

CEP: TELEFONE: DDD (

).

\section{II - DADOS SOBRE A PESQUISA CIENTÍFICA}

1.TÍTULO DO PROTOCOLO DE PESQUISA: "Treinamento Aeróbio e Resistido em Indivíduos Portadores de Diabetes Mellitus Tipo 1: Sistema de Monitoramento Contínuo da Glicose (CGMS), Microalbuminúria e MAPA."

2.PESQUISADOR: Marcela Nunes de Almeida Perazo

CARGO/FUNÇÃO: Professora de Educação Física

UNIDADE DO HCFMUSP: Endocrinologia

3. AVALIAÇÃO DO RISCO DA PESQUISA:

$\begin{array}{lll}\text { SEM RISCO } & \text { RISCO MÍNIMO } & \text { RISCO MÉDIO } \\ \text { RISCO BAIXO } & \text { RISCO MAIOR }\end{array}$

(probabilidade de que o indivíduo sofra algum dano como consequência imediata ou tardia do estudo) 


\section{III -REGISTRO DAS EXPLICAÇÕES DO PESQUISADOR AO PACIENTE OU SEU REPRESENTANTE LEGAL SOBRE A PESQUISA, CONSIGNADO:}

Esta pesquisa tem o objetivo de verificar o controle do açúcar no sangue (glicemia) durante a execução dos diferentes exercícios: musculação, no CECAFI (Centro de Estudos da Ciência da Atividade Física) - Rua Teodoro Sampaio, 474, telefone: 3088-0474 e bicicleta ergométrica, no INCOR - Av. Dr Enéas de Carvalho Aguiar, 44, Bloco 2, 1º Subsolo, Unidade de Reabilitação Cardiovascular e Fisiologia do Exercício, telefone: 3069-5043.

Você NÃO poderá escolher um programa de sua preferência e poderá ser colocado em qualquer um dos seguintes grupos (por sorteio): Treinamento Aeróbio, Treinamento Resistido ou Grupo Controle - Sem Exercício (este grupo não vai fazer nenhuma atividade).

Se você estiver num dos Programas, você realizará exercícios durante 4 meses, 3 vezes por semana, cerca de 50 minutos ao dia, no período da manhã - após o café da manhã ou no período da tarde - após o almoço.

Antes de iniciar e ao término das atividades, você realizará:

- Teste de esforço físico na bicicleta ergométrica, que servirá para avaliar seu coração. Antes de fazê-lo você receberá algumas instruções e deverá seguí-las para que não haja alteração nos resultados. O teste vai levar a um cansaço intenso, mas que em condições de laboratório, supervisionado pelo médico cardiologista, com registro do eletrocardiograma, apresenta um risco muito baixo para sua saúde.

- Exames laboratoriais e auto-monitorização da glicemia capilar (picada na ponta-de-dedo e utilização de uma gota de sangue), como você realiza no seu dia-a-dia para fazer o ajuste das doses de insulina - de acordo com a glicemia - antes das principais refeições.

- Monitorização da Pressão Arterial com um pequeno aparelho que fará a medição da sua pressão arterial por 24 horas.

- Monitorização da Glicemia com um aparelho que ficará conectado a você por 3 dias, utilizando uma agulha pequena e flexível colocada abaixo da pele (subcutâneo). A presença desta agulha poderá lhe causar algum tipo de desconforto, caso seja pressionado o local onde ela foi colocada, podendo também ocorrer perda do registro dos valores de glicose. É importante que você venha de banho tomado para a colocação desta agulha para evitar infecção. Você não conseguirá ver o valor da glicose através do aparelho, mas ele gravará os valores que serão vistos posteriormente.

- Após a primeira e a última aula ou sessão de exercício, você realizará uma coleta de urina simples. Porém esta deve ser feita depois de beber cerca de 2 litros de água. 


\section{IV - ESCLARECIMENTOS DADOS PELO PESQUISADOR SOBRE GARANTIAS DO SUJEITO DA PESQUISA;}

Ao paciente participante será permitido acesso, a qualquer tempo, às informações sobre procedimentos, riscos e benefícios relacionados à pesquisa, inclusive para esclarecer eventuais dúvidas.

Liberdade de retirar seu consentimento a qualquer momento e de deixar de participar do estudo, sem que isto traga prejuízo à continuidade da assistência.

Garantia de confidencialidade, sigilo e privacidade.

\section{INFORMAÇÕES DE NOMES, ENDEREÇOS E TELEFONES DOS RESPONSÁVEIS PELO ACOMPANHAMENTO DA PESQUISA, PARA CONTATO EM CASO DE INTERCORRÊNCIAS CLÍNICAS E REAÇÕES ADVERSAS.}

Pesquisadoras: Dra Karla Melo e Professora Marcela Nunes de Almeida Perazo (celular: 9953-0443)

Faculdade de Medicina

Av. Dr. Arnaldo, 455, $4^{\circ}$ andar, sala 4305 - Cerqueira César - Telefone: 3066-7467.

Ambulatório de Endocrinologia do Hospital das Clínicas - FMUSP

Av. Dr. Enéas de Carvalho Aguiar, 255 Cerqueira César Telefone: 3069-6383

\section{OBSERVAÇÕES COMPLEMENTARES:}

\section{CONSENTIMENTO PÓS-ESCLARECIMENTO}

Declaro que, após ter sido convenientemente esclarecido pelo pesquisador, e ter entendimento do que me foi explicado, consinto em participar do presente Protocolo de Pesquisa: "Treinamento Aeróbio e Resistido em Indivíduos Portadores de Diabetes Mellitus Tipo 1: CGMS, Microalbuminúria e MAPA".

São Paulo, 